\title{
Carnitine and paced muscles : improvement of vascular metabolism
}

Citation for published version (APA):

Dubelaar, M. L. (1992). Carnitine and paced muscles : improvement of vascular metabolism. [Doctoral Thesis, Maastricht University]. Datawyse / Universitaire Pers Maastricht. https://doi.org/10.26481/dis.19921008md

Document status and date:

Published: 01/01/1992

DOI:

10.26481/dis.19921008md

Document Version:

Publisher's PDF, also known as Version of record

\section{Please check the document version of this publication:}

- A submitted manuscript is the version of the article upon submission and before peer-review. There can be important differences between the submitted version and the official published version of record.

People interested in the research are advised to contact the author for the final version of the publication, or visit the DOI to the publisher's website.

- The final author version and the galley proof are versions of the publication after peer review.

- The final published version features the final layout of the paper including the volume, issue and page numbers.

Link to publication

\footnotetext{
General rights rights.

- You may freely distribute the URL identifying the publication in the public portal. please follow below link for the End User Agreement:

www.umlib.nl/taverne-license

Take down policy

If you believe that this document breaches copyright please contact us at:

repository@maastrichtuniversity.nl

providing details and we will investigate your claim.
}

Copyright and moral rights for the publications made accessible in the public portal are retained by the authors and/or other copyright owners and it is a condition of accessing publications that users recognise and abide by the legal requirements associated with these

- Users may download and print one copy of any publication from the public portal for the purpose of private study or research.

- You may not further distribute the material or use it for any profit-making activity or commercial gain

If the publication is distributed under the terms of Article $25 \mathrm{fa}$ of the Dutch Copyright Act, indicated by the "Taverne" license above, 


\section{CARNITINE AND PACED MUSCLES}

Improvement of vascular metabolism 



\title{
CARNITINE AND PACED MUSCLES
}

\author{
Improvement of vascular metabolism
}

\section{PROEFSCHRIFT}

ter verkrijging van de graad van doctor aan de Rijksuniversiteit Limburg te Maastricht, op gezag van de Rector Magnificus, Prof. Mr. M.J. Cohen, volgens het besluit van het College van Dekanen,

in het openbaar te verdedigen op donderdag, 8 oktober 1992 om 16.00 uur

door

\section{MARIA LOUISA DUBELAAR}

geboren te Amsterdam

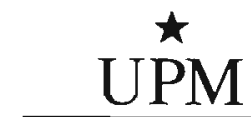

UNIVERSITAIRE PERS MAASTRICHT 


\section{Promotores:}

Prof. Dr. W.C. Hülsmann

Prof. Dr. G.J. van der Vusse

\section{Beoordelingscommissie:}

Prof. Dr. R.S. Reneman, voorzitter

Prof. Dr. A. Huson

Prof. Dr. H.J.J. Wellens

Prof. Dr. H.R. Scholte

(Erasmus Universiteit Rotterdam)

Prof. Dr. P. Verdouw

(Erasmus Universiteit Rotterdam)

\section{CIP-GEGEVENS KONINKLIJKE BIBLIOTHEEK, DEN HAAG}

Dubelaar, Maria Louisa

Carnitine and paced muscles. Improvement of vascular metabolism / Maria Louisa Dubelaar. - Maastricht :

Universitaire Pers Maastricht. -III.

Thesis Maastricht. - With ref. - With summary in Dutch.

ISBN 90-5278-037-4

NUGI 743

Subject headings: carnitine / muscles / vascular metabolism. 
Weet je ..... 


\section{LIST OF ABBREVIATIONS}

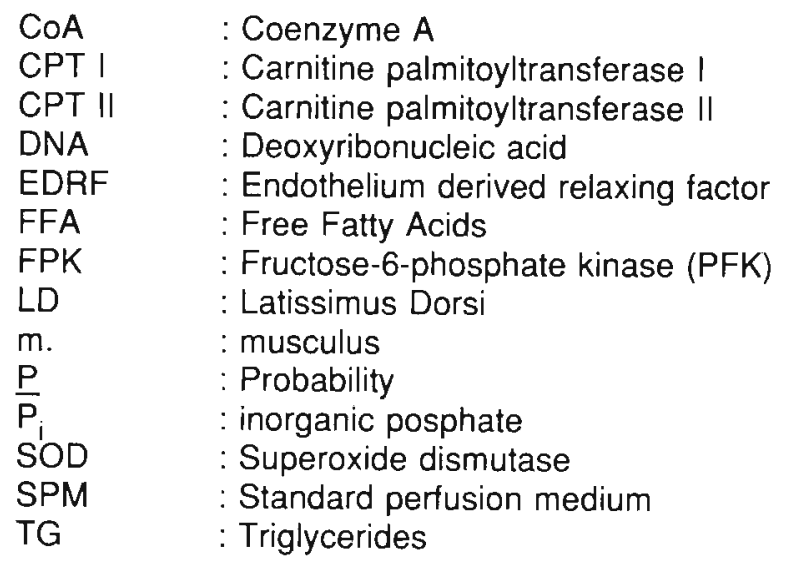




\section{CONTENTS}

$\begin{array}{ll}\text { Abbreviations } & 6\end{array}$

CHAPTER $1 \quad$ Introduction 11

Skeletal muscle $\quad 14$

Energy production in red and white muscles 14

Pacing of skeletal muscle $\quad 15$

$\begin{array}{ll}\text { Carnitine } & 16\end{array}$

$\begin{array}{ll}\text { Function of carnitine } & 17\end{array}$

Carnitine in muscle of several species 18

Aim of the thesis 20

References $\quad 22$

CHAPTER 2 Acute effect of L-carnitine upon skeletal muscle force 27 tests in the dog

$\begin{array}{ll}\text { Abstract } & 28\end{array}$

Introduction 29

Material and Methods $\quad 29$

Results 32

Discussion 33

$\begin{array}{ll}\text { References } & 37\end{array}$

Chapter 3 The effect of L-carnitine on force development of the 39 latissimus dorsi muscle in dogs

Abstract

Introduction $\quad 41$

Material and Methods $\quad 41$

Results $\quad 43$

Discussion $\quad 44$

References $\quad 46$ 
ChaPter 4 Carnitine in metabolism of paced cardiac and skeletal muscles; prevention of acidosis and improvement of vascular flow

Abstract

Introduction

Effect of carnitine on lactic acidosis in Langendorff heart

Acute effect of carnitine on skeletal muscle force in vivo

Carnitine and energy supply in blood vessels

Examples of improved function by carnitine in preischemic muscles

Mechanisms by which carnitine may improve blood flow

Long-chain acylcarnitine and loss of coronary flow

Carnitine and acute cholinomimetic effects on muscle

References

Chapter 5 Carnitine requirement of vascular endothelial and smooth muscle cells in imminent ischemia

Abstract

Introduction

Material and Methods

Results

Discussion

References

ChAPTER 6 Chronic L-carnitine administration combined with minimal electrical stimulation promotes transformation of canine latissimus dorsi muscle

Abstract

Introduction

Material and Methods

Results

Discussion

References

ChAPTER 7 On the mechanism of fat accumulation in wrapped latissimus dorsi muscle (cardiomyoplasty), and the effect of chronic L-carnitine administration

Abstract

Introduction

Material and Methods

Results

Discussion

References 
CHAPTER 8

General Discussion

91

References

96

Summary

97

Samenvatting

99

List of Publications

101

Nawoord

105

Curriculum Vitae 
CHAPTER 1

INTRODUCTION 
One of the remedies for patients suffering from severe heart failure is heart transplantation. Lack of donors and problems with rejection of the graft have inspired many investigators to find alternatives for heart transplantation. The use of grafts constructed by the patients own muscle material overcomes the problem of tissue rejection. In Maastricht investigations are currently performed to explore the possibility to use the latissimus dorsi muscle to support the failing heart.

For the so-called cardiomyoplasty procedure (2) the patients latissimus dorsi muscle is mobilized from its surrounding tissue, leaving its origo near the scapula intact, thus leaving vascular and nerve structures intact. Subsequently the muscle is transposed into the thorax, wrapped around the heart and electrically stimulated by means of a pacemaker, to augment the function of the failing heart. Some details of these studies are described in the thesis of Lucas (46). It can be expected that the use of the predominantly white (type II, fast) latissimus dorsi muscle encounters some problems. For instance fatigue is likely to occur in this muscle, that is only used for incidental contractions, when it is forced to do continuous work. Also the metabolic properties of the heart muscle (as well as red skeletal muscles) are different from that of the latissimus dorsi muscle, which has a predominantly glycolytic metabolism. Several measures are taken to adjust the muscle to the changed demands, such as a gradual adaptation of the stimulation protocol of the wrapped muscle. Beginning with only brief contractions (1 pulse), synchronized to every third or second heart beat, then two weeks later 2 pulses, ending with a burst of 6 pulses, synchronized to every heart beat. The whole 'training period' takes 6-12 weeks. Since cardiac function of the patients is already depressed at the moment of operation it is important to shorten this 'training' period, or at least have an optimal strength of the muscle during this period. In other words we would like to stimulate the muscle not only electrically but also biochemically. Because red fibres derive a large part of their energy from fatty acid oxidation, and because carnitine is a key substance in fatty acid oxidation we decided to investigate the role of carnitine in latissimus dorsi muscle performance. In this thesis the acute effect of carnitine on electrically stimulated (paced) skeletal muscle has been investigated as part of the cardiomyoplasty project. Since basic knowledge of the basic properties of skeletal and cardiac muscle and of carnitine is required to be able to improve adaptation of $\mathrm{m}$. latissimus dorsi to the altered circumstances, some aspects of muscle physiology and carnitine chemistry will be discussed below. 
Following the Introduction, information regarding specific parts of the studies performed in this thesis is presented in the form of published papers.

\section{SKELETAL MUSCLE}

Striated muscles are generally classified into two types:

\section{1) Skeletal muscle \\ 2) Cardiac muscle}

Smooth muscle, which occurs for instance in the walls of blood vessels and in various abdominal organs, will not be discussed in this Introduction.

Both skeletal and cardiac muscle have a striated appearance in the light microscope, caused by the organization of the contractile proteins. Skeletal muscle is under voluntary nervous control, whereas heart muscle is not. Smooth muscle lacks the striated appearance under the light microscope and is not under voluntary control.

The striated fibres of skeletal muscle are very long, up to $10 \mathrm{~cm}$. Some run from the origin of a muscle to its insertion. The diameter of these cylindrical cells varies from 30 to $60 \mu \mathrm{m}$, and each may contain thousands of nuclei, which usually lie near the surface of the cell. Striated muscles are composed of myofilaments, containing four important proteins for contraction: actin, myosin, troponin and tropomyosin. The interaction is described in the 'sliding filament theory' (for a extensive description of muscle contraction see (71)). During contraction neither actin nor myosin filaments themselves shorten, there are crossbridges formed between the proteins, this is an energy dependent process. Hence, fast muscles consume more ATP per unit time than slow muscles. For maintenance work we therefore use the slow tonic 'red' muscles, rich in myoglobin, whereas the myoglobin-poor muscles are used for rapid movements (38).

Heart muscle has fibres that are much shorter than those in skeletal muscles. Individual cells are connected to their neighbours and so the whole muscle consists of a network. The points of adhesion between adjacent cells are called intercalated discs. The cross striations are similar to those in skeletal muscle cells. There are, however, one or two nuclei in each cell, lying near the centre of the cell.

\section{ENERGY PRODUCTION IN RED AND WHITE MUSCLES}

The colour difference between red (type I) and white (type II) muscles is mainly based on a higher content of myoglobin and blood vessels in red than in white muscles. Red fibres usually have a smaller diameter than white fibres, they are rich in sarcoplasm and contain more lipids. The amount of glycogen varies and does not relate to the fibre type. Red fibres contain more mitochondria than white fibres.

Red muscles are also 'slow' muscles, their contraction and relaxation times are longer than in white muscles. A white, or fast muscle is able to generate fast contractions, but is easily fatigued. The classification used here will be type I (slow 
twitch) and type II (fast twitch) fibres and is based on the presence of heavy chain myosin in type I fibres. The classification Type I/II is originally based on the sensitivity of myosin for retaining or losing ATPase activity after exposure to either high or low $\mathrm{pH}$. Type I fibres show a loss of ATPase activity after preincubation of the muscle sections at $\mathrm{pH}$ 10.3. Type II fibres stain intensely after alkaline preincubation. Preincubation at $\mathrm{pH} 4.3$ results in a loss of ATPase staining in a majority of the type II whereas type I fibres stain intensely.

The fast twitch fibres can be subdivided: Type Ila is considered intermediate in that its fast contraction speed is combined with a moderately well developed capacity for both aerobic and anaerobic energy transfer. These fibres are also called fastoxidative glycolytic or FOG fibres. Another subdivision type IIb possesses the greatest anaerobic potential and is the true fast-glycolytic fibre (or FG fibre). Type Ilc is normally a rare and undifferentiated fibre that may be involved in re-innervation or motor unit transformation.

Biochemically, red muscles show a high level of enzymes that are involved in the aerobic part of carbohydrate metabolism and have a higher capacity for oxidation of lipids. White muscles, however, show a higher activity of enzymes involved in glycolysis and glycogenolysis. The combination of high myoglobin levels, high capacity of aerobic metabolism, a dense capillary distribution and a slow contraction pattern, is favourable for a continuous aerobic ATP resynthesis, that is required for the maintenance of long term contractions. White muscles are dependent on glyco(geno)lysis for ATP synthesis. The contraction time of a white muscle is therefore limited by the amount of glycogen present in the muscle. An additional source of energy can be glucose, extracted from the extracellular space.

\section{PACING OF SKELETAL MUSCLE}

Delivering electrical pulses to a muscle by means of electrodes either placed around a nerve, or directly in the muscle tissue, is called pacing. The electrical pulses can either be generated from a pulse generator, or as in this study from an implanted pacemaker. The pulse amplitude, pulse frequency, interpulse intervals and other characteristics of the pulse(s) can be programmed with an extracorporeal programmer. This combination of implanted pacemaker and (muscle) electrodes allows us to measure contractile characteristics and fatigue of in situ paced latissimus dorsi muscle in vivo (76).

Fatigue is the decrease in contractile strength that occurs in a contracting muscle. Failure of the inward spread of action potential, deficient release of calcium from intracellular stores and lowered sensitivity of the contractile system to calcium due to lowered $\mathrm{pH}$ are mechanisms that have been proposed to explain fatigue. Also a specific change of the actin-myosin interaction has been suggested to cause fatigue. Metabolic changes that occur in muscle fatigue lead to, among others, reduced concentrations of phosphocreatine and ATP and to accumulation of ADP, $\mathrm{H}^{+}$, lactate and $\mathrm{Pi}$. The review of Fitts and Metzger (27) discusses several aspects of fatigue in high intensity exercise of short duration and in endurance exercise. They described a lower affinity of $\mathrm{Ca}^{2+}$ to contractile proteins during acidosis as part of the fatigue process. 
It has been demonstrated that skeletal muscle will adapt to increased functional demands, such as those imposed by chronic electrical stimulation and muscle that has been conditioned in this way shows an increased resistance to fatigue. Pette $(59,60)$ has shown that chronic nerve stimulation with a frequency resembling that of a slow motor neuron transforms fast-twitch into slow-twitch muscle and results into a uniform histochemical appearance in all fibres $(59,60)$.

Especially in the light of the latissimus dorsi muscle as a potential functional replacement for the failing myocardium, this muscle must be able to perform sustained work without fatiguing. The adaptation of latissimus dorsi muscle to these increased demands has been studied by several groups (compare $1,39,50,76$ ). Lucas (46) discussed extensively the findings of our group with regards to muscle training, adaptation and functional aspects of cardiomyoplasty.

\section{CARNITINE}

Carnitine was discovered by Krimberg in 1905 in a bovine muscle extract (31). Carnitine is one of the most widely and naturally occurring constituents of many biological systems, from micro-organisms to mammals $(17,24,29)$. The review of Fraenkel and Friedman (30) as early as 1957 evoked a series of investigations carried out in order to elucidate the biosynthesis and physiological function of carnitine.

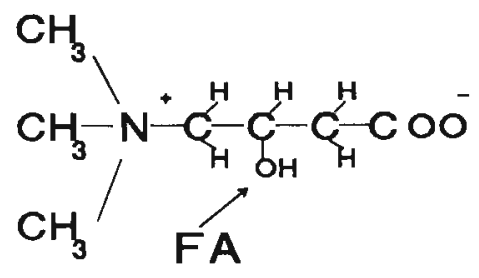

Figure 1.1.Structural formula of carnitine, the arrow indicates the site of fatty acid (FA) esterification.

Chemically, carnitine is beta-hydroxy-gamma-trimethylamino-butyric acid. The Lisomer is the naturally occurring compound. In the studies described in this thesis only the $\mathrm{L}$-isomers of carnitine and its derivatives are used. A number of studies on the biosynthesis of carnitine in both animals and microorganisms has resulted in the establishment of a general pathway for its synthesis.

It is generally agreed that the precursor of carnitine is $\varepsilon$-n-trimethyl-L-lysine, which can be formed from lysyl residues in proteins $(10,17)$. Wolf and Berger $(80)$ and Bremer (10) demonstrated "in vivo" the transfer of methyl groups from methionine to carnitine. Later studies indicated that carnitine is synthesized by the liver and distributed from the liver to other tissues. $(7,24)$. 


\section{Carnitine and paced muscles}

\section{Improvement of vascular metabolism}

Marie-Louise Dubelaar 


\section{CARNITINE AND PACED MUSCLES}

Improvement of vascular metabolism 



\title{
CARNITINE AND PACED MUSCLES
}

\author{
Improvement of vascular metabolism
}

\section{PROEFSCHRIFT}

ter verkrijging van de graad van doctor aan de Rijksuniversiteit Limburg te Maastricht, op gezag van de Rector Magnificus, Prof. Mr. M.J. Cohen, volgens het besluit van het College van Dekanen,

in het openbaar te verdedigen op donderdag, 8 oktober 1992 om 16.00 uur

door

\section{MARIA LOUISA DUBELAAR}

geboren te Amsterdam

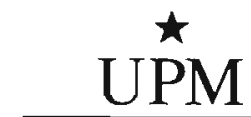

UNIVERSITAIRE PERS MAASTRICHT 


\section{Promotores:}

Prof. Dr. W.C. Hülsmann

Prof. Dr. G.J. van der Vusse

\section{Beoordelingscommissie:}

Prof. Dr. R.S. Reneman, voorzitter

Prof. Dr. A. Huson

Prof. Dr. H.J.J. Wellens

Prof. Dr. H.R. Scholte

(Erasmus Universiteit Rotterdam)

Prof. Dr. P. Verdouw

(Erasmus Universiteit Rotterdam)

\section{CIP-GEGEVENS KONINKLIJKE BIBLIOTHEEK, DEN HAAG}

Dubelaar, Maria Louisa

Carnitine and paced muscles. Improvement of vascular metabolism / Maria Louisa Dubelaar. - Maastricht :

Universitaire Pers Maastricht. -III.

Thesis Maastricht. - With ref. - With summary in Dutch.

ISBN 90-5278-037-4

NUGI 743

Subject headings: carnitine / muscles / vascular metabolism. 
Weet je ..... 


\section{LIST OF ABBREVIATIONS}

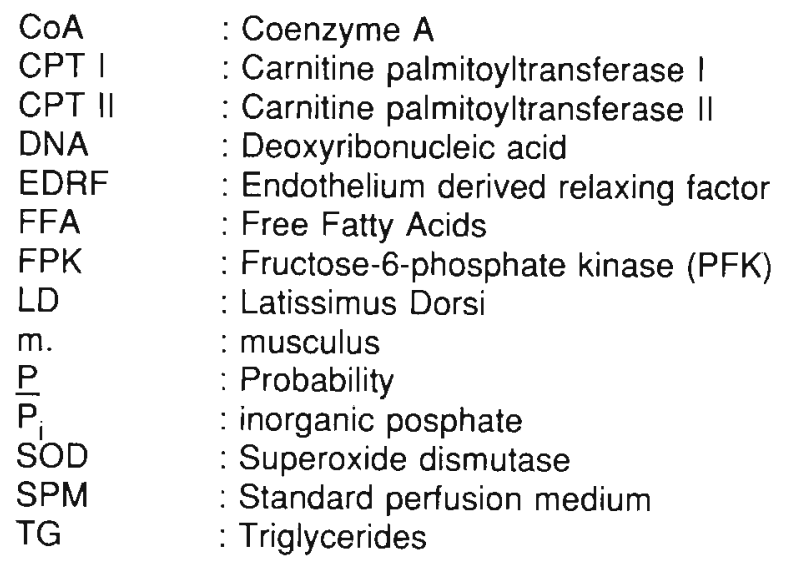




\section{CONTENTS}

$\begin{array}{ll}\text { Abbreviations } & 6\end{array}$

CHAPTER $1 \quad$ Introduction 11

Skeletal muscle $\quad 14$

Energy production in red and white muscles 14

Pacing of skeletal muscle $\quad 15$

$\begin{array}{ll}\text { Carnitine } & 16\end{array}$

$\begin{array}{ll}\text { Function of carnitine } & 17\end{array}$

Carnitine in muscle of several species 18

Aim of the thesis 20

References $\quad 22$

CHAPTER 2 Acute effect of L-carnitine upon skeletal muscle force 27 tests in the dog

$\begin{array}{ll}\text { Abstract } & 28\end{array}$

Introduction 29

Material and Methods $\quad 29$

Results 32

Discussion 33

$\begin{array}{ll}\text { References } & 37\end{array}$

Chapter 3 The effect of L-carnitine on force development of the 39 latissimus dorsi muscle in dogs

Abstract

Introduction $\quad 41$

Material and Methods $\quad 41$

Results $\quad 43$

Discussion $\quad 44$

References $\quad 46$ 
ChaPter 4 Carnitine in metabolism of paced cardiac and skeletal muscles; prevention of acidosis and improvement of vascular flow

Abstract

Introduction

Effect of carnitine on lactic acidosis in Langendorff heart

Acute effect of carnitine on skeletal muscle force in vivo

Carnitine and energy supply in blood vessels

Examples of improved function by carnitine in preischemic muscles

Mechanisms by which carnitine may improve blood flow

Long-chain acylcarnitine and loss of coronary flow

Carnitine and acute cholinomimetic effects on muscle

References

Chapter 5 Carnitine requirement of vascular endothelial and smooth muscle cells in imminent ischemia

Abstract

Introduction

Material and Methods

Results

Discussion

References

ChAPTER 6 Chronic L-carnitine administration combined with minimal electrical stimulation promotes transformation of canine latissimus dorsi muscle

Abstract

Introduction

Material and Methods

Results

Discussion

References

ChAPTER 7 On the mechanism of fat accumulation in wrapped latissimus dorsi muscle (cardiomyoplasty), and the effect of chronic L-carnitine administration

Abstract

Introduction

Material and Methods

Results

Discussion

References 
CHAPTER 8

General Discussion

91

References

96

Summary

97

Samenvatting

99

List of Publications

101

Nawoord

105

Curriculum Vitae 
CHAPTER 1

INTRODUCTION 
One of the remedies for patients suffering from severe heart failure is heart transplantation. Lack of donors and problems with rejection of the graft have inspired many investigators to find alternatives for heart transplantation. The use of grafts constructed by the patients own muscle material overcomes the problem of tissue rejection. In Maastricht investigations are currently performed to explore the possibility to use the latissimus dorsi muscle to support the failing heart.

For the so-called cardiomyoplasty procedure (2) the patients latissimus dorsi muscle is mobilized from its surrounding tissue, leaving its origo near the scapula intact, thus leaving vascular and nerve structures intact. Subsequently the muscle is transposed into the thorax, wrapped around the heart and electrically stimulated by means of a pacemaker, to augment the function of the failing heart. Some details of these studies are described in the thesis of Lucas (46). It can be expected that the use of the predominantly white (type II, fast) latissimus dorsi muscle encounters some problems. For instance fatigue is likely to occur in this muscle, that is only used for incidental contractions, when it is forced to do continuous work. Also the metabolic properties of the heart muscle (as well as red skeletal muscles) are different from that of the latissimus dorsi muscle, which has a predominantly glycolytic metabolism. Several measures are taken to adjust the muscle to the changed demands, such as a gradual adaptation of the stimulation protocol of the wrapped muscle. Beginning with only brief contractions (1 pulse), synchronized to every third or second heart beat, then two weeks later 2 pulses, ending with a burst of 6 pulses, synchronized to every heart beat. The whole 'training period' takes 6-12 weeks. Since cardiac function of the patients is already depressed at the moment of operation it is important to shorten this 'training' period, or at least have an optimal strength of the muscle during this period. In other words we would like to stimulate the muscle not only electrically but also biochemically. Because red fibres derive a large part of their energy from fatty acid oxidation, and because carnitine is a key substance in fatty acid oxidation we decided to investigate the role of carnitine in latissimus dorsi muscle performance. In this thesis the acute effect of carnitine on electrically stimulated (paced) skeletal muscle has been investigated as part of the cardiomyoplasty project. Since basic knowledge of the basic properties of skeletal and cardiac muscle and of carnitine is required to be able to improve adaptation of $\mathrm{m}$. latissimus dorsi to the altered circumstances, some aspects of muscle physiology and carnitine chemistry will be discussed below. 
Following the Introduction, information regarding specific parts of the studies performed in this thesis is presented in the form of published papers.

\section{SKELETAL MUSCLE}

Striated muscles are generally classified into two types:

\section{1) Skeletal muscle \\ 2) Cardiac muscle}

Smooth muscle, which occurs for instance in the walls of blood vessels and in various abdominal organs, will not be discussed in this Introduction.

Both skeletal and cardiac muscle have a striated appearance in the light microscope, caused by the organization of the contractile proteins. Skeletal muscle is under voluntary nervous control, whereas heart muscle is not. Smooth muscle lacks the striated appearance under the light microscope and is not under voluntary control.

The striated fibres of skeletal muscle are very long, up to $10 \mathrm{~cm}$. Some run from the origin of a muscle to its insertion. The diameter of these cylindrical cells varies from 30 to $60 \mu \mathrm{m}$, and each may contain thousands of nuclei, which usually lie near the surface of the cell. Striated muscles are composed of myofilaments, containing four important proteins for contraction: actin, myosin, troponin and tropomyosin. The interaction is described in the 'sliding filament theory' (for a extensive description of muscle contraction see (71)). During contraction neither actin nor myosin filaments themselves shorten, there are crossbridges formed between the proteins, this is an energy dependent process. Hence, fast muscles consume more ATP per unit time than slow muscles. For maintenance work we therefore use the slow tonic 'red' muscles, rich in myoglobin, whereas the myoglobin-poor muscles are used for rapid movements (38).

Heart muscle has fibres that are much shorter than those in skeletal muscles. Individual cells are connected to their neighbours and so the whole muscle consists of a network. The points of adhesion between adjacent cells are called intercalated discs. The cross striations are similar to those in skeletal muscle cells. There are, however, one or two nuclei in each cell, lying near the centre of the cell.

\section{ENERGY PRODUCTION IN RED AND WHITE MUSCLES}

The colour difference between red (type I) and white (type II) muscles is mainly based on a higher content of myoglobin and blood vessels in red than in white muscles. Red fibres usually have a smaller diameter than white fibres, they are rich in sarcoplasm and contain more lipids. The amount of glycogen varies and does not relate to the fibre type. Red fibres contain more mitochondria than white fibres.

Red muscles are also 'slow' muscles, their contraction and relaxation times are longer than in white muscles. A white, or fast muscle is able to generate fast contractions, but is easily fatigued. The classification used here will be type I (slow 
twitch) and type II (fast twitch) fibres and is based on the presence of heavy chain myosin in type I fibres. The classification Type I/II is originally based on the sensitivity of myosin for retaining or losing ATPase activity after exposure to either high or low $\mathrm{pH}$. Type I fibres show a loss of ATPase activity after preincubation of the muscle sections at $\mathrm{pH}$ 10.3. Type II fibres stain intensely after alkaline preincubation. Preincubation at $\mathrm{pH} 4.3$ results in a loss of ATPase staining in a majority of the type II whereas type I fibres stain intensely.

The fast twitch fibres can be subdivided: Type Ila is considered intermediate in that its fast contraction speed is combined with a moderately well developed capacity for both aerobic and anaerobic energy transfer. These fibres are also called fastoxidative glycolytic or FOG fibres. Another subdivision type IIb possesses the greatest anaerobic potential and is the true fast-glycolytic fibre (or FG fibre). Type Ilc is normally a rare and undifferentiated fibre that may be involved in re-innervation or motor unit transformation.

Biochemically, red muscles show a high level of enzymes that are involved in the aerobic part of carbohydrate metabolism and have a higher capacity for oxidation of lipids. White muscles, however, show a higher activity of enzymes involved in glycolysis and glycogenolysis. The combination of high myoglobin levels, high capacity of aerobic metabolism, a dense capillary distribution and a slow contraction pattern, is favourable for a continuous aerobic ATP resynthesis, that is required for the maintenance of long term contractions. White muscles are dependent on glyco(geno)lysis for ATP synthesis. The contraction time of a white muscle is therefore limited by the amount of glycogen present in the muscle. An additional source of energy can be glucose, extracted from the extracellular space.

\section{PACING OF SKELETAL MUSCLE}

Delivering electrical pulses to a muscle by means of electrodes either placed around a nerve, or directly in the muscle tissue, is called pacing. The electrical pulses can either be generated from a pulse generator, or as in this study from an implanted pacemaker. The pulse amplitude, pulse frequency, interpulse intervals and other characteristics of the pulse(s) can be programmed with an extracorporeal programmer. This combination of implanted pacemaker and (muscle) electrodes allows us to measure contractile characteristics and fatigue of in situ paced latissimus dorsi muscle in vivo (76).

Fatigue is the decrease in contractile strength that occurs in a contracting muscle. Failure of the inward spread of action potential, deficient release of calcium from intracellular stores and lowered sensitivity of the contractile system to calcium due to lowered $\mathrm{pH}$ are mechanisms that have been proposed to explain fatigue. Also a specific change of the actin-myosin interaction has been suggested to cause fatigue. Metabolic changes that occur in muscle fatigue lead to, among others, reduced concentrations of phosphocreatine and ATP and to accumulation of ADP, $\mathrm{H}^{+}$, lactate and $\mathrm{Pi}$. The review of Fitts and Metzger (27) discusses several aspects of fatigue in high intensity exercise of short duration and in endurance exercise. They described a lower affinity of $\mathrm{Ca}^{2+}$ to contractile proteins during acidosis as part of the fatigue process. 
It has been demonstrated that skeletal muscle will adapt to increased functional demands, such as those imposed by chronic electrical stimulation and muscle that has been conditioned in this way shows an increased resistance to fatigue. Pette $(59,60)$ has shown that chronic nerve stimulation with a frequency resembling that of a slow motor neuron transforms fast-twitch into slow-twitch muscle and results into a uniform histochemical appearance in all fibres $(59,60)$.

Especially in the light of the latissimus dorsi muscle as a potential functional replacement for the failing myocardium, this muscle must be able to perform sustained work without fatiguing. The adaptation of latissimus dorsi muscle to these increased demands has been studied by several groups (compare $1,39,50,76$ ). Lucas (46) discussed extensively the findings of our group with regards to muscle training, adaptation and functional aspects of cardiomyoplasty.

\section{CARNITINE}

Carnitine was discovered by Krimberg in 1905 in a bovine muscle extract (31). Carnitine is one of the most widely and naturally occurring constituents of many biological systems, from micro-organisms to mammals $(17,24,29)$. The review of Fraenkel and Friedman (30) as early as 1957 evoked a series of investigations carried out in order to elucidate the biosynthesis and physiological function of carnitine.

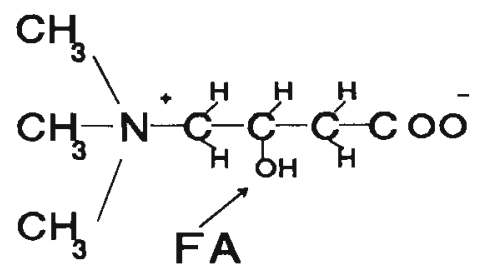

Figure 1.1.Structural formula of carnitine, the arrow indicates the site of fatty acid (FA) esterification.

Chemically, carnitine is beta-hydroxy-gamma-trimethylamino-butyric acid. The Lisomer is the naturally occurring compound. In the studies described in this thesis only the $\mathrm{L}$-isomers of carnitine and its derivatives are used. A number of studies on the biosynthesis of carnitine in both animals and microorganisms has resulted in the establishment of a general pathway for its synthesis.

It is generally agreed that the precursor of carnitine is $\varepsilon$-n-trimethyl-L-lysine, which can be formed from lysyl residues in proteins $(10,17)$. Wolf and Berger $(80)$ and Bremer (10) demonstrated "in vivo" the transfer of methyl groups from methionine to carnitine. Later studies indicated that carnitine is synthesized by the liver and distributed from the liver to other tissues. $(7,24)$. 


\section{Carnitine and paced muscles}

\section{Improvement of vascular metabolism}

Marie-Louise Dubelaar 


\section{CARNITINE AND PACED MUSCLES}

Improvement of vascular metabolism 



\title{
CARNITINE AND PACED MUSCLES
}

\author{
Improvement of vascular metabolism
}

\section{PROEFSCHRIFT}

ter verkrijging van de graad van doctor aan de Rijksuniversiteit Limburg te Maastricht, op gezag van de Rector Magnificus, Prof. Mr. M.J. Cohen, volgens het besluit van het College van Dekanen,

in het openbaar te verdedigen op donderdag, 8 oktober 1992 om 16.00 uur

door

\section{MARIA LOUISA DUBELAAR}

geboren te Amsterdam

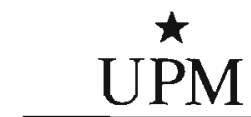

UNIVERSITAIRE PERS MAASTRICHT 


\section{Promotores:}

Prof. Dr. W.C. Hülsmann

Prof. Dr. G.J. van der Vusse

\section{Beoordelingscommissie:}

Prof. Dr. R.S. Reneman, voorzitter

Prof. Dr. A. Huson

Prof. Dr. H.J.J. Wellens

Prof. Dr. H.R. Scholte

(Erasmus Universiteit Rotterdam)

Prof. Dr. P. Verdouw

(Erasmus Universiteit Rotterdam)

\section{CIP-GEGEVENS KONINKLIJKE BIBLIOTHEEK, DEN HAAG}

Dubelaar, Maria Louisa

Carnitine and paced muscles. Improvement of vascular metabolism / Maria Louisa Dubelaar. - Maastricht :

Universitaire Pers Maastricht. -III.

Thesis Maastricht. - With ref. - With summary in Dutch.

ISBN 90-5278-037-4

NUGI 743

Subject headings: carnitine / muscles / vascular metabolism. 
Weet je ..... 


\section{LIST OF ABBREVIATIONS}

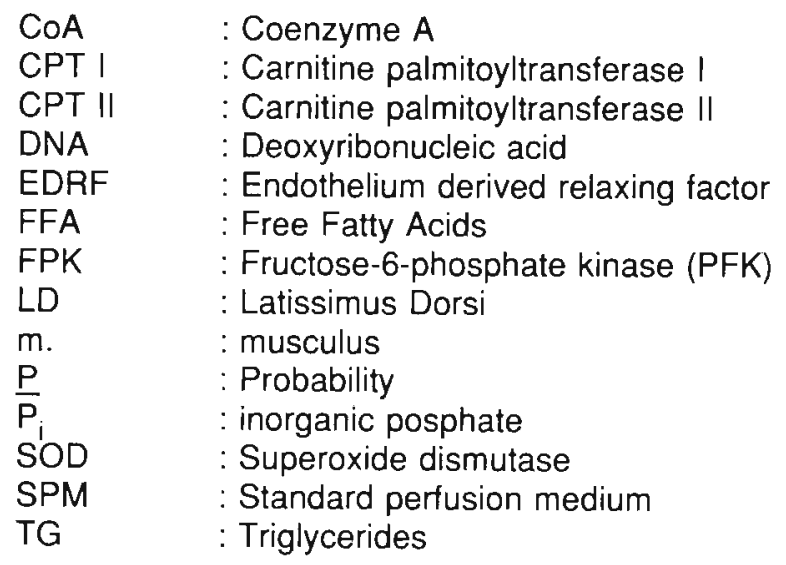




\section{CONTENTS}

$\begin{array}{ll}\text { Abbreviations } & 6\end{array}$

CHAPTER $1 \quad$ Introduction 11

Skeletal muscle $\quad 14$

Energy production in red and white muscles 14

Pacing of skeletal muscle $\quad 15$

$\begin{array}{ll}\text { Carnitine } & 16\end{array}$

$\begin{array}{ll}\text { Function of carnitine } & 17\end{array}$

Carnitine in muscle of several species 18

Aim of the thesis 20

References $\quad 22$

CHAPTER 2 Acute effect of L-carnitine upon skeletal muscle force 27 tests in the dog

$\begin{array}{ll}\text { Abstract } & 28\end{array}$

Introduction 29

Material and Methods $\quad 29$

Results 32

Discussion 33

$\begin{array}{ll}\text { References } & 37\end{array}$

Chapter 3 The effect of L-carnitine on force development of the 39 latissimus dorsi muscle in dogs

Abstract

Introduction $\quad 41$

Material and Methods $\quad 41$

Results $\quad 43$

Discussion $\quad 44$

References $\quad 46$ 
ChaPter 4 Carnitine in metabolism of paced cardiac and skeletal muscles; prevention of acidosis and improvement of vascular flow

Abstract

Introduction

Effect of carnitine on lactic acidosis in Langendorff heart

Acute effect of carnitine on skeletal muscle force in vivo

Carnitine and energy supply in blood vessels

Examples of improved function by carnitine in preischemic muscles

Mechanisms by which carnitine may improve blood flow

Long-chain acylcarnitine and loss of coronary flow

Carnitine and acute cholinomimetic effects on muscle

References

Chapter 5 Carnitine requirement of vascular endothelial and smooth muscle cells in imminent ischemia

Abstract

Introduction

Material and Methods

Results

Discussion

References

ChAPTER 6 Chronic L-carnitine administration combined with minimal electrical stimulation promotes transformation of canine latissimus dorsi muscle

Abstract

Introduction

Material and Methods

Results

Discussion

References

ChAPTER 7 On the mechanism of fat accumulation in wrapped latissimus dorsi muscle (cardiomyoplasty), and the effect of chronic L-carnitine administration

Abstract

Introduction

Material and Methods

Results

Discussion

References 
CHAPTER 8

General Discussion

91

References

96

Summary

97

Samenvatting

99

List of Publications

101

Nawoord

105

Curriculum Vitae 
CHAPTER 1

INTRODUCTION 
One of the remedies for patients suffering from severe heart failure is heart transplantation. Lack of donors and problems with rejection of the graft have inspired many investigators to find alternatives for heart transplantation. The use of grafts constructed by the patients own muscle material overcomes the problem of tissue rejection. In Maastricht investigations are currently performed to explore the possibility to use the latissimus dorsi muscle to support the failing heart.

For the so-called cardiomyoplasty procedure (2) the patients latissimus dorsi muscle is mobilized from its surrounding tissue, leaving its origo near the scapula intact, thus leaving vascular and nerve structures intact. Subsequently the muscle is transposed into the thorax, wrapped around the heart and electrically stimulated by means of a pacemaker, to augment the function of the failing heart. Some details of these studies are described in the thesis of Lucas (46). It can be expected that the use of the predominantly white (type II, fast) latissimus dorsi muscle encounters some problems. For instance fatigue is likely to occur in this muscle, that is only used for incidental contractions, when it is forced to do continuous work. Also the metabolic properties of the heart muscle (as well as red skeletal muscles) are different from that of the latissimus dorsi muscle, which has a predominantly glycolytic metabolism. Several measures are taken to adjust the muscle to the changed demands, such as a gradual adaptation of the stimulation protocol of the wrapped muscle. Beginning with only brief contractions (1 pulse), synchronized to every third or second heart beat, then two weeks later 2 pulses, ending with a burst of 6 pulses, synchronized to every heart beat. The whole 'training period' takes 6-12 weeks. Since cardiac function of the patients is already depressed at the moment of operation it is important to shorten this 'training' period, or at least have an optimal strength of the muscle during this period. In other words we would like to stimulate the muscle not only electrically but also biochemically. Because red fibres derive a large part of their energy from fatty acid oxidation, and because carnitine is a key substance in fatty acid oxidation we decided to investigate the role of carnitine in latissimus dorsi muscle performance. In this thesis the acute effect of carnitine on electrically stimulated (paced) skeletal muscle has been investigated as part of the cardiomyoplasty project. Since basic knowledge of the basic properties of skeletal and cardiac muscle and of carnitine is required to be able to improve adaptation of $\mathrm{m}$. latissimus dorsi to the altered circumstances, some aspects of muscle physiology and carnitine chemistry will be discussed below. 
Following the Introduction, information regarding specific parts of the studies performed in this thesis is presented in the form of published papers.

\section{SKELETAL MUSCLE}

Striated muscles are generally classified into two types:

\section{1) Skeletal muscle \\ 2) Cardiac muscle}

Smooth muscle, which occurs for instance in the walls of blood vessels and in various abdominal organs, will not be discussed in this Introduction.

Both skeletal and cardiac muscle have a striated appearance in the light microscope, caused by the organization of the contractile proteins. Skeletal muscle is under voluntary nervous control, whereas heart muscle is not. Smooth muscle lacks the striated appearance under the light microscope and is not under voluntary control.

The striated fibres of skeletal muscle are very long, up to $10 \mathrm{~cm}$. Some run from the origin of a muscle to its insertion. The diameter of these cylindrical cells varies from 30 to $60 \mu \mathrm{m}$, and each may contain thousands of nuclei, which usually lie near the surface of the cell. Striated muscles are composed of myofilaments, containing four important proteins for contraction: actin, myosin, troponin and tropomyosin. The interaction is described in the 'sliding filament theory' (for a extensive description of muscle contraction see (71)). During contraction neither actin nor myosin filaments themselves shorten, there are crossbridges formed between the proteins, this is an energy dependent process. Hence, fast muscles consume more ATP per unit time than slow muscles. For maintenance work we therefore use the slow tonic 'red' muscles, rich in myoglobin, whereas the myoglobin-poor muscles are used for rapid movements (38).

Heart muscle has fibres that are much shorter than those in skeletal muscles. Individual cells are connected to their neighbours and so the whole muscle consists of a network. The points of adhesion between adjacent cells are called intercalated discs. The cross striations are similar to those in skeletal muscle cells. There are, however, one or two nuclei in each cell, lying near the centre of the cell.

\section{ENERGY PRODUCTION IN RED AND WHITE MUSCLES}

The colour difference between red (type I) and white (type II) muscles is mainly based on a higher content of myoglobin and blood vessels in red than in white muscles. Red fibres usually have a smaller diameter than white fibres, they are rich in sarcoplasm and contain more lipids. The amount of glycogen varies and does not relate to the fibre type. Red fibres contain more mitochondria than white fibres.

Red muscles are also 'slow' muscles, their contraction and relaxation times are longer than in white muscles. A white, or fast muscle is able to generate fast contractions, but is easily fatigued. The classification used here will be type I (slow 
twitch) and type II (fast twitch) fibres and is based on the presence of heavy chain myosin in type I fibres. The classification Type I/II is originally based on the sensitivity of myosin for retaining or losing ATPase activity after exposure to either high or low $\mathrm{pH}$. Type I fibres show a loss of ATPase activity after preincubation of the muscle sections at $\mathrm{pH}$ 10.3. Type II fibres stain intensely after alkaline preincubation. Preincubation at $\mathrm{pH} 4.3$ results in a loss of ATPase staining in a majority of the type II whereas type I fibres stain intensely.

The fast twitch fibres can be subdivided: Type Ila is considered intermediate in that its fast contraction speed is combined with a moderately well developed capacity for both aerobic and anaerobic energy transfer. These fibres are also called fastoxidative glycolytic or FOG fibres. Another subdivision type IIb possesses the greatest anaerobic potential and is the true fast-glycolytic fibre (or FG fibre). Type Ilc is normally a rare and undifferentiated fibre that may be involved in re-innervation or motor unit transformation.

Biochemically, red muscles show a high level of enzymes that are involved in the aerobic part of carbohydrate metabolism and have a higher capacity for oxidation of lipids. White muscles, however, show a higher activity of enzymes involved in glycolysis and glycogenolysis. The combination of high myoglobin levels, high capacity of aerobic metabolism, a dense capillary distribution and a slow contraction pattern, is favourable for a continuous aerobic ATP resynthesis, that is required for the maintenance of long term contractions. White muscles are dependent on glyco(geno)lysis for ATP synthesis. The contraction time of a white muscle is therefore limited by the amount of glycogen present in the muscle. An additional source of energy can be glucose, extracted from the extracellular space.

\section{PACING OF SKELETAL MUSCLE}

Delivering electrical pulses to a muscle by means of electrodes either placed around a nerve, or directly in the muscle tissue, is called pacing. The electrical pulses can either be generated from a pulse generator, or as in this study from an implanted pacemaker. The pulse amplitude, pulse frequency, interpulse intervals and other characteristics of the pulse(s) can be programmed with an extracorporeal programmer. This combination of implanted pacemaker and (muscle) electrodes allows us to measure contractile characteristics and fatigue of in situ paced latissimus dorsi muscle in vivo (76).

Fatigue is the decrease in contractile strength that occurs in a contracting muscle. Failure of the inward spread of action potential, deficient release of calcium from intracellular stores and lowered sensitivity of the contractile system to calcium due to lowered $\mathrm{pH}$ are mechanisms that have been proposed to explain fatigue. Also a specific change of the actin-myosin interaction has been suggested to cause fatigue. Metabolic changes that occur in muscle fatigue lead to, among others, reduced concentrations of phosphocreatine and ATP and to accumulation of ADP, $\mathrm{H}^{+}$, lactate and $\mathrm{Pi}$. The review of Fitts and Metzger (27) discusses several aspects of fatigue in high intensity exercise of short duration and in endurance exercise. They described a lower affinity of $\mathrm{Ca}^{2+}$ to contractile proteins during acidosis as part of the fatigue process. 
It has been demonstrated that skeletal muscle will adapt to increased functional demands, such as those imposed by chronic electrical stimulation and muscle that has been conditioned in this way shows an increased resistance to fatigue. Pette $(59,60)$ has shown that chronic nerve stimulation with a frequency resembling that of a slow motor neuron transforms fast-twitch into slow-twitch muscle and results into a uniform histochemical appearance in all fibres $(59,60)$.

Especially in the light of the latissimus dorsi muscle as a potential functional replacement for the failing myocardium, this muscle must be able to perform sustained work without fatiguing. The adaptation of latissimus dorsi muscle to these increased demands has been studied by several groups (compare $1,39,50,76$ ). Lucas (46) discussed extensively the findings of our group with regards to muscle training, adaptation and functional aspects of cardiomyoplasty.

\section{CARNITINE}

Carnitine was discovered by Krimberg in 1905 in a bovine muscle extract (31). Carnitine is one of the most widely and naturally occurring constituents of many biological systems, from micro-organisms to mammals $(17,24,29)$. The review of Fraenkel and Friedman (30) as early as 1957 evoked a series of investigations carried out in order to elucidate the biosynthesis and physiological function of carnitine.

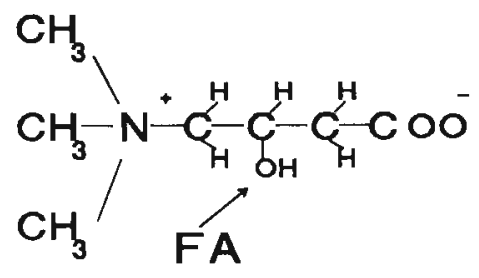

Figure 1.1.Structural formula of carnitine, the arrow indicates the site of fatty acid (FA) esterification.

Chemically, carnitine is beta-hydroxy-gamma-trimethylamino-butyric acid. The Lisomer is the naturally occurring compound. In the studies described in this thesis only the $\mathrm{L}$-isomers of carnitine and its derivatives are used. A number of studies on the biosynthesis of carnitine in both animals and microorganisms has resulted in the establishment of a general pathway for its synthesis.

It is generally agreed that the precursor of carnitine is $\varepsilon$-n-trimethyl-L-lysine, which can be formed from lysyl residues in proteins $(10,17)$. Wolf and Berger $(80)$ and Bremer (10) demonstrated "in vivo" the transfer of methyl groups from methionine to carnitine. Later studies indicated that carnitine is synthesized by the liver and distributed from the liver to other tissues. $(7,24)$. 
The physiological role of carnitine was soon acknowledged as intermediate in lipid metabolism. It was found that carnitine serves as a carrier of fatty acyl groups across the mitochondrial membrane $(11,13,14,34,43,55,80)$.

Muscles are particularly rich in carnitine as will be discussed below, while in some other tissues, such as epididymis, high carnitine levels are found as well (8).

\section{FUNCTION OF CARNITINE}

Carnitine has a fundamental role as long chain fatty acid carrier across the mitochondrial membrane and in ketone body formation. In 1955 Fritz (33) reported that carnitine stimulates the oxidation of fatty acids in liver homogenates. In the same year Friedman and Fraenkel (32) showed that carnitine can undergo reversible acetylation. It has been shown that carnitine can be acylated with carboxylic acids with chain lengths varying from 2 (acetate) to 22 (erucate) carbon atoms.

The crucial role of carnitine in fatty acid oxidation can be explained by its role in the transport of fatty acids across the mitochondrial membranes to the mitochondrial matrix, where beta-oxidation occurs. This process consists of the following steps: First, fatty acids are activated to their CoA derivatives by acylCoA synthetases (E.C. 6.2.1.3) at the cytoplasmic site of the outer mitochondrial and endoplasmic reticular membrane. At the outer mitochondrial membrane the enzyme Carnitine Palmitoyl Transferase I (E.C. 2.3.1.21) facilitates the transfer of the acylgroup from CoA to carnitine. The acylcarnitine thus formed, permeates the mitochondrial inner membrane via Carnitine translocase. At the inner site of the innermitochondrial membrane Carnitine Palmitoyl Transferase II (E.C. 2.3.1.21) transfers the acylgroup to CoA, present in the mitochondrial matrix. The carnitine residue is transferred back to the outer membrane through the action of the Carnitine translocase in exchange for acylcarnitine (21). This process is also illustrated in figure 4.1.

Separate carnitine acyltransferases exist with chain length specificities that overlap. Six acyltransferases have been isolated from mitochondria; three from the innerand three from the outer-mitochondrial membrane (12). These are: acetyltransferase, utilizing fatty acyl groups of two to three carbons in length, octanoyl transferase using fatty acyl groups from six to 10 carbons, and palmitoyl transferase utilizing fatty acyl groups of more than 12 carbons in length. Within each group isoenzymes may be present $(4,78)$. It should be noted that the transport of medium chain fatty acids into the mitochondrion can also take place in a carnitine-independent manner (12). Also extramitochondrial carnitine palmitoyltransferases exist, apparently serving other functions. Peroxisomes contain acyltransferases, microsomes contain an isoenzyme of carnitine palmitoyltransferase (78) and also plasmamembranes of erythrocytes have a malonyl-CoA sensitive carnitine palmitoyltransferase $(61,67)$.

Carnitine levels required for optimal activity of the different carnitine acyltransferases are found to vary appreciably. Low muscle and liver carnitine levels are associated with low blood plasma carnitine levels. In primary and secondary carnitine deficiency syndromes multiple phenomena are often observed: tissue lipidosis, cardiomyopathy, muscle weakness, hepatic encephalopathy by hypoglycaemia and hypoketonemia (68). Hypoglycaemia can occur during a carnitine deficient state due to increased glucose utilization by carnitine deficient tissues and impaired 
gluconeogenesis which requires the product of fatty acid oxidation: acetyl-CoA, for stimulation of pyruvate carboxylase $(5,72)$. A few other suggested functions of carnitine are:

- Stimulation of the activity of pyruvate dehydrogenase by decreasing the acetyl CoA/CoA ratio.

- Carnitine, by accepting acyl groups from acyl-CoA, makes more free CoA available for the conversion of $\alpha$-ketoglutarate into succinyl-CoA in the tricarboxylic acid cycle, thereby enhancing the metabolic flux through this cycle (38).

- Prevention of adenylate translocase inhibition by long chain acyl-COA and subsequent activation of the transport of adenine nucleotides across the inner mitochondrial membrane (73).

- Stimulation of the oxidation of branched chain amino acids during exercise. This probably occurs through conversion of branched chain acyl-CoA esters to branched chain acyl-carnitines, thus removing the feedback inhibition on the branched chain 2w0xo acid dehydrogenase complex. In addition, CoA once liberated becomes available for other metabolic processes $(56,77,79)$.

Since blood plasma and urine are easy to obtain, these biological fluids are often used for assessment of carnitine status and carnitine excretion, respectively. The concentration of total carnitine in human plasma at rest varies between 20 and 60 $\mu \mathrm{M}$. Free carnitine represents between 70 and $85 \%$ of the total amount $(3,16,44,51)$. The remaining esterified fraction contains, at rest, mainly acetylcarnitine. The total carnitine store of an average sized adult male (30 kg of muscle mass) can be estimated at $20-25 \mathrm{~g}$. The daily (urinary) excretion of carnitine is $100-300 \mu \mathrm{mol}$, or $15-50$ mg (12).

The actual tissue carnitine concentration is the resultant of a variety of metabolic processes, i.e. carnitine uptake, synthesis, transport of carnitine and carnitine excretion. Because most tissues have a carnitine concentration that is one order of magnitude higher than that of plasma, an active uptake of carnitine by the cells must take place.

\section{CARNITINE IN MUSCLE OF SEVERAL SPECIES}

The concentration of carnitine in different species and in different tissues varies over a wide range. It is found to vary between $0.6-1.4 \mathrm{mM}$ in rat muscles, $3-6 \mathrm{mM}$ in human skeletal muscle and even higher levels $(3-7 \mathrm{mM})$ in horse gluteal muscle $(28,70)$ and $15 \mathrm{mM}$ in sheep skeletal muscle $(74))$.

It is assumed that the level of carnitine is high in cells with a high oxidative capacity, especially in cells that have a preferential fatty acid oxidation.

In tables 1.1-1.3 the distribution of carnitine in several muscles of the rat (table 1.1), the dog (table 1.2) and in man (table 1.3) is shown.

In several species it can be found that the carnitine level is of the same order in various muscles within an animal. 
TABLE 1.1. The content of total carnitine in several rat muscie tissues. The values are all calculated from the values in the cited reference to give values in $\mu \mathrm{mol}$ per $\mathrm{g}$ wet weight.

\begin{tabular}{|c|c|c|c|c|}
\hline references & white & mixed & red & heart \\
\hline 8 & & 0.8 & & 1.1 \\
\hline 18 & & 0.5 & & 0.8 \\
\hline 23 & & 2.1 & & 2.8 \\
\hline 25 & 0.9 & 0.8 & 0.7 & \\
\hline 26 & 0.7 & & 0.3 & \\
\hline 35 & 0.6 & & 0.7 & \\
\hline 42 & 0.7 & & 1.1 & 0.8 \\
\hline 45 & 0.8 & 0.7 & 0.7 & 1.0 \\
\hline 48 & & 1.2 & & 1.0 \\
\hline 47 & & & & 1.3 \\
\hline 53 & & 0.7 & & 1.3 \\
\hline 54 & & 0.6 & & 1.2 \\
\hline 57 & & 0.9 & & \\
\hline 63 & & 0.7 & & \\
\hline mean & & 0.9 & & \\
\hline
\end{tabular}

The conclusion can be drawn that only in rat a higher carnitine content is found in heart than in skeletal muscles, whereas the amount in red, white or mixed skeletal muscles is approximately the same (table 1.1). Only the study of Lennon \& Mance (45) shows a higher level of carnitine in the (white) superficial vastus lateralis than in the (red) deep vastus lateralis or the (mixed type) gastrocnemius of the rat.

TABLE 1.2. The content of total carnitine in several dog muscle tissues. The values are all calculated from the values in the cited reference to give values in $\mu \mathrm{mol}$ per $\mathrm{g}$ wet weight.

\begin{tabular}{|c|c|c|c|c|}
\hline references & white & mixed & red & heart \\
\hline 2 & & & & 2.3 \\
\hline 36 & 3.7 & 3.4 & 2.4 & 1.7 \\
\hline 62 & 3.7 & 4.7 & 2.5 & 1.4 \\
\hline 64 & & 3.8 & & \\
\hline 75 & & & & 1.7 \\
\hline mean & 3.7 & 4.0 & 2.4 & 1.8 \\
\hline
\end{tabular}

In rabbit the highest carnitine level is also found in muscle and not in heart (58), despite its higher rate of $\beta$-oxidation of fatty acids. In cow (68) the level in heart is only one third of that in skeletal muscle. The level of carnitine in sheep muscle is 
extremely high $13 \mu \mathrm{mol} / \mathrm{g}$ wet weight (68). In humans (table 1.3) there is some controversy. Cederblad (19) and Mitchell (52) state that carnitine is generally lower in heart than in skeletal muscle while others $(8,65)$ found the highest level in heart.

TABLE 1.3. The content of total carnitine in several human muscle tissues. The values are all calculated from the values in the cited reference to give values in $\mu \mathrm{mol}$ per $\mathrm{g}$ wet weight.

\begin{tabular}{|c|c|c|c|c|}
\hline references & white & mixed & red & heart \\
\hline 4 & & 3.6 & & \\
\hline 8 & & 2.0 & & 4.8 \\
\hline 9 & & 2.0 & & 1.1 \\
\hline 15 & & 2.8 & & \\
\hline 19 & & 1.3 & 3.0 & 0.9 \\
\hline 20 & & 3.2 & & \\
\hline 37 & & 5.5 & & \\
\hline 40 & & 4.3 & & 0.9 \\
\hline 44 & & 4.4 & & \\
\hline 49 & & 3.3 & & \\
\hline 52 & & 4.0 & & \\
\hline 65 & & 3.3 & & \\
\hline 66 & & 4.0 & & \\
\hline 69 & & 3.3 & & \\
\hline mean & & & & \\
\hline
\end{tabular}

Maybe the carnitine level is not (or not only) related to the (fatty acid) oxidative capacity of the muscle, but to the overall oxidative (both fatty acids and glucose) capacity of the cell. It is also possible that skeletal muscle mainly serves as an intracellular storage site for carnitine. In line with this hypothesis is the observation that in blowfly (pharmia regina) the muscle does not use fats in flight, but nevertheless has an abundance of carnitine and a very active carnitine transferase (comp $6,22)$.

\section{AIM OF THE THESIS}

It was the objective of this study to evaluate the possibilities to use carnitine to improve $\mathrm{m}$. latissimus dorsi adaptation to changed functional demands. Changing muscle fibre typing by training muscles through electrical stimulation is time consuming. We would like to be able to shorten the time needed to reach complete adaptation, or at least have an optimal performance of the muscle during the training (adaptation) period. Both heart and red (type I, slow) skeletal muscle highly depend on 
fatty acid metabolism to provide energy for contraction, in contrast to white (type II) muscle. The latissimus dorsi consists for $60 \%$ of white (type II, fast) muscle, this fact combined with the knowledge. that carnitine plays a crucial role in fatty acid metabolism led us to attempt to improve muscle transformation not only through electrical stimulation but also by generating circumstances favourable for "red (type I, slow) metabolism", i.e. by supplying carnitine.

Our first aim was to investigate whether L-carnitine had an influence on muscle performance. This was inspired by the wish to have an optimal latissimus dorsi muscle force in the initial period after the cardiomyoplasty operation, when there are just a few assisted heart beats. A simple model to investigate the strength of the $\mathrm{m}$. latissimus dorsi, is the in situ latissimus dorsi that can be stimulated through muscle electrodes connected to an implanted pacemaker. In chapter 2 attention has been focused on the influence of L-carnitine on latissimus dorsi force. In chapter 3 the same in situ model is used to investigate the effect of two carnitine derivatives. This chapter also demonstrates the effect of carnitine on muscle blood flow during contraction. The possible mechanism of the acute effect of L-carnitine on muscle force is discussed in the next two chapters. Chapter 4 discusses also the role of carnitine in heart muscle and the relation between the effects in heart and skeletal muscle. We propose an important role of carnitine in the metabolism of endothelial and smooth muscle cells. In chapter 5 experiments that illustrate this role are presented. We subsequently studied the long term effects of L-carnitine administration. An effect of carnitine on muscle fibre typing has been described and therefore we studied the effect of chronic L-carnitine administration on the fibre typing of the in situ $\mathrm{m}$. latissimus dorsi (chapter 6). One of the complications we saw in $\mathrm{m}$. latissimus dorsi several months after wrapping it around the heart (cardiomyoplasty) was an extensive lipidosis in the muscle. In chapter 7 the effect of chronic L-carnitine on fat accumulation in the wrapped latissimus dorsi muscle is described. 


\section{REFERENCES}

1. Acker M, Anderson WA, Hammond RL, DiMeo F jr, McCullum J, Staum M, Velchik M, Brown W, Gale D, Salmons S, Stephenson LW. Oxygen consumption of chronically stimulated skeletal muscle. J Thorac Cardiovasc Surg (1987)94:702-709.

2. Al Makdessi $S$, Andrieu $\mathrm{J}-\mathrm{L}$, Herilier $\mathrm{H}$, Faucon $\mathrm{G}$. Effect of isoproterenol on the metabolism of myocardial fatty acids. J Mol Cell Cardiol (1987)19:141-149.

3. Angelini C, Vergani L, Costa L, Martinuzzi A, Dunner E, Marescotti C, Nosadini R. Use of carnitine in exercise physiology. Adv Clin Enzymol (1986)4:103-110.

4. Arenas J, Ricoy JR, Encinas AR, Pola P, D'lddio S, Zevciani M, DiDonato S, Corsi M. Carnitine in muscle, serum and urine of non-professional athletes: effect of physical exercise, training and $L$ carnitine administration. Muscle \& Nerve (1991)14:598-605.

5. Atkins $J$, Clandinin MT. Nutritional significance of factors affecting carnitine dependent transport of fatty acids in neonates: a review. Nutr Res (1990) 10:117-128.

6. Beenakkers AMT, Henderson PT. The localization and function of carnitine acetyl-transferase in flight muscle of the locust. Eur J Biochem (1967)1:187-192.

7. Bфhmer T, Conversion of butyrobetaine to carnitine in the rat in vivo. Biochim Biophys Acta (1974)343:551-557.

8. Bфhmer T, Mфlstad P. Carnitine transport across the plasma membrane. In: Carnitine, biosynthesis, metabolism and functions. RA Frenkel \& JD McGarry, eds. Academic Press Inc. New York, London, (1980) pp 73-90.

9. Bertoli M, Batistella PA, Vergani L, Naso A, Gasparotto ML, Romagnoli GF, Angelini C. Carnitine deficiency induced during haemodialysis and hyperlipidaemia: effect of replacement therapy. Am $J$ Clin Nutr (1981)34:1496-1500.

10. Bremer J. Biosynthesis of carnitine in vivo. Biochim Biophys Acta (1961)48:622-624.

11. Bremer J. Carnitine in intermediary metabolism. Reversible acetylation of carnitine by mitochondria. $J$ Biol Chem (1962)237:2228-2231

12. Bremer J. Carnitine - metabolism and functions. Physiol Rev (1983)63:1:420-480.

13. Bressler R. Comprehensive Biochemistry. Elsevier Amsterdam (1970) pp331.

14. Bressler R, Friedberg SJ. Effect of carnitine on the rate of palmitate incorporation into phospholipids. $J$ Biol Chem (1964)239:1364-1368.

15. Brevetti F, Chiariello M, Ferulano G, Policicchio A, Nevola E, Rossini A, Attisano T, Ambrosio G, Siliprandi N, Angelini $C$. Increase in walking distance in patients with peripheral vascular disease treated with L- carnitine; a double blind, crossover study. Circulation (1988)77:767-773.

16. Carlin JL, Reddan WG, Sanjak M, Hodach R. Carnitine metabolism during prolonged exercise and recovery in humans. Eur J Appl Physiol (1986)61:1275-1278.

17. Carter HE, Bhattacharyya PK, Weidman KR, Fraenkel G. Chemical studies on vitamin $B_{\text {Tisolation }}$ and characterisation as carnitine. Arch Biochem Biophys (1952)38:405-416.

18. Carter AL, Lennon DLF, Stratman FW. Increased acetyl carnitine in rat skeletal muscle as a result of high-intensity short duration exercise. FEBS lett (1981)126: 21-24.

19. Cederblad $\mathrm{G}$, Lindstedt $\mathrm{S}$, Lundholm $\mathrm{K}$. Concentration of carnitine in human muscle tissue. Clin Chim Acta (1974)53:311-321.

20. Cederblad G, Carlin JJ, Constantin-Teodosin D, Harper P, Hultman E. Radioisotopic assays of $\mathrm{CoASH}$ and carnitine and their acetylated forms in human skeletal muscle. Anal Biochem (1990)185:274-278.

21. Cerretelli P. Marconi C. L-carnitine supplementation in humans. The effects on physical performance. Int J Sports Med (1990)11:1-14.

22. Childress CC, Sacktor B. Traynor DR. Function of carnitine in the fatty acid oxidase-deficient insect flight muscle. J Biol Chem (1966)242:754-760.

23. Ciman M, Caldesi-Valeri V. Silliprandi N. Carnitine and acetylcarnitine in skeletal and cardiac muscle. Int J Nutr Res (1978)48:177-182.

24. Cox RA, Hoppel CL. Carnitine and trimethylaminobutyrate synthesis in rat tissues. Biochem $J$ (1974) 142:699-701.

25. Decombaz JE, Reffet B, Bloemhard Y. L-carnitine supplementation, caffeine and fuel oxidation in the exercising rat. Nutr Res (1987)7:923-933.

26. Decombaz JE, Reffet B, Bloemhard Y. Effect of 1-Carnitine and stimulated lipolysis on muscle substrates in the exercising rat. Experientia (1990)46:457-459. 
27. Fitts RH, Metzger JM. Mechanisms of muscular fatigue. In: Principles of exercise biochemistry. Med Sport Sci Basel, Karger, (1988), vol 27, pp 212-229.

28. Foster CVL, Harris RC, Snow DH. The effects of oral L-carnitine supplementation on the muscle and plasma concentrations in the thoroughbred horse. Comp Biochem Physiol (1988)91A:827-835.

29. Fraenkel $G$. Studies on the distribution of vitamin $B_{T}$ (carnitine). Biol Bull (1953)104:359-369.

30. Fraenkel G, Friedman S. Carnitine. In: Vitamins and hormones, edited by RS Harris, Marrian GF, and Thimann KV. New York: Academic, (1957)vol 15,p73-118.

31. Fraenkel $\mathrm{G}$. The proposed vitamin role of carnitine. In: Carnitine biosynthesis, metabolism and functions. (Fraenkel RA, McGarry JD, eds) New York. Academic Press. (1980),pp 1-5.

32. Friedman S, Fraenkel G. Reversible enzymatic acetylation of carnitine. Arch Biochem Biophys (1955) 59:491-501

33. Fritz IB. The effects of muscle extracts on the oxidation of palmitic acid by liver slices and homogenates. Acta Physiol Scand (1955)34:367-385.

34. Fritz IB, Yue KTN. Long chain acylcarnitine acyltransferase and the role of acylcarnitine derivatives in the catalytic increase of fatty acid oxidation induced by carnitine. J Lipid Res (1963)4:279-288.

35. Fröberg SO, Östman $J$, Sjöstrand NO. Effect of training on esterified fatty acids and carnitine in muscle and on lipolysis in adipose tissue in vitro. Acta Physiol Scand (1972)86:166-172.

36. Glatz JFC, Van Der Vusse GJ, Havenith MG, Van Der Veen FH, Lucas CMHB, Penn OCKM, Wellens HJJ. Adaptation of energy metabolism of canine latissimus dorsi muscle in response to chronic electrical stimulation. Pflügers Archiv (1992)420:1-8.

37. Hiatt WR, Regensteiner JG, Wolfel EE, Ruff L, Brass EP. Carnitine and acylcarnitine metabolism during exercise in humans. -dependence on skeletal muscle metabolic state- J Clin Invest (1989)84:1167-1173.

38. Hülsmann WCH, Siliprandi D, Ciman M, Siliprandi N. Effects of carnitine on the oxidation of $\alpha$ oxoglutarate to succinate in the presence of acetoacetate or pyruvate. Biochim Biophys Acta (1964)93:166-168.

39. lanuzzo CD, Hamilton N, O'Brien PJ. Biochemical transformation of canine skeletal muscle for use in cardiac-assist devices. J Appl Physiol (1990)68:1481-1492

40. Janssen GME, Scholte HR, Vaandrager-Verduin MHM, Ross JD. Muscle carnitine levels in endurance training and running a marathon. Int J Sports Med (1989)10:S153-S155.

41. Jobsis AC. Histochemische indrukken en biochemische waarden. Een vergelijkend onderzoek toegepast op skeletspier na experimentele innervatie wijziging. Thesis University of Amsterdam, (1971).

42. Kerner J, Bieber LL. The effect of electrical stimulation, fasting and anaesthesia on the carnitine(s) and acylcarnitines of rat white and red skeletal muscle fibres. Comp Biochem Physiol (1983)75B:311. 316

43. Kopec B, Fritz IB. Properties of a purified carnitine palmitoyltransferase, and evidence for the existence of other acyltransferases. Can J Biochem (1971)49:941-948.

44. Lennon DFL, Stratmann FW, Shrago E, Nagle FJ, Madden M, Hanson P, Carter AL. Effect of acute moderate-intensity exercise on carnitine metabolism in men and women. J Applied Physiol (1983)55:489-495.

45. Lennon DFL, Mance MJ. Interorgan cooperativity in carnitine metabolism in the trained state. $J$ Applied Physiol (1986)60:1659-1664.

46. Lucas CMHB. Use of the latissimus dorsi muscle for cardiac assist. Thesis University of Limburg (1992).

47. Maccari F, Arseni A, Chiodi P, Ramacci MT, Angelucci L. The effect of exogenous L-Carnitine on biochemical parameters in serum and in heart of hyperlipidaemic rat. Basic Res Cardiol (1986)82(suppl1):75-81.

48. Maccari F, Arseni A, Chiodi P, Ramacci MT, Angelucci L. Levels of carnitines in brain and other tissues of rats of different ages: effect of acetyl-I-carnitine administration. Exptl Gerontology (1990)25:127-134.

49. Maebashi M, Kawamura N, Sato $M$, Yoshinaga K, Suzuki M. Urinary excretion of carnitine in man. J Lab Clin Med (1976)87:760-766.

50. Mannion JD, Bitto T, Hammond R, Rubenstein NA, Stephenson LW. Histochemical and fatigue characteristics of conditioned canine latissimus dorsi muscle. Circ Res (1986)58:298-304.

51. Marconi C, Sassi G, Carpinelli A, Cerreteli P. Effects of L-carnitine loading on the aerobic and anaerobic performance of endurance athletes. Eur J Appl Physiol (1985)54:313-314. 
52. Mitchell ME. Carnitine metabolism in human subjects. I Normal metabolism. II values of carnitine in biological fluids and tissues of 'normal' subjects. III Metabolism in disease. Am J Clin Nutr (1978)31:293-306; 481-491; 645-659.

53. Negrao CE, Ji LL, Schaver JE, Nagle FJ, Lardy HA. Carnitine supplementation and depletion: tissue carnitines and enzymes in fatty acid oxidation. J Applied Physiol (1987)63:315-321.

54. Nishida N, Sugimoto T, Araki A, Woo M, Sakari Y, Kobayashi Y. Carnitine metabolism in Valproatetreated rats: The effect of $L$-carnitine supplementation. Pediatric Res (1987)22:500-503.

55. Norum K, Bremer J. Acyl Coenzyme A as an intermediate in the mitochondrial acylation of carnitine by ketoacids. Biochim Biophys Acta (1963)78:77-84.

56. Paul HS, Adibi SA. Effect of carnitine on branched chain amino acid oxidation by liver and skeletal muscle. Am J Physiol (1978)234:E494-E499.

57. Paulson DJ, Shug AL. Tissue specific depletion of L-carnitine in rat heart and skeletal muscle by Dcamitine. Life Sci (1981)28:2931-2938.

58. Penn D, Schmidt-Sommerfeld $E$. The carnitine deprived newborn rabbit: A potential model to study carnitine deficiency. J Nutr (1988) 118:1535-1539.

59. Pette D, Staudte HW, Vrbova G. Physiological and biochemical changes induced by long-term stimulation of fast muscle. Naturwissenschaften (1972)59:469-470.

60. Pette D, Smith ME, Staudte HW, Vrbova G. Effects of long term electrical stimulation on some contractile and metabolic characteristics of fast rabbit muscles. Pflügers Arch (1973)338:257-272.

61. Ramsay RR, Mancinelli G, Arduini AA. Carnitine palmitoyltransferase in human erythrocyte membrane. Properties and malonyl CoA sensitivity. Biochem J (1991)275:685-688.

62. Rebouche CJ, Engel AG. Kinetic compartmental analysis of carnitine metabolism in the dog. Arch Biochem Biophys (1983)220:60-70.

63. Rebouche CJ. Carnitine transport and tissue carnitine accretion in rats. Biochim Biophys Acta (1989)1033:111-113.

64. Rodriquez J, Bruyns J, Askanazi J, DiMauro W, Bordley IV J, Elwyn DH, Kinney JW. Carnitine metabolism during fasting in dogs. Surgery (1986)99:684-687.

65. Rudman D, Sewell CW, Ansley JD. Deficiency of carnitine in cachetic patients. J Clin Invest (1977)60:716-723.

66. Sahlin K. Muscle carnitine metabolism during incremental exercise in humans. Acta Physiol Scand (1990) 138:259-262.

67. Scholte HR, Jennekens FGI, Bouvy JJBJ. Carnitine palmitoyltransferase II deficiency with normal carnitine palmitoyltransferase II in skeletal muscle and leucocytes. J Neurol Sci (1979)40:39-51.

68. Scholte HR, De Jonge PC. Metabolism, function and transport of carnitine in health and disease. In: Carnitin in der medizin, R Gitzelmann, K Baerlocher, B Steinmann, eds. Schattauer, Stuttgart, New York (1987), pp 21-59.

69. Scholte HR, Rodrigues-Pereira R, Busch HFM, Jennekens FGI, Luyt-Houwen IEM, VaandragerVerduin MHM. Carnitine deficiency, mitochondrial dysfunction and the heart. Identical defect of oxidative phosphorylation in muscle mitochondria and in cardiomyopathy due to carnitine loss and in Duchenne muscular dystrophy. Wiener Klin Wschr (1989)101:12-17.

70. Scholte HR, Verduin MHM, Ross JD, Van Den Hoven R, Wensing T, Breuking HJ, Meijer AEFH. Equine exertional rhabdomyolysis: activity of the mitochondrial respiratory chain and the carnitine system in skeletal muscle. Equine Vet J(1991)23:142-144.

71. Schmidt RF, Thews G. Human Physiology. Springer Verlag Berlin Heidelberg New York (1983) pp 32-50.

72. Scrutton MC, Utter MF. Pyruvate carboxylase, part 9. Some properties of the activation by certain acyl derivatives of coenzyme A. J Biol Chem (1967)242:1723-1737.

73. Shug AL, Subramanian $\mathrm{A}$. Modulation of adenine nucleotide translocase activity during myocardial ischemia. Z Kardiol (1987)76,suppl.5:26-33.

74. Snoswell AM, Koundakjian P. Relationships between carnitine and coenzyme A esters in tissues of normal and alloxan-diabetic sheep. Biochem J (1972)127:133.

75. Suzuki $Y$, Kamikawa T, Kobayashi A, Masumura $Y$, Yamazaki N. Effects of L-carnitine on tissue levels of acylcarnitine, acyl coenzyme A, and high energy phosphate in ischemic dog hearts. Jpn Circ J (1981)45:687-694.

76. Van der Veen FH, Dassen WRM, Havenith MG, Lucas C, Van Der Nagel T, Penn OCKM, Wellens $\mathrm{HJJ}$. In vivo contraction analyses as a measure of muscle adaptation following chronic electrical 
stimulation. In Chiu RC-J, Bourgeois IM (eds): Transformed muscle for cardiac assist ans repair. Mount Kisco, New York, Futura Publishing Co., Inc. (1989) pp 105-115.

77. Van Hinsbergh VW, Veerkamp JH, Engelen PJM, Ghijsen WJ. Effect of L-carnitine on the oxidation of leucine and valine by rat skeletal muscle. Biochem Med (1978)20:115-124.

78. Van Tol A, Hülsmann WC. The localization of palmitoyl-CoA: carnitine palmitoyl transferase in rat liver. Biochim Biophys Acta (1969)189:342-353.

79. Wagenmakers AJM. L-Carnitine supplementation and performance in man. In: Advances in nutrition and top sport. Brouns F (ed): Medicine Sport Sci. Karger, Basel (1991)32:110-127.

80. Wolf $G$, Berger CRA. Studies on the biosynthesis and turnover of carnitine. Arch Biochem Biophys (1961) $92: 360-365$. 


\title{
CHAPTER 2
}

\section{ACUTE EFFECT OF L-CARNITINE UPON SKELETAL MUSCLE FORCE TESTS IN THE DOG}

\author{
Marie - Louise DUBELAAR \\ Carolien MHB LUCAS \\ Willem C HÜLSMANN
}

This chapter was published in :

Am J Physiol (1991)260:E189-E193. 


\section{ABSTRACT}

Using the mixed type musculus latissimus dorsi of the dog in the present work, we show the effect of carnitine on an in situ fatigue test. L-carnitine appears to improve force of this muscle by $34 \%$ while stimulated in situ. This effect of carnitine is acute, and (stereo)specific, since neither D-carnitine nor the structural analogue choline (also a tertiary amine) has a positive effect on contractile force. Because skeletal muscle is rich in carnitine and because carnitine transport is slow, its effect must be exerted outside the striated muscle cells. Insulin (with glucose) administration abolished the carnitine effect. It is speculated that facilitation of fatty acid oxidation in the blood vessel wall is the basis for this positive effect of carnitine. 


\section{INTRODUCTION}

Carnitine administration has been shown earlier to have a positive influence upon skeletal muscle function (3). This effect may be of importance to overcome the problem of muscle fatigue, also known to occur in early stages of cardiomyoplasty, whereby a skeletal muscle is used to assist the pump function of the failing heart (1). For this purpose the musculus latissimus dorsi has generally been used. Continuous stimulation of untrained muscle may be expected to induce fatigue, which is partly due to accumulation of lactic acid. Our aim is to support muscle force in the first period after cardiomyoplasty. During this period the optimal pacing rates can not be administered, which makes stimulation of force most important. Therefore, we studied the effects of carnitine on the latissimus dorsi muscle. L-carnitine is known to stimulate fatty acid oxidation (10) and the oxidative removal of pyruvate (8), both leading to increased ATP generation and limited lactate production. It is important to study the basis of the relation between carnitine and exercise, now that carnitine is being used as a therapeutic agent to improve exercise $(3,5)$. We investigated the effect of carnitine administration in an in situ test, using a pacemaker stimulated musculus latissimus dorsi. Because chronic stimulation converts the mixed fibre type latissimus dorsi to a muscle made up mainly of type I fatigue resistant fibres $(6,11)$, we also investigated the effect of carnitine upon the muscle in the trained state. To get more insight into the mechanism of action of carnitine, we investigated the effect of euglycemic insulin and a combination of euglycemic insulin and carnitine upon contractile force of the musculus latissimus dorsi, as insulin not only affects glucose metabolism but also lipid metabolism in the muscle.

\section{MATERIAL AND METHODS}

Ten mongrel dogs, ranging in weight from 25 to $35 \mathrm{~kg}$, were used on different days, with at least one week interval, for a control experiment followed by a test with the substances indicated. The two tests were separated by a rest period during which either a placebo or the substance to be tested was infused. Four weeks before the first measurement, two electrodes were implanted in the proximal part of the left latissimus dorsi muscle near the main branches of the nervus thoracodorsalis. These electrodes were connected to an Itrel pacemaker (Medtronic SP7420) (22).

The pacemaker was used for delivering pulses for force measurements and outside these measurement sections switched off. Only to obtain trained latissimus 
dorsi the pacemaker was programmed for continuous stimulation with a frequency that was increased every 2 wk until a frequency of 60 contractions/min was reached, as described earlier (22). In these dogs $(n=4)$ there was a period of 16 weeks between pacemaker implantation and force measurements.

Both enzyme-histochemical (myosin-adenosinetriphosphatase (ATPase) activity at $\mathrm{pH} 4.1$ ) and immunohistochemical methods (mouse monoclonal antibodies against $\beta$ myosin heavy chain) were used to monitor changes in fibre type composition of the latissimus dorsi muscle during training (11).

For force measurements, the dogs were premedicated with a drug mixture 10.2 $\mathrm{ml} / \mathrm{kg}$ ) intramuscularly $(1 \mathrm{ml}$ containing $10 \mathrm{mg}$ oxycodon hydrochloride, $1 \mathrm{mg}$ acepromazine and $0.5 \mathrm{mg}$ atropinesulfate. Subsequently, anaesthesia was induced by intravenous administration of $5-7 \mathrm{mg} / \mathrm{kg}$ body weight of pentobarbital sodium (Narcovet) and maintained by infusion of $2 \mathrm{mg} . \mathrm{kg}^{-1} \cdot \mathrm{hr}^{-1}$ of pentobarbital sodium. The dogs were intubated and ventilated with a mixture of $O_{2}$ and $N_{2}$ (1:2 by volume). Force measurements were performed after positioning of the dog on its right side on the operating table. In trained latissimus dorsi the continuous stimulation programme of the pacemaker was temporarily switched of to allow programming of the measurement protocol. Subsequently, the left forefoot was connected with straps to a force-displacement transducer (Grass FT 10, Grass Instruments, Quincy, MA) in a position in line with the paw and the latissimus dorsi to allow measurement of the isolated force of the latissimus dorsi. The optimal positioning of the paw was tested by administering twitch contractions at varying length of the latissimus dorsi muscle, and the length which yielded maximal force was used for further testing. To restrict compensatory movements of the dog during contraction of the left latissimus dorsi muscle, the dog was fixed against two vertical bars, one in front of the thorax, the other at the back of the animal against the scapulae. With this test protocol, the contractions of the muscle can be considered isometric. All force measurements were recorded on a multichannel Schwarzer recorder at a speed of $25 \mathrm{~mm} / \mathrm{sec}$.

An 8-min test was performed by programming the pacemaker with the following parameters: pulse width, $210 \mu \mathrm{s}$; burst frequency, $85 \mathrm{~Hz}$; time on, $0.25 \mathrm{~s}$; time off, $0.375 \mathrm{~s}(\approx 100$ contractions $/ \mathrm{min})$. Supramaximal voltage was used. The test was repeated after a rest period of 30 min during which the drug to be investigated was infused. The drugs used were either saline or $0.15 \mathrm{mmol} / \mathrm{kg}$ of $\mathrm{L}$ - or D- carnitine or choline, as indicated. They were infused at a rate of $0.15 \mathrm{mmol} / \mathrm{min}$. Only one drug was tested in each experiment.

In another experiment, we investigated the response time; after the first test and a subsequent $30-\mathrm{min}$ rest period, we administered L-carnitine as a bolus injection, immediately followed by the second test.

In the insulin experiments, after the first test, a continuous infusion of $5 \%$ glucose with $6 \mathrm{U}$ insulin/l was started at a rate of $300 \mathrm{ml} / \mathrm{h}$ to obtain a euglycemic insulinemia (8). Plasma glucose levels were measured and were found to be maintained between 4 and $6 \mathrm{mM}$. After $30 \mathrm{~min}$, a second test was performed, followed by another $30-\mathrm{min}$ rest period in which also $0.15 \mathrm{mmol} / \mathrm{kg} \mathrm{L}$-carnitine was infused. A third test was performed after the 30 -min rest period.

In the L-carnitine experiments, blood samples were taken before and immediately after each test, and biopsies of $\approx 200 \mathrm{mg}$ were taken from the left latissimus dorsi muscle after the experimental protocol. The samples were rapidly 

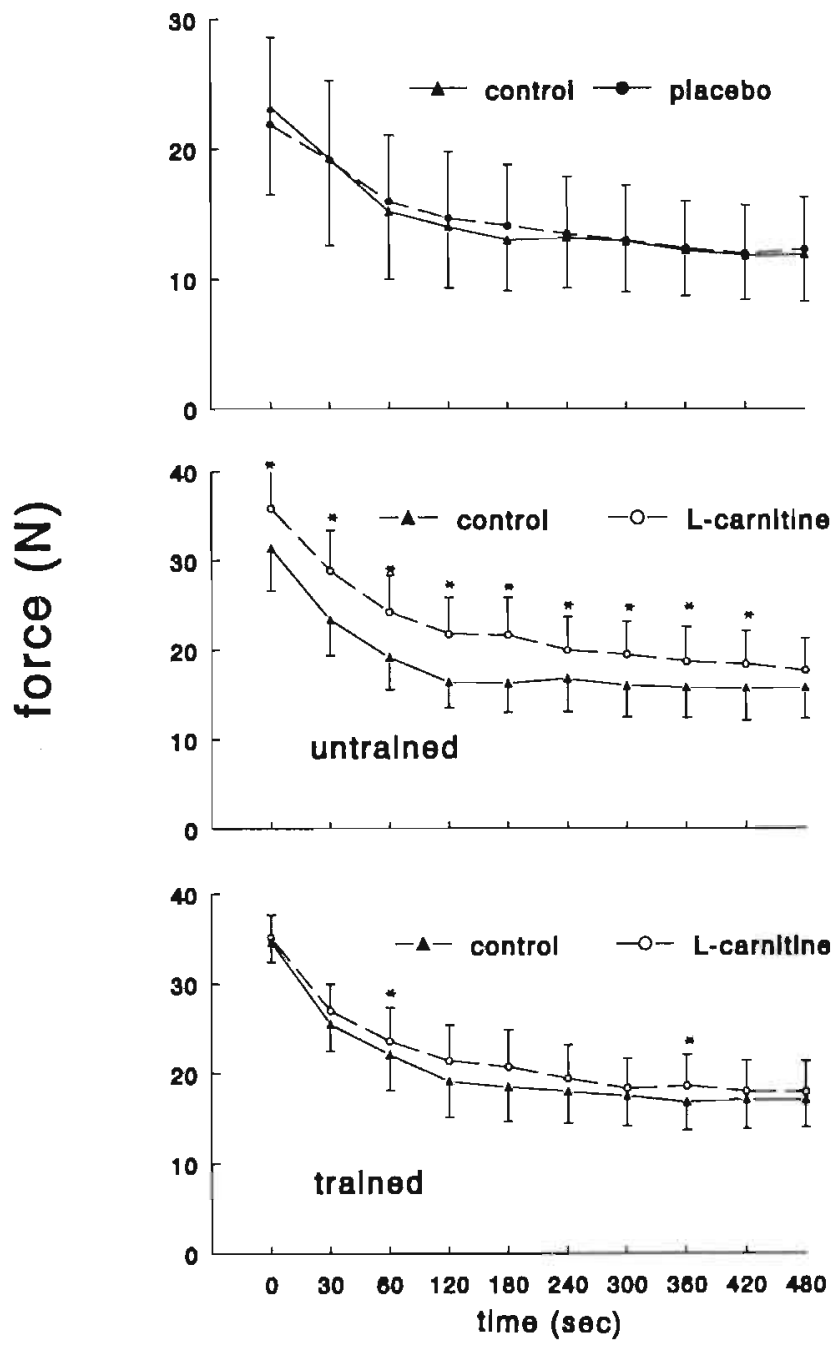

Figure 2.1 Repeated force tests in musculus latissimus dorsi of the dogs. Shown is developed force of 2 tests of $8 \mathrm{~min}$. Between tests, there was a 30 -min rest period during which (top) saline (placebo, $n=7$ dogs) or $0.15 \mathrm{mmol} / \mathrm{kg}$ L-carnitine was infused (middle,bottom). Middle: effects in untrained dogs $(n=10)$, bottom: effect in trained dogs $(n=6)$. Values significantly different from appropriate control values.

frozen in liquid $\mathrm{N}_{2}$ and stored at $-80^{\circ} \mathrm{C}$ until carnitine determination. Carnitine in blood was determined by a radioisotope method (4). Tissue carnitine was measured exactly as described (16).

Fatty acids were determined after activation and oxidation of acyl-CoA (21). A test combination from Wako pure chemical Industries Ltd (Osaka,Japan) was used. Glucose was determined enzymatically (24). Triacylglycerols were determined en- 
zymatically (23) using a commercially available test combination from BoehringerMannheim (FRG). Lactate was measured exactly as described (7).

All chemicals were of the highest purity grade available and obtained from Merck (Darmstadt, FRG). Insulin (Actrapid HM) was from Novo Industries (Bagsvaerd, Denmark).

L- and D-carnitine were kindly donated by Sigma-Tau (Rome, Italy).

\section{Statistics}

Values are given as means $\pm \mathrm{SE}$. Differences between the control tests were evaluated for statistical significance using analysis of variance (ANOVA), showing no significant difference between the individual control tests so that a paired $t$ test could be used to evaluate each set of measurements. The experiments with both insulin and carnitine were evaluated with ANOVA. $\underline{P}$ values $\leq 0.05$ were considered to be statistically significant.

\section{RESULTS}

When two control tests were repeated at a 30 -min interval during which only saline was infused, no significant change in force occurred (Figure 2.1). Also, a third test after another 30-min rest period showed a superimposable pattern. Administration of L-carnitine however resulted in a significant increase in force in the second test (Figure 2.1). L-Carnitine improved muscle force throughout the entire test, resulting in a significantly higher amount of work carried out by the muscle. As depicted in the bottom part of Figure 2.1, the effect of L-carnitine on contractile force was less pronounced in animals in which the latissimus dorsi muscle was conditioned for 12 wk. During this training period, the percentage of type I muscle fibers, which are characterized by a high myosin ATPase activity and by the presence of B-myosin heavy-chain, dramatically increased from $23 \pm 3$ to $69 \pm 16 \%(n=6)$. Moreover, the contraction characteristics (decreased ripple) and biochemical paramaters also confirmed that the muscle was now converted to a muscle made up mainly of type I fibers (reference 46 of chapter 1).

After intravenous administration of carnitine plasma total carnitine levels rose from $23 \pm 0.6$ to $322 \pm 61 \mathrm{nmol} / \mathrm{ml}(n=4)$. The concentration of total carnitine in latissimus dorsi biopsies however was not significantly different between the control $(4,670 \pm 690 \mathrm{nmol} / \mathrm{g}$ wet $\mathrm{wt}, \mathrm{n}=9)$ and L-carnitine treated $(4,880 \pm 830 \mathrm{nmol} / \mathrm{g}$ wet $w t, n=4$ ) animals.

To investigate the response time, we administered carnitine after the control test and a subsequent 30-min rest period as a bolus, immediately followed by a second test. As can be seen from Figure 2.2, a significant rise in force was seen already after 60 $\mathrm{s}$ in the test.

Neither D-carnitine (Figure 2.3, bottom panel), nor the structural analogue choline (Figure 2.3, top panel) improved force. On the contrary, D-carnitine decreased the contraction force significantly during the last minutes of the test (Figure 2.3, bottom panel). This indicates the (stereo)- specificity of the carnitine effect. 


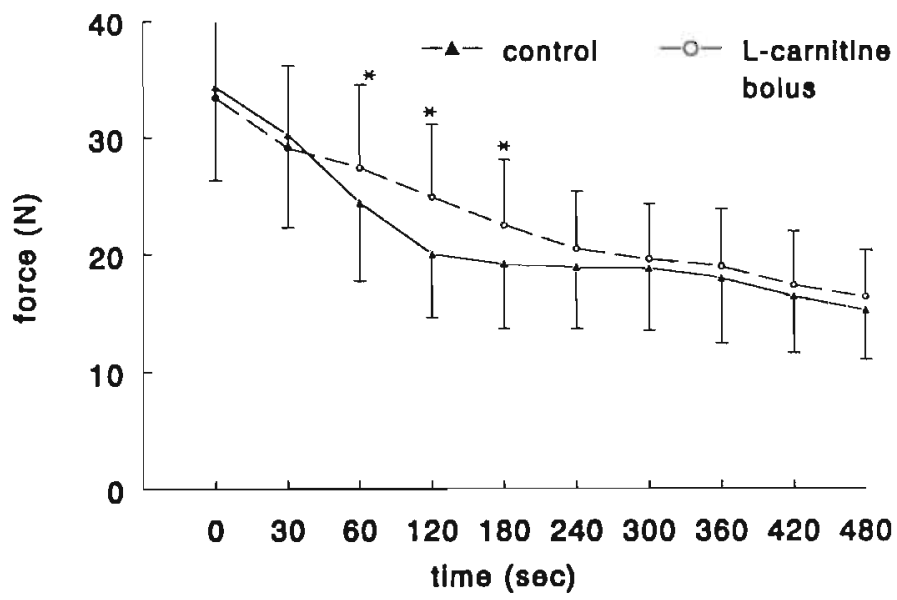

Figure 2.2. Acute effect of L-carnitine upon contractile force of musculus latissimus dorsi of dogs. Values are given as means \pm SE. Figure shows force compared with first fatigue test and a 30 -min rest period, after which a bolus injection of $0.03 \mathrm{mmol} / \mathrm{kg}$ L-carnitine was given, immediately followed by the second fatigue test $(n=5)$. Values significantly different from control test.

To study the possible involvement of fatty acids in the carnitine effect, we measured the effect of carnitine in the presence of a high (euglycemic) insulin level (known to inhibit fatty acid oxidation). It can be seen from Figure 2.4 that insulin itself had no significant effect on contractile force. The stimulation of force by carnitine however was no longer seen in the presence of insulin and glucose. Why there is a significant decrease in force in the last minutes of the test is not known.

Insulin lowered plasma fatty acid levels (Table 2.1) from 0.4 to $0.2 \pm 0.1 \mathrm{mmol} / \mathrm{l}$ $(n=4)$.

Neither plasma triglyceride, free fatty acid glucose levels changed significantly during exertion or by carnitine administration, as can be seen from Table 2.1. Lactate levels show a small but insignificant increase due to exertion, and there is no difference between the control and the carnitine-treated test.

\section{DISCUSSION}

Effects of carnitine administration on both skeletal muscle and heart performance have been described by a number of authors (cf. 3,8 ). Carnitine is mainly known for its effect upon fatty acid oxidation (10), but cholinergic effects of acetylcarnitine have also been described (10). The present paper shows the positive effect of carnitine upon contractile force of the musculus latissimus dorsi. This effect is more pronounced in the untrained than in the trained state (Figure 2.1). This acute effect of carnitine on skeletal muscle performance is rather unexpected, considering the absence of carnitine deficiency. In untreated dogs, the plasma value of total carnitine was $23 \mathrm{nmol} / \mathrm{ml}$ and the skeletal muscle carnitine concentrations were $4,700 \mathrm{nmol} / \mathrm{g}$ 


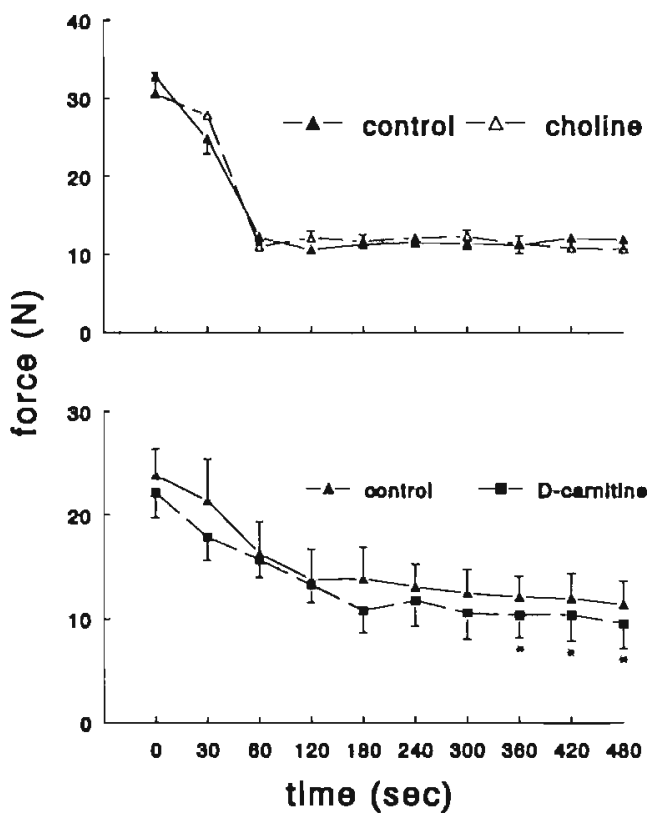

Figure 2.3. Effect of choline (top panel) and D-carnitine (bottom panel) on contractile force of musculus latissimus dorsi. Values are given as means \pm SE. Shown is force of 2 tests. Between tests there was a 30 - $\mathrm{min}$ rest period in which either choline $(n=4)$ or D-carnitine $(n=5)$ was infused $(0.15 \mathrm{mmol} / \mathrm{kg} \mathrm{i.v.).}$ Values significantly different from control test.

wet wt, which are normal values $(19,20)$. Although the infusion of L-carnitine resulted in a drastic increase in blood levels of carnitine, it cannot be expected to give rise to a rapid and significant increase in carnitine levels within the muscle cells, as carnitine transport across the plasmalemma is known to be slow $(2,19)$. Indeed, no significantly increased levels of total carnitine in latissimus dorsi biopsies were found (see RESULTS). Therefore, we have to consider an extramyocytal effect of carnitine. Whether this is a direct effect of L-carnitine remains to be determined. In this respect, it is important to realize that the effect of carnitine observed can only be obtained by L-carnitine and not by D-carnitine (Figure 2.3). Also, choline instead of $L$-carnitine had no effect. This excludes the possibility that there is a nonspecific tertiary amine effect of carnitine upon force development.

Because D-carnitine inhibits muscle force, the explanation of the effect of L-carnitine may be stimulation of oxidative phosphorylation, as D-carnitine is known to inhibit the activity of carnitine palmitoyltransferase | (10). Moreover, insulin, which is known to inhibit fatty acid oxidation, abolishes the L-carnitine effect. The decrease in the last few minutes of the third test is probably due to low plasma fatty acid levels at the end of the test $\alpha 0.1 \pm 0.1 \mathrm{mM}, \mathrm{n}=4)$. The question arises whether there is a compartment in muscle, other than the striated muscle cells, from which carnitine can be lost during muscle performance. The question could be rephrased, Do endothelial and/ or vascular smooth muscle cells loose carnitine during muscle stimulation? We (13) have described that ischemia of a Langendorff perfused rat 


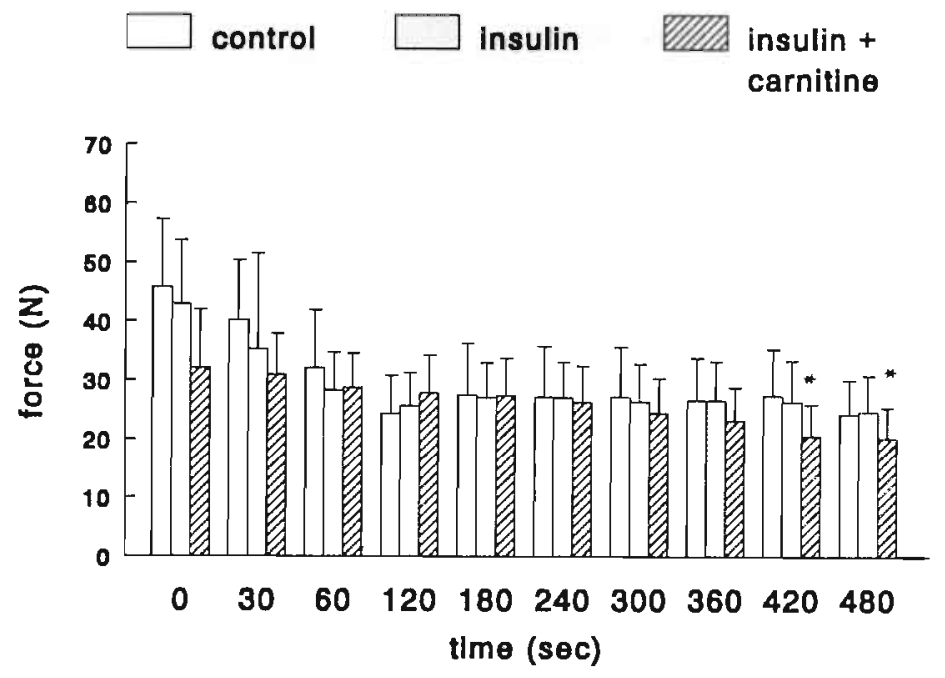

Figure 2.4. Effect of carnitine in the presence of insulin on contractile force of musculus latissimus dorsi. Values are given as means \pm SE. $(n=5)$. Shown is control test and test after a 30 -min rest period in which (euglycemic) insulin was infused, followed by a test after a 30 -min rest period during which insulin + carnitine $(0.15 \mathrm{mmol} / \mathrm{kg})$ were infused. "Values significantly different from appropriate control values.

heart results in the preferential loss of soluble components from the vascular wall. Therefore, also a loss of carnitine is to be expected from vascular cells. These cells use fat as respiratory substrate (17). We have shown that, in cultured endothelial cells, the bulk of ATP may come from carnitine-dependent fatty acid oxidation (14). This also holds for cultured rat aorta smooth muscle cells (chapter 5). Therefore it is possible that cells of the vascular wall loose carnitine due to relative ischemia during latissimus dorsi stimulation. This might endanger energy metabolism. Carnitine stimulates fatty acid oxidation, which contributes to ATP generation and limits lactate production $(15,18)$.

The lesser effect of carnitine in the trained muscle is in line with this hypothesis, since the number of capillaries is known to increase by training. We also observed this same response in the present experiments in which a $40 \%$ increase in the number of capillaries was found in trained muscle. This will lead to a better oxygenation, which may be expected to prevent functional decompensation of the relatively vulnerable vascular cells. Also in accordance with our hypothesis is the observation that during acidosis of the Langendorff rat heart, coronary flow is impaired. This decrease in flow is prevented when fluorocarbons are present in the perfusion medium (leading to a better tissue oxygenation) (12). The possible effect of carnitine on blood flow in the musculus latissimus dorsi is presently under investigation. Preliminary results indeed show an increased flow in the presence of carnitine. 
TABLE 2.1 Plasma values of some metabolites

Values are mean $\pm S E$ for $n$, no of dogs. FFA, free fatty acid; TG, triglyceride. No values are significantly different from the control (ANOVA). Control sample (untrained dogs) was taken before first test, exercise sample was taken immediately after 8 minutes stimulation of the latissimus dorsi muscle, carnitine sample was taken at 30 min into the rest period, during which L-carnitine was infused, and carnitine + exercise sample was taken immediately after 2 nd period of stimulation.

\begin{tabular}{|c|c|c|c|c|}
\hline & $\begin{array}{c}\text { Triglycerides } \\
\text { (mM) }\end{array}$ & $\begin{array}{l}\text { Fatty acids } \\
\text { (mM) }\end{array}$ & $\begin{array}{c}\text { Glucase } \\
(\mathrm{mM})\end{array}$ & $\begin{array}{c}\text { Lactate } \\
(\mu M)\end{array}$ \\
\hline control & $\begin{array}{c}0.42 \pm 0.06 \\
(n=10)\end{array}$ & $\begin{array}{c}0.39 \pm 0.07 \\
(n=10)\end{array}$ & $\begin{array}{c}5.16 \pm 0.27 \\
(n=5)\end{array}$ & $\begin{array}{l}309 \pm 61 \\
(n=6)\end{array}$ \\
\hline exercise & $\begin{array}{c}0.38 \pm 0.05 \\
(n=5)\end{array}$ & $\begin{array}{c}0.23 \pm 0.04 \\
(n=5)\end{array}$ & $\begin{array}{c}5.45 \pm 0.44 \\
(n=3)\end{array}$ & $\begin{array}{l}336 \pm 35 \\
(n=4)\end{array}$ \\
\hline carnitine & $\begin{array}{c}0.43 \pm 0.05 \\
(n=6)\end{array}$ & $\begin{array}{c}0.47 \pm 0.17 \\
(n=6)\end{array}$ & $\begin{array}{c}5.38+0.06 \\
(n=3)\end{array}$ & $\begin{array}{l}306 \pm 37 \\
(n=4)\end{array}$ \\
\hline $\begin{array}{l}\text { carnitine } \\
+ \text { exercise }\end{array}$ & $\begin{array}{c}0.46 \pm 0.06 \\
(n=9)\end{array}$ & $\begin{array}{c}0.45 \pm 0.16 \\
(n=9)\end{array}$ & $\begin{array}{c}5.36 \pm 0.05 \\
(n=3)\end{array}$ & $\begin{array}{l}375 \pm 43 \\
(n=4)\end{array}$ \\
\hline
\end{tabular}

\section{ACKNOWLEDGEMENTS}

We thank Professors GJ Van Der Vusse, RS Reneman, and HJJ Wellens, and Drs. FH Van Der Veen and JFC Glatz for interest and advice. We also thank J Habets, Th Van Der Nagel, R Kruger and P Willemsen for technical assistance.

This work was supported by the Netherlands Heart Foundation and Sigma-Tau (Rome, Italy). 


\section{REFERENCES}

1. Acker MA, Hammond RC, Mannion JD, Salmons S, Stephenson LW. An autologous biologic pump motor. J Thorac Cardiovasc Surg (1986)92:733-746.

2. B $\phi$ hmer $T$, Molstad P. Carnitine transport across the plasmamembrane. In: Frenkel RA, McGarry JD (eds) Carnitine, biosynthesis, metabolism and functions. Academic press inc, New York, (1980) pp 73-89.

3. Brevetti G, Attisano T, Perna S, Rossini A, Policicchio A, Corsi M. Effect of L-Carnitine om the reactive hyperemia in patients affected by peripheral vascular disease: A double blind crossover study. Angiology (1989)40:857-862.

4. Cederblad $G$, Lindstedt $C D$. A method for the determination of carnitine in the picomolar range. Clin Chim Acta (1972)37:235-243.

5. Cerretelli P, Marconi C. L-carnitine supplementation in humans. The effects on physical performance. Int J Sports Med (1990)11:1-14.

6. Clark III BJ, Acker MA, McCully K, Subramanian HV, Hammond RL, Salmons S, Chance B, Stephenson $L W$. In vivo "P-NMR spectroscopy of chronically stimulated canine skeletal muscle. J Physiol (1988)254:C258-C266.

7. Epstein CS, Puchner SE, Brachfeld N. Improved automated lactate determination. Anal Biochem (1970)38:20-34.

8. Ferrari $R$, Cucchini $F$, Visioli $O$. The metabolic effects of $L$-carnitine in angina pectoris. Int $J$ Cardiol (1984)5:213-216.

9. Ferrannini E, Buzzigoli G, Bevilacqua S, Boni C, Del Chiaro D, Oleggini M, Brandi L, Maccari F. Interaction of carnitine with insulin stimulated glucose metabolism in humans. Am J Physiol (1988)255:E946-E952.

10. Fritz IB Carnitine and its role in fatty acid metabolism. In: Paoletti R, Kritchevsky D (eds). Adv Lipid Res (1963)1:285-334.

11. Glatz JFC, Havenith MG, Van Der Veen FH, Surtel DAM, Van Der Vusse GJ, Penn OCKM, Wellens HJJ. Disparity of metabolic and histochemical adaptation following chronic electrical stimulation of canine latissimus dorsi muscle. In: Chiu RCJ, Bourgeois J (eds). Transformed muscle for cardiac assist and repair. Futura, New York (1989) pp 139-148.

12. Hülsmann WC, De Wit LEA. Acidosis, cardiac stunning and its prevention by oxygen. Cell Biol Int Rep (1990) 14:311-315.

13. Hülsmann WC, Dubelaar M-L. Early damage of vascular endothelium during cardiac ischemia. Cardiovasc Res (1987)21:674-677.

14. Hülsmann WC, Dubelaar M-L. Aspects of fatty acid metabolism in vascular endothelial cells. Biochimie (1988)70:681-686.

15. Hülsmann WC, Siliprandi D, Ciman M, Siliprandi N. Effect of carnitine on the oxidation of $\alpha$ oxoglutarate to succinate in the presence of acetoacetate or pyruvate. Biochim Biophys Acta (1964)93:166-168.

16. McGarry JD, Foster DW. An improved and simplified radioisotopic assay for the determination of free and esterified carnitine. J Lipid Res (1976)17:277-280.

17. Odessey $Y Y$, Chace KV. Utilization of endogenous lipid oxygen and protein by rabbit aorta. Am J Physiol (1982)243:H128-H132.

18. Randle PJ, Garland PB, Hales CN, Newsholme EA. The giucose fatty acid cycle. Its role in insulin sensitivity and the metabolic disturbances of diabetes mellitus. Lancet (1963)1:785-789.

19. Rebouche CJ, Engel AG. Kinetic compartmental analysis of carnitine metabolism in the dog. Archiv Biochem Biophys (1983)220:60-70.

20. Rodriguez J, Bruyns J, Askanazi J, DiMauro W, Bordley IV J, Elwyn DH, Kinney JW. Carnitine metabolism during fasting in dogs. Surgery (1986)99:684-687.

21. Shimizu $S$, Tani $Y$, Yamada $H$, Tabat M, Murochi $T$. Enzymatic determination of serum free fatty acids: a colorimetic method. Anal Biochem (1980)107:193-198.

22. Van der Veen FH, Dassen WRM, Havenith MG, Lucas C, Van Der Nagel T, Penn OCKM. Wellens HJJ. In vivo contraction analysis as a measure of latissimus dorsi muscle adaptation following chronic electrical stimulation. In: Chiu RCJ, Bourgeois $J$ (eds) Transformed muscle for cardiac assist and repair. Futura, New York (1989) pp 105-117. 
23. Wahlefeld AW In: Bergmeyer HU (ed). Methoden der enzymatischen Analyse. 3rd.ed, Verlag Chemie, Weinheim, F.R.G. (1974) pp 1878-1883.

24. Werner $W$, Rey HG, Wielinger $Z$. über die eigenschaften eines neuen chromogens für die blutzuckerbestimmung nach der GOD/POD-methode. $Z$ Anal Chem (1970)252:224-228. 


\title{
CHAPTER 3
}

\section{THE EFFECT OF L-CARNITINE ON FORCE DEVELOPMENT OF THE LATISSIMUS DORSI MUSCLE IN DOGS}

\author{
Marie-Louise Dubelaar \\ Carolien MBH Lucas \\ Willem C Hülsmann
}

This chapter was published in the Journal of Cardiac Surgery. J Cardiac Surg (1991): 6: suppl. 1, 270-275. 


\section{ABSTRACT}

Using the latissimus dorsi (LD) muscle of the dog in situ, the effect of carnitine was tested for increase of force in the first period after stimulation. Carnitine administration resulted in an increase of force of $31 \pm 6 \%$ (mean \pm SEM). It is hypothesized that, during muscle stimulation, a relative carnitine deficiency occurs in cells of the vascular compartment. The previously observed lesser effect of carnitine in the trained muscle than in the untrained muscle is in line with this hypothesis, since the number of capillaries is known to increase by training. Also in agreement with this hypothesis is the observation that carnitine increased flow during exercise of the muscle. 


\section{INTRODUCTION}

Carnitine is a cofactor for the transport of long chain fatty acids across the mitochondrial membrane and thus is essential for the mitochondrial $\beta$-oxidation of fatty acids. It is known that carnitine deficiency leads to decreased muscle force $(4,17)$. Exercise or electrical stimulation can cause a decrease of muscle carnitine levels $(8,11)$. These phenomena are of interest in the light of the fatigue that occurs in untrained latissimus dorsi (LD) muscle, when this muscle is used for a cardiomyoplasty procedure. In a previous paper we have shown a positive effect of carnitine on skeletal muscle force development in the dog (3).

It is the aim of the present study to further elucidate the mechanism of action of this effect of carnitine. In a previous article we speculated that facilitation of fatty acid metabolism of vascular cells of the muscle could be the basis for this phenomenon, resulting in stimulation of capillary blood flow, thereby increasing oxygenation of the tissue and subsequently oxidative metabolism. Another mechanism could be an (acetyl) cholinergic effect of carnitine (although choline itself had no effect (3)). It has been observed earlier that certain carnitine derivatives have cholinomimetic properties on cortical neurons (5). To test these hypotheses we studied the effect of acetylcarnitine as well as of tensilon ${ }^{\mathrm{TM}}$ (Roche, Mijdrecht, The Netherlands), a choline esterase inhibitor, on force development of the LD muscle. We also studied the effect of carnitine on LD blood flow.

\section{MATERIAL AND METHODS}

Ten mongrel dogs, ranging in weight from 25-35 kg, were used on different days (with at least one week interval) for a control experiment followed by a test with the substances indicated. Pacemaker and electrode implantation as well as force measurements were performed exactly as described before $(3,19)$. No stimulation of the muscle occurred other than during the measurement sessions. An eight minute test was performed by programming the pacemaker with the following parameters: pulse width $210 \mu \mathrm{sec}$, burst frequency $85 \mathrm{~Hz}$, time on $0.25 \mathrm{sec}$, time off $0.375 \mathrm{sec}$ (about 100 contractions per minute), supra maximal voltage was used. The test was repeated after a rest period of 30 minutes during which the drug to be investigated was infused. The drugs used were either L-carnitine, L-propionylcarnitine, L-acetylcarnitine or Tensilon $^{\mathrm{TM}}$, or a combination of Tensilon ${ }^{\mathrm{TM}}$ and carnitine, as indicated. Carnitine or its derivatives were infused at a rate of $0.15 \mathrm{mmol} / \mathrm{min}$. Only one drug was tested in each experiment. The blood flow in different regions of the in situ 


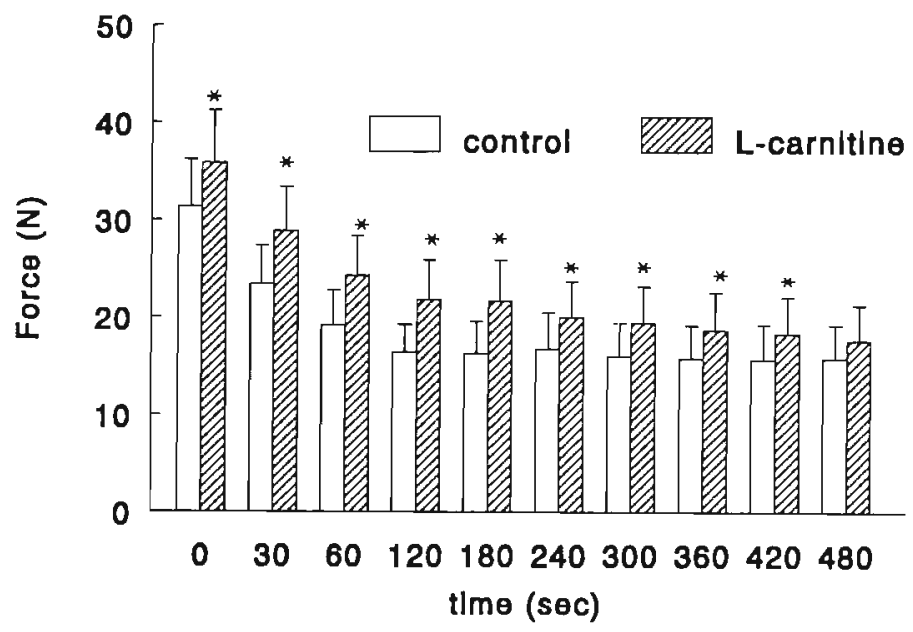

Figure 3.1. The effect of L-carnitine on latissimus dorsi (LD) force tests. Open bars represent the control test, hatched bars show force of the same muscle after a rest period of 30 minutes, during wich $1 \mathrm{~g}$ of $\mathrm{L}$ carnitine was infused intravenously. The experiment was carried out in ten dogs $(n=10)$. "Represents values significantly different from control values.

latissimus dorsi muscle was measured using $15 \mu \mathrm{m}$ radioactive microspheres as described earlier $(12,15)$. The microspheres were labelled with $\mathrm{Nb}^{95}, \mathrm{Ru}^{103}, \mathrm{Sn}^{113}, \mathrm{Ce}^{141}$ (NEN Research Products, Boston USA). At each determination $3 \times 10^{6}$ microspheres were injected into the left atrium. In a final experiment the same protocol as described above was used with the following extensions: Five minutes before the start of the stimulation protocol isotope 1 was injected (rest); one minute after commencing stimulation isotope 2 was injected (exercise). After infusion of carnitine isotope 3 was injected (carnitine rest), and one minute after commencing the second stimulation protocol isotope 4 was injected (carnitine exercise). A reference sample was taken from the femoral artery. After the experiment the animals were killed with an overdose of pentobarbital. Both the left (which is the muscle with the pacemaker) and the right LD muscles were prepared free of surrounding tissue and excised, rinsed and stored in $5 \%$ formaldehyde. Before dissection, nonmuscle structures were removed (fat, vessels, electrodes). Subsequently the muscle was cut in 50 pieces with an average weight of approximately $3 \mathrm{~g}$. The tissue samples were weighed and subsequently counted in a gamma counter (Packard Multichannel analyzer, Packard Instrument Co, Meriden, CT). L-carnitine and derivatives were kindly donated by Sigma-Tau (Pomezia, Rome, Italy). Tensilon ${ }^{T M}$ (edrophonium chloride $10 \mathrm{mg} / \mathrm{ml}$ ) was from Roche, Mijdrecht, The Netherlands.

\section{Statistics}

Values are given as mean \pm SEM. Differences between the control tests were evaluated for statistical significance using ANOVA. $\underline{P}$ values $\leq 0.05$ were considered to be statistically significant. 


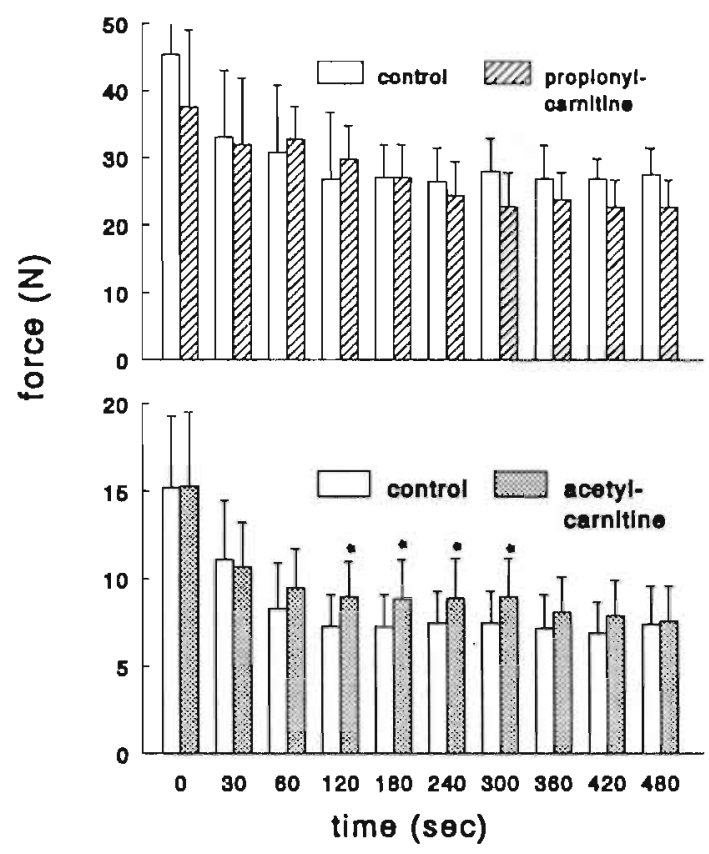

Figure 3.2. Shows the effect of L-propionyl (upper panel) and L -acetyl carnitine (lower panel) upon LD force tests. Open bars represent the control test, hatched bars show the force of the same muscle after a rest period of 30 minutes, during which $1 \mathrm{~g}$ of the mentioned substance was infused intravenously $(\mathrm{n}=$ 4). "Represents values significantiy different from control values.

\section{RESULTS}

In a previous article (3) we described that L-carnitine has a positive effect on LD force (approximately $30 \%$ increase in force). This can also be seen in Figure 3.1. Lpropionylcarnitine failed to exert a comparable effect on LD force. In contrast, Lacetylcarnitine has a stimulatory effect (Figure 3.2) similar to that of L-carnitine. Tensilon $^{\mathrm{TM}}$ also has a positive effect upon LD force (Figure 3.3 ), which is of the same magnitude as the carnitine effect. When carnitine was combined with tensilon no additional effect of carnitine was observed.

Table 3.1 shows the results of the experiments with microspheres $(n=4)$ to assess flow in the muscle in several situations. The central part of the muscle is in line with the a. thoracodorsalis, the other regions are more peripheral. As can be seen L-carnitine has a positive effect on the blood flow in exercising muscle. This effect is most pronounced in the central part of the muscle. 
Tabel 3.1. Flow in several regions of the latissimus dorsi muscle, during rest or exercise. " $=$ Significantly different from exercise values. Shown is the mean \pm SEM of 4 experiments.

\begin{tabular}{|c|c|c|c|}
\cline { 2 - 4 } \multicolumn{1}{c|}{} & CENTRAL & INTERMEDIATE & PERIPHERAL \\
\cline { 2 - 4 } \multicolumn{1}{c|}{} & \multicolumn{3}{c|}{ Flow in ml per min per g wet weight } \\
\hline Rest & $0.07 \pm 0.01$ & $0.09 \pm 0.01$ & $0.10 \pm 0.02$ \\
\hline $\begin{array}{c}\text { Rest }+ \\
\text { carnitine }\end{array}$ & $0.06 \pm 0.01$ & $0.07 \pm 0.01$ & $0.08 \pm 0.01$ \\
\hline $\begin{array}{c}\text { Exercise } \\
\text { Exercise }+\end{array}$ & $0.61 \pm 0.04$ & $0.89 \pm 0.04$ & $0.94 \pm 0.05$ \\
\hline $\begin{array}{c}\text { Exernitine } \\
\text { carc }\end{array}$ & $0.66 \pm 0.04$ & $1.04 \pm 0.05^{\circ}$ & $1.18 \pm 0.05^{\circ}$ \\
\hline
\end{tabular}

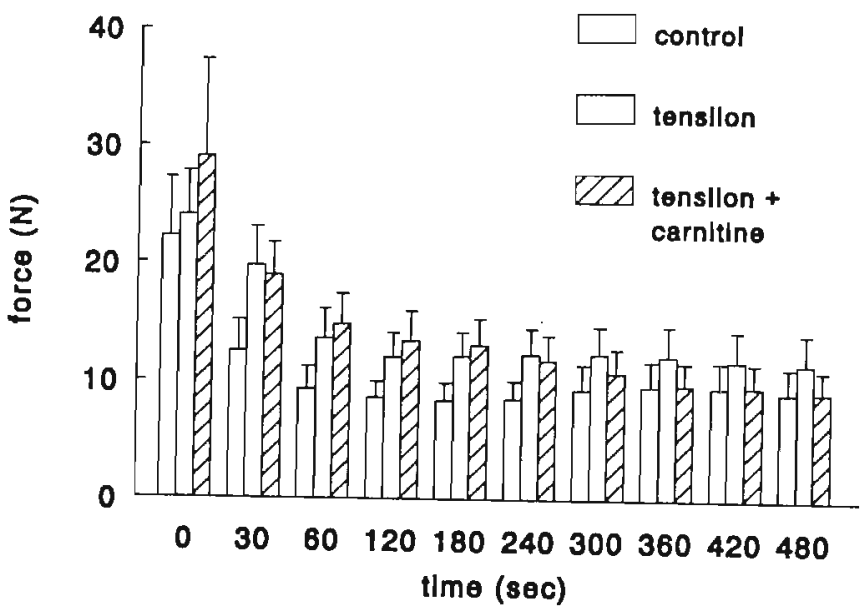

Flgure 3.3. The effects of Tensilon ${ }^{T M}$ (in the absence or presence of L-carnitine) upon LD force. Open bars show the control experiment, dotted bars the experiment in the presence of Tensilon ${ }^{\mathrm{TM}}$ ( $2 \mathrm{mg}$. i.v.bolus) and the hatched bars the experiment with both Tensilon ${ }^{\top M}$ and carnitine. The experiment was carried out in five dogs. "Represents values significantly different from control.

\section{DISCUSSION}

One of the complications with cardiomyoplasty is fatigue of the untrained LD used. To overcome fatigue a scheduled adaptation program is required. Especially in the initial period after cardiomyoplasty, when a full stimulation protocol is impossible it is important to obtain maximal support from the few assisted beats. In order to obtain maximal benefit, we attempted to increase force of the muscle contractions. As can be seen from figure 1 this was accomplished in dog LD muscle in situ by using car- 
nitine. Carnitine administration results in a $30 \%$ increase in force compared to the control (Table 1).

Carnitine, a key substance in fatty acid oxidation (7), also influences glycolysis (6). Preferential fatty acid oxidation not only occurs in striated muscle but also in blood vessels (14). A relative deficiency of unesterified carnitine in ischemia not only applies to muscular, but also to vascular tissue. The carnitine level may decrease in ischemia (18), strenuous exercise (8), or after electrical stimulation (11) partly due to the accumulation of acyl-carnitines. The target for the administered carnitine may be myocytes or vascular cells (endothelial and/or smooth muscle cells). Since carnitine administration did not increase carnitine levels in the muscle biopsies (3), and since the effect of carnitine is acute (3), we favour the vascular compartment as the target for carnitine.

Cholinomimetic effects of carnitine and its derivatives have been described $(7,1)$. The fact that acetylcarnitine, in contrast to propionylcarnitine, also showed a positive effect could be in line with a cholinergic effect. Further investigations into the mechanism of action of carnitine showed that tensilon, a choline esterase inhibitor (13), had an effect similar to that of carnitine. Moreover, the carnitine effect was abolished in the presence of tensilon. This points to a mutual component in the mechanism of action. Since carnitine is not a choline esterase inhibitor, the common component may be blood supply $(2,20)$.

It has been shown in $\mathrm{pH} 7.0$ perfused, stimulated, rat hearts that fatty acid oxidation in muscle delays reduction of flow (9). The factor responsible for flow reduction preceding complete ischemia is metabolic acidosis (9). Limitation of tissue acidosis by fatty acid oxidation is known to be due to limitation of anaerobic glycolysis. This not only results in a lower rate of lactate formation but also in inhibition of the glucose/fatty acid cycle, as the level of glycerol-3-phosphate decreases as well $(9,10)$. A low level of fatty acid recycling will result in a higher availability of fatty acids for oxidative phosphorylation, contributing to ATP generation. This will increase the ATP/ADP ratio, which together with a lower $[\mathrm{H}+]$, will influence the phosphorylation state and activity of ion channels (16), possibly leading to more efficient tissue perfusion. Indeed, as can be seen from figure 4 , more microspheres enter the LD muscle during exercise in the presence of carnitine.

The fact that the effect of carnitine upon the LD muscle is more pronounced in the untrained than in the trained state (3), is in agreement with our hypothesis of improved flow, since the amount of capillaries increases during training. A better blood supply offers the possibility to meet a higher imposed work load.

\section{ACKNOWLEDGEMENTS}

The authors wish to thank the Netherlands Heart Foundation and Sigma-Tau, Rome (Italy) for financial support. Professors GJ Van Der Vusse, RS Reneman, HJJ Wellens, Dr. FH Van Der Veen and Dr. JFC Glatz are thanked for interest and advice and $J$ Habets, $T$ Van Der Nagel and R Kruger for technical assistance. 


\section{REFERENCES}

1. Bettini V, De Varda E, Guerra B, Pulliero G, Ton P. Studio sperimentale sugli effetti colinomimetici della carnitina in preparati isolati di anteria aorta e masseterina. Cardiologia (1987)32:1039-1042.

2. Coffman JD, Cohen RA: Cholinergic vasodilation mechanisms in human fingers. Am J Physiol (1987)252:H594-H597.

3. Dubelaar M-L, Lucas CMBH, Hülsmann WC. Acute effect of L-carnitine upon skeletal muscle force tests in the dog. Am J Physiol (1991)260:E189-E193.

4. Duran M, Loof NE, Ketting D, Dorland L. Secondary carnitine deficiency. J Clin Chem Clin Biochem (1990)28:359-363.

5. Falchetto S, Kato G, Provini L. The action of carnitines on cortical neurones. Can J Physiol Pharmacol (1971)49:1-7.

6. Ferrannini E, Buzzigoli G, Bevilacqua S, Boni C, Del Chiaro D, Oleggini M, Brandi L, Maccari F. Interaction of carnitine with insulin stimulated glucose metabolism in humans. Am J Physiol (1988)255:E946-E952.

7. Fritz IB. Carnitine and its role in fatty acid metabolism. In: Paoletti R, Kritchevsky D, eds, Adv Lipid Res (1963) 1:285-334.

8. Hiatt WR, Regensteiner JG, Wolfel EE, Ruff L, Brass EP. Carnitine and acylcarnitine metabolism during exercise in humans. dependence on skeletal muscle metabolic state. $J$ Clin Invest (1989)84:1167-1173.

9. Hülsmann WC, De Wit LEA, Schneydenberg C, Verkleij AJ. Loss of cardiac contractility and severe morphologic changes by acutely lowering the $\mathrm{pH}$ of the perfusion medium: protection by fatty acids. Biochim Biophys Acta (1990)1033:214-218

10. Hülsmann WC, De Wit LEA, Stam H, Schoonderwoerd K. Hormonal control of cardiac lypolysis by glyco(geno)lysis. Biochim Biophys Acta (1990)1055:189-192.

11. Kerner J, Bieber LL. The effect of electrical stimulation fasting and anaesthesia on the carnitine(s) and acyl-carnitines of rat white and red skeletal muscle fibres. Comp Biochem Physiol (1983)75b:311-316.

12. Mannion JD, Velchik M, Hammond R, Alavi A, Mackler T, Duckett S, Staum M, Hurwitz S, Brown W, Stephenson LW. Effects of collateral blood vessel ligation and electrical conditioning on blood flow in dog latissimus dorsi muscle. J Surg Res (1989)47:332-340.

13. Martindale J. The extra pharmacopoeia. $29^{\text {th }}$ ed. The pharmaceutical press, London, (1989): pp1330-1331.

14. Odessey $Y Y$, Chace KV. Utilization of endogenous lipid oxygen and protein by rabbit aorta. Am $J$ Physiol (1982)243:H128-H132.

15. Prinzen FW, Van Der Vusse GJ, Reneman RS. Blood flow distribution in the left ventricular free wall in open chest dogs. Basic Res Cardiol (1981)76:431-437.

16. Quast $U$, Cook NS. Moving together: $K^{+}$channel openers and ATP sensitive $K^{*}$ channels. Trends Pharmacol Sci (1989)10:431-435

17. Scholte HR, Rodrigues Pereira R, De Jonge PC, Luyt-Houwen IEM, Verduin MHM, Ross JD. Primary carnitine deficiency. J Clin Chem Clin Biochem (1990)28:351-357.

18. Spagnoli $L G$, Corsi $M$, Villaschi S. Myocardial carnitine deficiency in acute myocardial infarction Lancet (1982)1:1419-1420.

19. Van der Veen FH, Dassen WRM, Havenith MG, Lucas C, Van Der Nagel T, Penn OCKM, Wellens HJJ. In vivo contraction analysis as a measure of latissimus dorsi muscle adaptation following chronic electrical stimulation. In: Chiu RCJ, Bourgeois J (eds). Transformed muscle for cardiac assist and repair. Futura, New York (1989) pp 105-1177.

20. Weinstock $M$, McCarty $R$. Vasodilator responses to cholinergic and adrenergic stimulants in spontaneously hypertensive (SHR) and Wistar-Kyoto (WKY) normotensive rats (41545). Proc Soc Exp Biol Med (1983)172:194-201. 


\section{CHAPTER 4}

\section{CARNITINE IN METABOLISM OF PACED CARDIAC} AND SKELETAL MUSCLES;

Prevention of acidosis and improvement of vascular flow

\section{Willem C Hülsmann}

Marie - Louise Dubelaar

This chapter was published in: L-carnitine and its role in medicine, from function to therapy. R. Ferrari, S. DiMauro, G. Sherwood, eds. pp 345-358, 1992. 


\section{ABSTRACT}

During pacing of muscles, a considerable lowering of interstitial $\mathrm{pH}$ may occur. This is mainly due to secretion of lactic acid from pre-ischemic, striated muscle cells. Local acidosis influences plasmalemmal changes, resulting in alteration of cellular ion fluxes, including $\mathrm{Ca}^{2+}$. The resulting positive inotropy and limitation of vascular flow aggravates local acidosis. Continued pacing leads to further decline of flow and finally results in fully developed ischemia. Administration of L-carnitine in the preischemic state, has been shown to have a positive effect on muscle function, due to limitation of lactic acidosis. The mechanism cannot only be the decline of the cellular acetylcoA/CoA ratio, due to export of acetylcarnitine from the cells, but must be largely explained by inhibition of glyco(geno)lysis, as fatty acids or acetylcarnitine have been shown to delay loss of function during pacing as well. 


\section{INTRODUCTION}

This chapter discusses the acute effects of L-carnitine on pre-ischemic cardiac and skeletal muscles. The effects of carnitine on training will not be reported, as changes of muscle type and of altered hormonal states may be involved. A comprehensive review of literature has not been attempted.

In 1959 Fritz (16) reported that carnitine stimulates fatty acid oxidation. Acetylcarnitine and fatty acid esters of carnitine are rapidly oxidized in isolated mitochondria. These carnitine derivatives can be transported through the mitochondrial inner membrane and oxidized after conversion to their coenzyme A (CoA) derivatives (for classical reviews see Fritz (17) and Bremer (4)). Figure 4.1 shows the involvement of carnitine in mitochondrial $\beta$-oxidation. The acyltransferase involved in the synthesis of long-chain acylcarnitine from fatty acyl-coenzyme $A$, carnitine palmitoyl-CoA transferase-1 (CPT-1), is located in the outer membrane (36). CPT-2, the inner membrane isoenzyme, converts long-chain acyl carnitine back to long-chain acylCoA, then present in the inner membrane-matrix compartment, where beta-oxidation of fatty acids takes place. This compartment also contains pyruvate dehydrogenase and the citric acid cycle activity. It is relatively rich in CoA, compared to the extra-mitochondrial cytosol, whereas the latter contains the bulk of cellular carnitine (30). Mitochondrial carnitine acetyltransferase is localized in the innermembrane, probably facing the matrix. Hence carnitine may liberate CoA from acetyl-CoA by exporting acetylcarnitine from the mitochondria. In this way it would stimulate citric acid cycle activity, which would be inhibited by a high acetyl-CoA CoA ratio (23). This situation could occur during a shortage of cellular oxygen, as a decline in respiratory chain activity would limit citric acid cycle velocity and thus limit the use of respiratory substrates (such as pyruvate, ketone bodies and fatty acids).

Fatty acids may be stored in the cytosol as triglycerides, whereas pyruvate (mostly after reduction to lactate) may diffuse out of the cell. Hence, if carnitine administration were able to delay metabolic disruption, by lowering the acetylCoA/CoA ratio in the cell, it would probably be in a hypoxic or pre-ischemic state.

Carnitine could diminish lactic acidosis of tissues if it could stimulate citric acid cycle activity, as the resulting increased rate of ATP synthesis is known to inhibit glycolysis (cf. 40). In addition, stimulation of pyruvate removal by acetylcarnitine formation may be expected. It must be stressed that this can only happen if at least some oxygen is available for pyruvate dehydrogenase plus oxidative phosphorylation. Therefore, carnitine could operate in conditions of imminent ischemia, but not once it was fully developed. To verify this assumption in vitro, the erythrocyte-free 


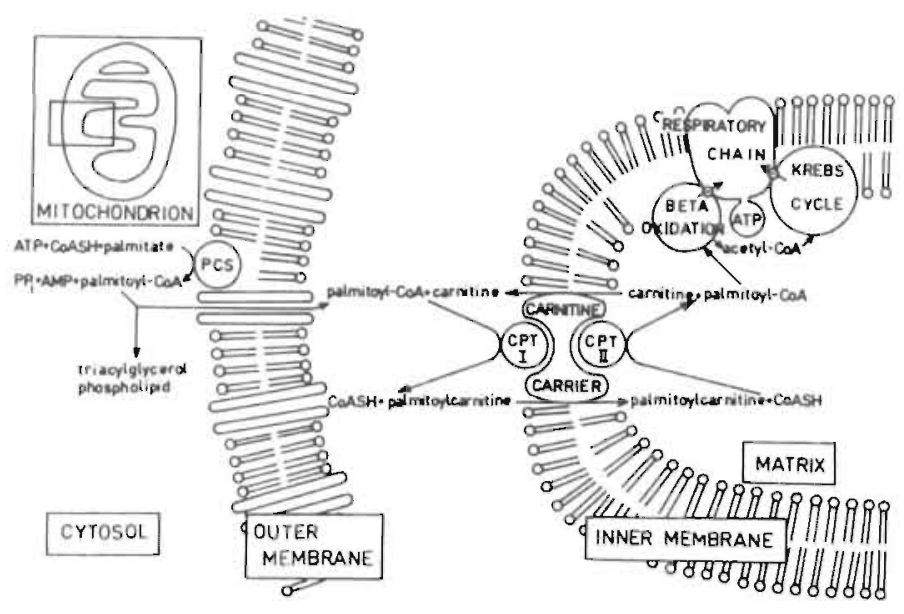

Figure 4.1. Mitochondrial beta-oxidation.

Long-chain fatty acids are activated by palmitoyl-CoA synthetase (PCS). The CoA-ester passes through pores in the outer membranes, is converted into a carnitine ester by the action of carnitine palmitoyl transferase I (CPT-1), moves through the inner membrane via the carnitine carrier, and is reconverted into a CoA-ester by carnitine palmitoyl transferase II (CPT-HI). Acyl-COA is oxidized by enzymes of betaoxidation and the respiratory chain to acetyl-CoA, which is further oxidized by enzymes of the citric acid cycle and the respiratory chain. From: H.R. Scholte et al. Neurology 38(1988)1659-1660

perfused and paced Langendorff heart is suitable. This preparation is borderline hypoxic, as judged by the continuous production of lactate from glucose or glycogen, particularly when the hearts are subjected to increased cellular $\mathrm{Ca}^{2+}$ turnover $(20$,27,28 ). The latter can be accomplished by including glucagon in the perfusion medium (35) or by brief acidification, known to cause release of plasmalemmal-bound $\mathrm{Ca}^{2+}$ into the cytosol $(27,48)$, and the release of noradrenaline (norepinephrine) into the interstitial space.

Before citing examples that indicate inhibition of lactic acidosis by carnitine administration, two types of experiment will be described, one with the paced Langendorff rat heart, as mentioned above, and one with paced dog skeletal muscle in vivo. The term lactic acidosis refers to acidosis caused by endogenous lactic acid production. This is different from lactate formed from added pyruvate, which may not be accompanied by acidosis (by contrast, the lactate dehydrogenase reaction per se may consume protons, while forming lactate from pyruvate).

\section{Effect of carnitine on lactic acidosis in langendorff heart}

Incluction of acidosis by changing the $\mathrm{pH}$ of the perfusion medium during pacing from 7.5 to 7.0 results in dramatic alterations in the heart. After an initial increase of car- 
diac contractility (indicating transiently increased cytosolic $\mathrm{Ca}^{2+}$ ), accompanied by the release of $\mathrm{Ca}^{2+}$ from the cytosolic side of the plasmalemma, contractility decreased progressively $(20,27)$. In approximately $60 \%$ of cases contractility ceased completely. The coronary flow initially increased after switching to $\mathrm{pH} 7.0$ perfusion, but gradually decreased after contractility started to fall. This frequently resulted in complete cardiac arrest and strongly reduced flow after about 6 min of perfusion at $\mathrm{pH} 7.0$ perfusion. The addition of oleate to the perfusion medium minimized these phenomena and prevented irreversible changes, as judged by complete restoration of cardiac functions upon reperfusion with $\mathrm{pH} 7.5$ medium (27). Perfusion with $5 \mathrm{mM}$ $\mathrm{L}$-carnitine instead of oleate did not protect against the $\mathrm{pH} 7.0$ induced deterioration $(n=3)$. In these experiments we used hearts with normal (low) endogenous triglyceride content and no fatty acid in the perfusion medium. Therefore, no stimulation of fatty acid metabolism could have taken place.

The addition of $5 \mathrm{mM} \mathrm{L}$-carnitine not only failed to improve cardiac function, but also failed to influence metabolism. In the absence or presence of added carnitine, lactate and acetylcarnitine levels in the hearts after $10 \mathrm{~min} \mathrm{pH} 7.0$ perfusion were 8.9 \pm 1.8 and $0.20 \pm 0.03 \mu \mathrm{mol}$ per $g$ wet weight respectively (mean $\pm S E M, n=3$ ). In the presence of $5 \mathrm{mM} \mathrm{L}$ - carnitine, lactate and acetyl carnitine levels were $10.9 \pm 1.9$ and $0.25 \pm 0.03 \mu \mathrm{mol}$ per $\mathrm{g}$ wet weight respectively (mean $\pm \mathrm{SEM}, \mathrm{n}=3$ ). Hence, under the conditions of this test, there was no effect of carnitine in Langendorff perfused hearts subjected to acidosis. The absence of a positive effect of carnitine at low fatty acid supply has also been observed in skeletal muscle (see below). Hülsmann et al (26) demonstrated that $5 \mathrm{mM}$ carnitine prevented triglyceride accumulation during Intralipid perfusion of rat Langendorff hearts. Thus, carnitine might only be effective when fatty acids are present in high concentrations.

\section{Acute effect of carnitine on skeletal muscle force in vivo}

We have studied the effect of carnitine administration in an in situ fatigue test in the dog, using a pacemaker-stimulated latissimus dorsi muscle connected to a forcedisplacement transducer $(10,11)$. Intravenous carnitine injection increased muscular force by about one third in untrained dogs $(n=10)$. After training, the effect on the muscle was less pronounced. The acute effect of carnitine administration was unexpected as none of the dogs was carnitine deficient and had average plasma levels of $23 \mathrm{nmol} \mathrm{m}^{-1}$ prior to injection. The skeletal muscle concentrations were about 4700 $\mathrm{nmol}$ per $\mathrm{g}$ wet weight and not increased by carnitine administration. We explained the effect of $L$-carnitine as stimulation of oxidative phosphorylation. The effect of $L$ carnitine could not be mimicked by choline or by D-carnitine, which even inhibited force to some extent. Also, injection of insulin (while maintaining glycaemia) inhibited force production. Both D-carnitine (an inhibitor of carnitine palmitoyltransferase I) and hyperinsulinemia are known inhibitors of $\beta$-oxidation. L-carnitine not only increased force of the stimulated muscle, but also improved vascular flow, which was demonstrated after injection of microspheres (11). Hence the acute effect of carnitine may be explained by increasing muscle aerobiosis by increasing flow $(10,11)$. The lesser effect of $L$-carnitine in trained muscle is in line with this hypothesis since the number of capillaries increased by $40 \%$ as a result of training. 
These experiments did not reveal the mechanism by which carnitine injection increased flow in stimulated, untrained muscle. Carnitine may have decreased local acidosis, known also to be vasoconstrictive in skeletal muscle (46). That carnitine probably does not act solely by accepting acetyl-groups in the pyruvate dehydrogenase reaction is demonstrated during hyperinsulinemia. In this situation, when pyruvate dehydrogenase may be expected to be activated, carnitine was found to be ineffective in stimulating muscle force (10). The explanation for this phenomenon could have been the expected low rate of beta oxidation of fatty acids during hyperinsulinemia. In addition, L-acetylcarnitine was as good a stimulator of force as L-carnitine (11). Hence the carnitine effect must have a predominant catalytic char-

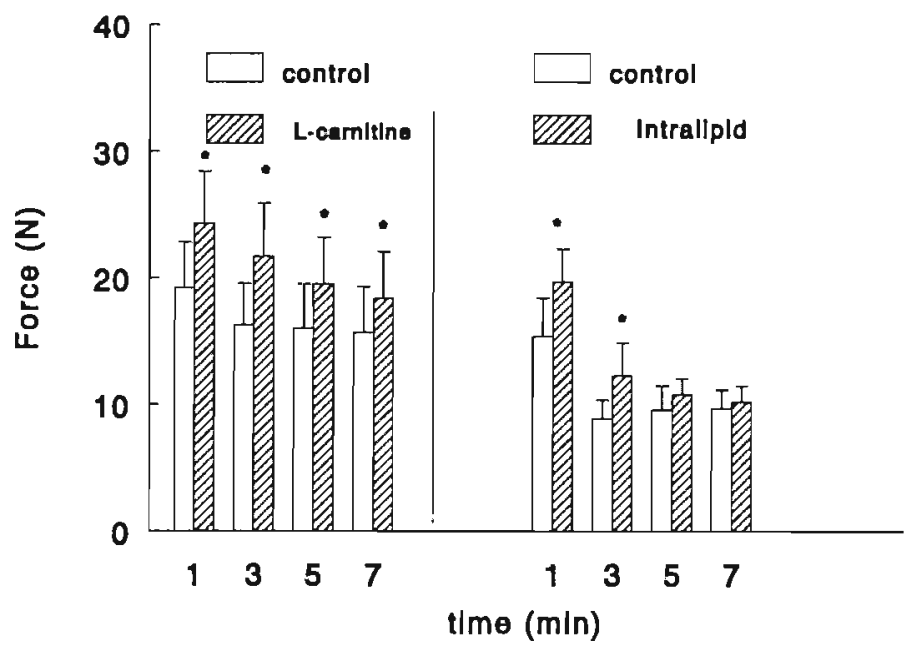

Figure 4.2. Effects of carnitine or high plasma fatty acid levels on muscle performance. LEFT: The effect of L-carnitine on latissimus dorsi (LD) force tests. Open bars represent the control test, hatched bars show force of the same muscle after a rest period of 30 minutes, during which $1 \mathrm{~g}$ of L-carnitine was infused intravenously. The experiment was carried out in ten dogs. $(n=10)$.

RIGHT: The effect of high plasma fatty acid levels on LD force tests. Open bars represent the control test. dotted bars show force of the same muscle after a rest period of 30 minutes, during which $75 \mathrm{ml} 20 \%$ Intralipid ${ }^{@}$ together with $200 \mathrm{IU}$ heparin/kg (to increase lipolysis) was infused. The experiment was carried out in 3 dogs. * represent values significantly different from control values.

acter and not be solely caused by the trapping of acetyl-groups in the pyruvate dehydrogenase reaction.

Stimulation of ATP generation by carnitine could be most effective in preventing local acidosis. This is substantiated by increasing fatty acid availability to the paced skeletal muscle instead of increasing carnitine. Figure 4.2 shows that increasing the circulating free fatty acid level (by infusion of Intralipid with heparin to stimulate lipolysis), results in a considerably higher force of the musculus latissimus dorsi during pacing, similar to the effect we observed after elevating the circulating carnitine concentration. During increased fatty acid supply, carnitine had no additional stimulatory effect in these experiments. Therefore we can conclude that Lcarnitine or fatty acid supply may inhibit lactic acidosis and as such limit acidification 
of the interstitium, which is responsible for vascular flow decline, as we have shown in the heart $(20,28)$.

The beneficial effect of carnitine raised the question: Is there a carnitine-deficient compartment in muscle under the conditions of the tests? As the muscle cells are stores of carnitine in the body, it is unlikely that the sites of storage could be carnitine deficient. Perhaps subsarcolemmal or vascular sites could easily lose carnitine during local acidosis? In skeletal muscle and in heart two types of mitochondria can be distinguished $(19,24,25): M_{1}$ (superficial) and $M_{2}$ (interfibrillar) mitochondria. The $\mathrm{M}_{1}$ mitochondria have a relatively loose coupling of phosphorylation to oxidation, perhaps a reflection of higher vulnerability of the muscle compartment involved. This could also apply to mitochondria in cells of the blood vessels.

\section{Carnitine and energy supply in blood vessels}

Both vascular endothelial and smooth muscle cells contain carnitine palmitoyltransferases, as judged by the presence of (carnitine-dependent) fatty acid oxidation $(22,37)$. Van Hinsbergh et al (47) observed that cultured endothelial cells occasionally contain lipid droplets, that disappear after carnitine addition. We observed that adding carnitine to endothelial cells in a glucose-containing culture medium strongly stimulates oxidation of oleate (22). By comparing the rates of oleate oxidation and lactate formation, we have been able to calculate that fatty acid oxidation may contribute much more than glycolysis to aerobic ATP synthesis. This conclusion is at variance with that of others (34), who may have omitted carnitine from the culture medium.

In some species vascular endothelial cells may not be particularly sensitive to ischemia (6). In hypoperfused rat Langendorff hearts, however, we noted early leakage of the endothelial enzyme xanthine oxidase into the cardiac interstitium (21). The production of oxygen radicals, in the interstitial space, may have been partly responsible for the observed loss of cardiac contractility, as acute improvement of contractility was seen after addition of superoxide dismutase to the medium (21). Also, the addition of vasoxin, a strong alpha-adrenergic vasoconstrictor, increased cardiac contractility (21), which suggests increased cardiac performance by an increase of the perfusion pressure during perfusion by constant (low) flow instead of constant pressure.

High vascular vulnerability in dog hearts subjected to ischemia, has recently been observed by Dauber et al. (9). They noticed increased microvascular permeability and impaired endothelium-dependent vasodilation. Early involvement of vascular endothelium in ischemia has also been noted in humans as increased prostacyclin biosynthesis in obstructive arterial disease (15). Therefore, in certain species, there is early vascular involvement in oxygen deficient muscles which might lead to a lower carnitine concentration in endothelial cells. Whether vascular smooth muscle cells are as sensitive to ischemia remains to be seen. They probably contain carnitine under normal conditions, as human arterial smooth muscle cells in culture oxidize added oleate, a process completely inhibited by the carnitine palmitoyl transferase II inhibitor aminocarnitine (table 5.2). Even if smooth muscle cells in vitro are as sensitive to ischemia as endothelial cells, it need not be so in situ. Capillary 
endothelial cells may be more directly exposed to lactic acid (and perhaps also to long-chain acylcarnitine) produced by the bulk of striated muscle cells.

\section{Examples of improved function by carnitine in pre-ischemic muscles}

Local deficiency of carnitine might occur in ischemia followed by reperfusion. High intensity exercise has been shown to lead to a considerable loss of carnitine from skeletal muscle $(5,13,18,44)$. This also occurs in heart due to pacing or infarction (45). Carnitine could be lost from muscles by leakage through plasma membranes, together with other cytosolic compounds, as has been demonstrated after damage caused by the calcium-paradox (42). Conversion of carnitine to acylcarnitines is another way to produce deficiency. Overall carnitine levels in muscle are high, both in white and red muscle fibres (31), but localized areas might be deficient under certain circumstances.

Brevetti et al (5) showed a positive effect of carnitine administration on skeletal muscle function in humans, suffering from peripheral vascular disease. Walking distance improved, together with vascular flow. Ferrari et al (14) observed, in patients with angina pectoris, a decline of lactate output during pacing, indicative of improved oxygenation of cardiac tissue. We observed acute improvement of force in stimulated musculus latissimus dorsi of the dog, in situ, by carnitine injection, as has been discussed above. Siliprandi et al (44) recently showed that in seven out of ten humans subjected to physical exercise, a greater amount of work was carried out when exercise was started one hour after an oral dose of L-carnitine. The explanation given for this observation was stimulation of pyruvate removal in the form of acetylcarnitine, a phenomenon also observed by Ferrannini et al.(13).

\section{Mechanisms by which carnitine may improve blood flow}

The vascular system appears to be vulnerable in the pre-ischemic state of muscle $(9,21)$. One possibility is a loss of carnitine, and another is altered signal transduction, during acidification of interstitial spaces. This may result from glyco(geno)lysis, instead of fatty acid oxidation being the major source of ATP and from a increase in noradrenaline release. Inhibition of glycolysis may be accomplished by stimulation of respiratory chain phosphorylation. Both limitation of metabolic acidosis and increased ATP synthesis might result from carnitine suppletion, particularly when it concerns a muscle compartment relatively deficient in carnitine. This need not be the vascular compartment itself, but may be an area of striated muscle cells. Limitation of local acidosis may be expected to increase flow, as $\mathrm{pH}$ lowering has been shown to cause the release of bound $\mathrm{Ca}^{2+}$ not only in striated, but also in vascular smooth muscle cells (32). In addition to this important phenomenon, other factors may be involved, such as alteration of intracellular ATP levels. High concentrations of ATP may stimulate the closure of plasmalemmal, ATP. dependent, $\mathrm{K}^{+}$channels $(12,33,39)$, and limit the loss of cellular $\mathrm{K}^{+}$, generally seen in hypoxia/ischemia. Both vascular smooth muscle and endothelial cells contain ATP-sensitive $\mathrm{K}^{+}$channels (12). Blocking these $\mathrm{K}^{+}$channels caused depolarization and reduction of $\mathrm{Ca}^{2+}$ influx, so that the cellular $\mathrm{Ca}^{2+}$ level decreases. Cytosolic $\mathrm{Ca}^{2+}$ increase in endothelial cells not only enhances endothelial derived relaxing 
factor (EDRF), but also $\mathrm{PGl}_{2}$ release (33). Both autacoids are vasodilators and inhibition of their secretion may result in increased perfusion pressure. Acidosis may also affect plasmalemmal $\mathrm{Na}^{+}-\mathrm{Ca}^{2+}$ exchange, as the exchanger may be strongly inhibited at $\mathrm{pH} 6$ and stimulated at $\mathrm{pH} 9$ (39). The exchanger is present in arterial smooth muscle cells (2) and may cause a rapid efflux of $\mathrm{Ca}^{2+}$ after increasing cytosolic $\mathrm{Ca}^{2+}$.

From the above considerations we concluded that in the pre-ischemic state protons play a central role in the mechanism of $\left(\mathrm{Ca}^{2+}\right.$ dependent) vasoconstriction. Proton excess may affect plasmalemmal signal transduction, increased noradrenaline release and stimulation of the phosphatidyl inositol cycle (3) could play an important role, in the observed release of $\mathrm{Ca}^{2+}$ from the cytosolic side of plasma membranes $(20,27,48)$.

Acidosis may be prevented by inhibition of glyco(geno)lysis and by the stimulation of oxidative removal of pyruvate. Promotion of capillary flow is most important to remove metabolic products. Long-chain acyicarnitine can also flood the interstitium in the pre-ischemic state. It might affect both vascular smooth muscle and endothelial cells $(8)$, as will be discussed below.

\section{Long-chain acylcarnitine and loss of coronary flow}

From unpublished experiments we concluded, that in lipid-enriched Langendorff rat hearts, inhibition of beta-oxidation by aminocarnitine does not lead to accumulation of long-chain acylcarnitine as long as glycogen is present. Apparently, fatty acid levels are kept low by the operation of the glucose/fatty acid cycle (41). This takes place at the surface of the endoplasmic reticulum, so that only small amounts of fatty acids can be converted to their carnitine derivatives in the mitochondrial CPT-1 reaction. In ischemia, however, glycogen has disappeared and long-chain acylcarnitine can accumulate $(30,43)$. In pre-ischemia, the retardation of acidosis by carnitine addition could delay the loss of flow, and as such limit long-chain acyl carnitine accumulation.

An acute effect of carnitine administration could only be visualized if it had to act in a carnitine-deficient compartment. The bulk of the muscle mass, which must be mainly responsible for interstitial flooding with long-chain acylcarnitine accumulation in pre-ischemia, probably contains sufficient carnitine already. Therefore, it is not likely to ascribe the observed beneficial effect of carnitine addition to increase of myocytal long-chain acylcarnitine production. However, by promoting flow, carnitine addition may be expected to lower interstitial long-chain acylcarnitine levels.

When in the experiments mentioned above, the lipid-enriched rat hearts, were depleted of glycogen by preperfusion with glucagon, prior to 60 min perfusion with glucagon and aminocarnitine, they were found to accumulate an large amount of long-chain acylcarnitine $(0.3 \mu \mathrm{mol}$ per $\mathrm{g}$ wet weight), while considerable amounts of long chain acylcarnitine were secreted by the heart during perfusion. These hearts, paced at a rate of 300 beats $/ \mathrm{min}$, remained intact as judged by continued beating. There was no loss of myoglobin and coronary flow remained unaltered during constant pressure perfusion. These experiments, to be published elsewhere (29), indicate that cardiac membranes are not adversely affected by long-chain acylcarnitine during $\mathrm{pH} 7.5$ perfusion as long as flow continues. Although long-chain acylcarnitine 
cannot be the initiator of metabolic and functional disruption, its occurrence during acidosis, resulting in a progressive decline of flow as in pre-ischemia, may contribute to damage. We consider the beneficial effect of carnitine supplementation to be due to prevention of local acidosis and not to primary avoidance of interstitial flooding by long-chain acylcarnitine.

Finally, a possible cholinomimetic effect of carnitine requires discussion (although choline is not able to replace carnitine in stimulating force of paced dog latissimus dorsi muscle) (10).

\section{Carnitine and acute cholinomimetic effects on muscle}

Cholinomimetic effects of (acetyl)carnitine have been described by a number of authors (1, cf 16). We have observed that edrophonium chloride (Tensilon), a cholinesterase inhibitor, stimulated the force of the paced latissimus muscle of the dog in situ (11), as discussed above for carnitine. In the presence of Tensilon, carnitine did not have an additional effect. Both drugs may have promoted blood supply to the muscle, but cannot have the same mechanism of action. Carnitine is not an acetylcholine-esterase inhibitor, and carnitine has no cholinergic action in the absence of ischemia, whereas vasodilatory properties of true cholinergic agents may also be observed in the absence of ischemia $(7,49)$. It may be of interest to note that ischemia impairs endothelium-dependent relaxation to acetylcholine (9), which could be due to local acidosis and/or changes of membrane fluidity, caused by the accumulation of detergents (like long-chain acylcarnitine, and lysophospholipids).

\section{ACKNOWLEDGEMENTS}

The authors would like to thank Mrs C Lucas and LEA De Wit for help in some of the unpublished experiments mentioned. The department of Cardiology of the University of Limburg, the Dutch Heart Foundation (The Hague, the Netherlands) and Sigma Tau, Pomezia, Italy, are thanked for financial support. 


\section{REFERENCES}

1. Bettini V, De Varda E, Guerra B, Pulliero G, Ton P. Studio sperimentale sugli effetti colinomimetici della carnitina in preparati isolati di arteria aorta $\theta$ masseterina. Cardiologia (1987)32:1039-1042.

2. Bingham-Smith J, Cragoe EJ, Smith $\mathrm{L}$. $\mathrm{Na}^{+} / \mathrm{Ca}^{2+}$ Antiport in cultured arterial smooth muscle cells. Inhibition by magnesium and other divalent cations. J Biol Chem (1987)262:11988-11994.

3. Bingham-Smith J, Dwyer SD, Smith L. Lowering extracellular pH evokes inositol phosphate formation and calcium mobilisation. J Biol Chem (1989)264:8723-8728.

4. Bremer J. Carnitine- metabolism and functions. Physiol Rev (1983)63:1420-1480.

5. Brevetti G, Attisano T, Perna S, Rossini A, Policicchio A, Corsi M. Effect of L-Carnitine om the reactive hyperemia in patients affected by peripheral vascular disease: A double blind crossover study. Angiology (1989)40:857-862.

6. Buderus $S$, Siegmund B, Spahr $R$, Krützfeldt A, Piper HM. Resistance of endothelial cells to anoxiareoxygenation in isolated guinea pig hearts. Am J Physiol (1989)257:H488-H493.

7. Coffman JD, Cohen RA. Cholinergic vasodilation mechanisms in human fingers. Am J Physiol (1987)252:H594-H597.

8. Dainty IA, Bigaud M, McGrath JC, Spedding M. Interactions of palmitoyl carnitine with the endothelium in rat aorta. Br J Pharmacol (1990)100:241-246.

9. Dauber JM, Van Benthuysen KM, McMurthy JF, Wheeler GS, Lesnefsky EJ, Horwitz LD, Neil JV. Functional coronary microvascular injury evident as increased permeability due to brief ischemia and reperfusion. Circ Res (1990)66:986-998.

10. Dubelaar M-L, Lucas CMBH, Hülsmann WC. Acute effect of L-carnitine upon skeletal muscle force tests in the dog. Am J Physiol (1991)260:E189-E193.

11. Dubelaar M-L, Lucas CMHB, Hülsmann WC. The effect of I-carnitine on force development of the latissimus dorsi muscle in dogs. J Cardiac Surg (1991)6supl1:270-275.

12. Escande D, Thüringer $D$, Le Guern $S$, Courteix J, Laville $M$, Cavero J. Potassium-channel openers act through an activation of $\mathrm{K}^{+}$channels in guinea pig cardiac myocytes. Pflügers Arch (1989)414:669-675.

13. Ferrannini E, Buzzigoli G, Bevilacqua S, Boni C, Del Chiaro D, Oleggini M, Brandi L, Maccari F. Interaction of carnitine with insulin stimulated glucose metabolism in humans. Am J Physiol (1988)255:E946-E952.

14. Ferrari $R$, Cucchini $F$, Visioli $O$. The metabolic effects of $L$-carnitine in angina pectoris. Int $J$ Cardiol (1984)5:213-216.

15. FitzGerald GA, Smith B, Pedersen AK, Brash ER. Increased prostacyclin biosynthesis in patients with severe atherosclerosis and platelet activation. New Engl J Med (1984)310:1065-1068.

16. Fritz IB. Action of carnitine on long chain fatty acid oxidation by the liver. Am J Physiol (1959) 197:297-304

17. Fritz IB. Factors infiuencing the rate of long chain fatty acid oxidation. Synthesis in mammalian systems. Physiol Rev (1961) 41:52-129.

18. Hiatt WR, Regensteiner JG, Wolfel EE, Ruff L, Brass EP. Carnitine and acylcarnitine metabolism during exercise in humans. dependence on skeletal muscle metabolic state. J Clin Invest (1989)84:1167-1173.

19. Hülsmann WC. Two types of mitochondria in heart muscle from euthyroid and hypertyroid rats. Biochem J (1970)116:32-33.

20. Hülsmann WC, De Wit LEA. Acidosis, cardiac stunning and its prevention by oxygen. Cell Biol Int Rep (1990)14:311-315.

21. Hülsmann WC, Dubelaar M-L. Early damage of vascular endothelium during cardiac ischemia. Cardiovasc Res (1987)21:674-677

22. Hülsmann WC, Dubelaar M-L. Aspects of fatty acid metabolism in vascular endothelial cells. Biochimie (1988)70:681-686

23. Hülsmann WCH, Siliprandi $D$, Ciman $M$, Siliprandi N. Effects of carnitine on the oxidation of $\alpha$ oxoglutarate to succinate in the presence of acetoacetate or pyruvate. Biochim Biophys Acta (1964)93:166-168.

24. Hülsmann WC, De Jong JW, Van Tol A. Mitochondria with loosely and tightly coupled oxidative phosphorylation in skeletal muscle. Biochim Biophys Acta (1968)162:292-293.

25. Hülsmann WC, Meyer AEFH, Bethlem J, Wijngaarden GK. Different mitochondrial species in human skeletal muscle. Exerpta Medica Congress Series (1970)199:319-322. 
26. Hülsmann WC, Stam H, Maccari F. The effect of excess (acyl)carnitine on lipid metabolism in rat heart. Biochim Biophys Acta (1982)713:39-45.

27. Hülsmann WC, De Wit LEA, Schneydenberg C, Verkleij AJ. Loss of cardiac contractility and severe morphologic changes by acutely lowering the $\mathrm{pH}$ of the perfusion medium: protection by fatty acids. Biochim Biophys Acta (1990) 1033:214-218.

28. Hülsmann WC, De Wit LEA, Stam H. Schoonderwoerd K. Hormonal control of cardiac lypolysis by glyco(geno)lysis. Biochim Biophys Acta (1990)1055:189-192.

29. Hülsmann WC, Schneydenberg $C$, Verkleij AJ. Accumulation and excretion of long-chain acylcarnitines by rat heart, studies with aminocarnitine. Biochim Biophys Acta (1991)1097:263-267.

30. Idell-Wenger JA, Grotyohann LW, Neely JR. Coenzyme A and carnitine distribution in normal and ischemic hearts. J Biol Chem (1978)253:4310-4318.

31. Kerner J, Bieber LL. The effect of electrical stimulation, fasting and anaesthesia on the carnitine(s) and acylcarnitines of rat white and red skeletal muscle fibres. Comp Biochem Physiol (1983)75B:311 316

32. Kwan $\mathrm{CY}$, Daniel, EE. Calcium handling by membranes isolated from vascular smooth muscle in hypertension. Aoli MK, Frohlich ED (eds) In: Calcium in essential hypertension, Academic Press, Japan. Inc. (1989)pp 201-230.

33. Lückhoff $A$, Pohl $U$, Mülsch A, Busse R. Differential role of extra- and intracellular calcium in the release of EDRF and prostacyclin from cultured endothelial cells. Br J Pharmacol (1988)95:189-196.

34. Mertens S, Noll T, Spahr R, Krützfeldt A, Piper HM. Energetic response of coronary endothelial cells to hypoxia. Am J Physiol (1990)258:H689-H694.

35. Méry P-F, Brechler VE, Pavoine C. Pecher F, Fischmeister R. Glucagon stimulates the cardiac $\mathrm{Ca}^{2+}$ current by activation od adenylyl cyclase and inhibition of phosphpdiesterase. Nature $(1990) 345,158-$ 161

36. Murthy MSR, Pande SV. Some differences in the properties of carnitine palmitoyltransferase activities of the mitochondrial outer and inner membranes. Biochem J (1987)248:727-733.

37. Murthy MSR, Ramsay RR, Pande SV. Acyl CoA chain length affects the specificity of various carnitine palmitoyltransferases with respect to carnitine analogues. Biochem J (1990)267:273-276.

38. Odessey $Y Y$. Chace KV. Utilization of endogenous lipid oxygen and protein by rabbit aorta. Am J Physiol (1982)243:H128-H132.

39. Philipson KD, Bersohn MM. Nishimoto. Effects of $\mathrm{pH}$ on $\mathrm{Na}^{+}-\mathrm{Ca}^{2+}$ exchange in canine cardiac sarcolemmal vesicles. Circ Res (1982)50:287-293.

40. Quast $U$, Cook NS. Moving together: $\mathrm{K}^{+}$channel openers and ATP sensitive $\mathrm{K}^{+}$channels. Trends Pharmacol Sci (1989) 10:431-435.

41. Randle PJ, Garland PB, Hales CN, Newsholme EA. The glucose fatty acid cycle. Its role in insulin sensitivity and the metabolic disturbances of diabetes mellitus. Lancet (1963)1:785-789.

42. Scholte HR, Luyt-Houwen IEM, Dubelaar M-L. Hülsmann WC. The source of malonyl-CoA in rat heart. The calcium paradox releases acetyl-COA carboxylase and not propionyl-CoA carboxylase. FEBS lett. (1986)198:47-50.

43. Shug AL, Thomsen JD. Folts JD, Bittar N, Klein MI, Koke JR, Huth PJ. Changes in tissue levels of carnitine and other metabolites during myocardial ischemia and anoxia. Arch Biochem Biophys (1978) 187:4310-4318.

44. Siliprandi N, DiLisa F, Pieralsi G, Ripari P, Maccari F, Menabo R, Giamberardino MA, Vecchiet L. Metabolic changes induced by maximal exercise in human subjects following $L$-carnitine administration. Biochim Biophys Acta (1990)1034:17-21.

45. Spagnoli LG, Corsi M, Villaschi S. Myocardial carnitine deficiency in acute myocardial infarction. Lancet (1982)l:1419-1420.

46. Von Ardenne M, Reitnauer PG. Erhöhung des perfusionsdruckes bei konstanten perfusionsrate durch niedrige $\mathrm{pH}$-werte. Biomed Biochim Acta (1989)4:317-323.

47. Van Hinsbergh VMM, Emeis JJ, Havekes J. Interaction of lipoproteins with cultured endothelial cells. In: Thilo-Korner DGS, Freshney RI, eds. The endothelial cell- A pluripotent central cell of the vesse! wall. Karger, Basel, (1983) pp99-112.

48. Vandeplassche $\mathrm{G}$, Borgers $\mathrm{M}$. Ultrastructure and $\mathrm{Ca}^{2+}$ reallocation during ischemia, the $\mathrm{Ca}^{2+}$ paradox and metabolic acidosis. Cell Biol Int Rep (1990)14:317-334.

49. Weinstock M, McCarty R. Vasodilator responses to cholinergic and adrenergic stimulants in spontaneously hypertensive (SHR) and Wistar-Kyoto (WKY) normotensive rats (41545). Proc Soc Exp Biol Med (1983) 172:194-201. 


\section{CHAPTER 5}

\section{CARNITINE REQUIREMENT OF VASCULAR ENDOTHELIAL AND SMOOTH MUSCLE CELLS IN IMMINENT ISCHEMIA}

\section{Willem C Hülsmann}

Marie-Louise Dubelaar

This chapter was published in Molecular and Cellular Biochemistry 1992. 


\begin{abstract}
Vascular endothelial and -smooth muscle cells have been shown to use fatty acids as substrates for oxidative phosphorylation. Endothelial cells are more vulnerable to oxidative stress than muscle cells and are prone to loose carnitine early during hypoperfusion. This has been suggested by two observations. The first is that incubation of isolated endothelial cells in a low carnitine medium leads to oleate oxidation, dependent upon carnitine addition, whereas smooth muscle cells do not depend on carnitine addition during in vitro incubation, although aminocarnitine, a specific inner-membrane carnitine palmitoyltransferase inhibitor, inhibits fatty acid oxidation. The second observation is that rat hearts labelled in vivo with ${ }^{14} \mathrm{C}$-carnitine loose, as paced Langendorff heart, only $4 \%$ of their carnitine in 20 min perfusion, following $60 \mathrm{~min}$ global ischemia. The carnitine released had a much higher specific radioactivity than the carnitine that was not released. It indicates compartmentation of carnitine in heart. As earlier and presently discussed work shows endothelial vulnerability, it is to be expected that this cell type may become carnitine deficient during pacing and ischemia. Endothelial incompetence in flow regulation could be delayed by the presence of carnitine and fatty acids in pre-ischemia. It is speculated how activated fatty acids could protect endothelium.
\end{abstract}




\section{INTRODUCTION}

We have observed acute stimulation of function of paced muscle by intravenous administration of L-carnitine $(6,7)$. This was accompanied by the increase of flow, as determined by microsphere injection (7). The effect of carnitine is probably due to stimulation of fatty acid metabolism (6,7). Earlier we observed (14) that during hypoperfusion of heart endothelial cells are most vulnerable, judged by the early release of xanthine oxidase, an endothelial marker enzyme. This enzyme was probably involved in the production of oxygen free radicals in the interstitium, as the rapid loss of cardiac function due to hypoperfusion, could acutely be diminished by superoxide dismutase (SOD) administration. As we have observed that fatty acids are vasodilators (11) and delay acidosis-induced decrease in vascular flow (12), we decided to investigate fatty acid metabolism in vascular cells.

Fatty acid oxidation in vascular endothelium, has recently been demonstrated by us (15). Fatty acid oxidation in vascular smooth muscle cells will be reported in the present communication. We will also discuss the particular sensitivity of vascular endothelial cells to ischemia and the possible mechanisms by which fatty acids and (acyl)carnitines delay the loss of flow in pre-ischemia.

\section{MATERIAL AND METHODS}

\section{Cell culture}

Human umbilical artery smooth muscle cells were provided by Mr. A Verkerk, Department Cell Biology, Erasmus University, Rotterdam. They were isolated from pieces of arterial wall and cultured in a fibronectin coated 24 well plate (Costar) in medium M199 supplemented with 10\% fetal calf serum, 10\% human serum ,100 I.U. $/ \mathrm{ml}$ penicillin, $0.1 \mathrm{mg} / \mathrm{ml}$ streptomycin. The muscle cells were positively identified with a monoclonal antibody against smooth muscle alpha-actin (Sigma clone no 1 A4) and subcultivated by 1:3 splits when the culture reached confluency. A 7h incubation was carried out in (carnitine-free) Waymouth MB 721/1 medium supplemented with $2 \%$ fatty acid free bovine serum albumin and $0.9 \mathrm{mM}\left(9,10 \cdot{ }^{3} \mathrm{H}\right)$ oleate. After incubation the ${ }^{3} \mathrm{H}_{2} \mathrm{O}$ formed was determined as described (15). The carnitine and aminocarnitine used were gifts from Dr. F Maccari (Sigma Tau, Pomezia, Italy). 


\section{Rat heart perfusions}

were carried out according to the Langendorff technique with a modified Tyrode solution, containing $11 \mathrm{mM}$ glucose as substrate, as described before (11). Ischemia was produced by completely interrupting flow and keeping the heart at $37^{\circ} \mathrm{C}$ in medium saturated with $95 \% \mathrm{~N}_{2}$ and $5 \% \mathrm{CO}_{2}$. After 60 min of ischemia, reperfusion was started and effluent were collected over $20 \mathrm{~min}$. The radioactivity in the effluents and of the residual activity in the heart were determined. The percentual release of carnitine was calculated, based on radioactivity measurements, to include loss of acylcarnitines. The specific activities of carnitine in hearts and effluents were determined. Carnitine was measured by the method of Cederblad (1).

\section{Isolation of mitochondria; assay of mitochondrial components}

Rat hearts were finely minced with scissors and homogenized in a Potter-Elvehjem, teflon-glass homogenizer. Debris and nuclei were removed at $5 \mathrm{~min} 600 \mathrm{xg}$ and the supernatant spun for $10 \mathrm{~min}$ at $6000 \times \mathrm{g}$ to sediment the mitochondria. The isolation medium contained $0.1 \mathrm{M} \mathrm{KCl}, 0.05 \mathrm{M}$ Tris- $\mathrm{HCl}(\mathrm{pH} 7.4), 1 \mathrm{mM}$ EDTA, $5 \mathrm{mM} \mathrm{MgCl}{ }_{2}$, $1 \mathrm{mM}$ ATP, $0.8 \mathrm{mg} / \mathrm{ml}$ BSA. After isolation, the mitochondria were frozen in batches for analysis. Protein was determined by the biuret method. Carnitine acetyltransferase (26) and propionyl-CoA carboxylase (29) were measured as described.

\section{RESULTS}

\section{Fatty acid oxidation in vascular smooth muscle}

From Table 5.1 it can be seen that in cultured smooth muscle cells the addition of $\mathrm{L}$ carnitine to carnitine-free incubation medium slightly stimulated oxidation of ${ }^{3} \mathrm{H}$. labelled oleate. The carnitine content of the culture medium (present in serum) was 6 $\mu \mathrm{M}$ and apparently enough to obtain an optimal intracellular carnitine level that remained high during the subsequent $7 \mathrm{~h}$ incubation. The strong inhibition by aminocarnitine, a specific inhibitor of carnitine palmitoyl transferase II (17), indicated the requirement of carnitine-dependent transport of (activated) fatty acid into the mitochondrial matrix space.

Table 5.1. Oleate oxidation in cultured smooth nuscle cells. The cells were incubated for $7 \mathrm{~h}$ in Waymouth medium, enriched with $2 \%$ bovine serum albumin and $0.9 \mathrm{mM}^{3} \mathrm{H}$ oleate. Values are mean $\pm S D$ of 4 experiments.

\begin{tabular}{|c|c|}
\hline Addition & $\begin{array}{c}\text { nmol oleateimg } \\
\text { protein per } \mathrm{h}\end{array}$ \\
\hline None & $13.4 \pm 1.6$ \\
\hline Carnitine $60 \mu \mathrm{M}$ & $16.0 \pm 4.9$ \\
\hline Aminocarnitine $30 \mu \mathrm{M}$ & $0.5 \pm 0.6$ \\
\hline
\end{tabular}


Aminocarnitine also inhibited oleate oxidation in adventitia- and endothelium-free rat aorta (Table 5.2). This effect of carnitine addition was also small. The low dependence of fatty acid oxidation in smooth muscle on carnitine addition (Tables 5.1 and 5.2), compared to that in endothelial cells (15) during in vitro incubation, suggests a higher rate of carnitine loss from the latter cell type during in vitro incubation. More experiments are required to settle this point.

\begin{abstract}
Tabel 5.2. Oleate oxidation in adventitia and endothelium free rat aorta. Rat aortas, cleaned in saline at room temperature, were cut in small pieces and incubated in standard perfusion medium with $11 \mathrm{mM}$ glucose, $2 \%$ bovine serum albumin and $1.7 \mathrm{mM}^{3} \mathrm{H}$-oleate $(1 \mu \mathrm{mol}=0.835 \mu \mathrm{Ci})$. After $4 \mathrm{~h}$ of incubation at $37^{\circ} \mathrm{C}$ in siliconized scintilation vials (under $95 \% \mathrm{O}_{2}+5 \%$ $\mathrm{CO}_{2}$ ), we determined DNA contents as well as the amount of ${ }^{3} \mathrm{H}_{2} \mathrm{O}$ formed (for details see reference 6). Values are mean \pm $\mathrm{SD}$ for 3 deterinations.
\end{abstract}

\begin{tabular}{|c|c|}
\hline Addition & nmol/h/mg DNA \\
\hline None & $11.3 \pm 0.1$ \\
\hline L-carnitine $80 \mu \mathrm{M}$ & $14.7 \pm 1.4$ \\
\hline Aminocarnitine $40 \mu \mathrm{M}$ & $7.8 \pm 0.4$ \\
\hline
\end{tabular}

\title{
Relative resistance of muscle cells against ischemia
}

During hypoperfusion of Langendorff rat hearts, we observed that xanthine oxidase leaked through endothelial plasmalemma, while smooth muscle cells were functionally still intact as judged by prompt responses to vasodilator (nitroprusside) and vasoconstrictor (vasoxin). As there was no loss of myoglobin, we concluded that vascular endothelium is most vulnerable to ischemia (14).

After overnight in vivo labeling of rats with ${ }^{14} \mathrm{C}$ - $L$-carnitine, Langendorff perfusion of the electrically stimulated heart led to no measurable loss of label after the removal of blood (not shown). After one hour of global ischemia at $37^{\circ} \mathrm{C}$ the loss of carnitine was still low and the specific activity of the released carnitine much higher than that of the residual cardiac carnitine (Table 5.3). It suggests leakage of a carnitine containing cell compartment.

Table 5.3. Specific activity and loss of camitine from in vivo ${ }^{14} \mathrm{C}$-carnitine labelled rat hearts. Fifteen hours after in vivo labelinng with $5 \mu \mathrm{Ci}^{14} \mathrm{C}$-carnitine by intraperitoneal injection of each rat of about $250 \mathrm{~g}$. perfusions were carried out as described in the methods section. Shown are the values (mean \pm SD) of 4 experiments.

\begin{tabular}{|c|c|c|}
\hline Specific activity in etfluent & Specific activity in heart & $\begin{array}{c}\text { Amount of label removed } \\
\text { after ischemia }\end{array}$ \\
\hline$(\mathrm{pCi} / \mathrm{nmol})$ & $(\mathrm{pCi} / \mathrm{nmol})$ & percent $(\%)$ of total \\
\hline $2710 \pm 730$ & $22.4 \pm 2.3$ & $4.4 \pm 1.6$ \\
\hline
\end{tabular}

From the early leakage of enzymes from endothelium (14) it is most likely that leakage of carnitine after brief ischemia of muscle, is also predominantly from 
endothelial origin. Also the mitochondrial inner membrane of cardiomyocytes is relatively resistant to ischemia.

From Table 5.4 we can conclude that $30 \mathrm{~min}$. global ischemia of rat heart at $37^{\circ} \mathrm{C}$, followed by the isolation of mitochondria, at $0-5^{\circ} \mathrm{C}$, resulted in preservation of matrix components. That carnitine acetyl transferase is not lost, might be due to its firm binding to the innermembrane, but propionyl-CoA carboxylase is a looselybound matrix protein (34) and could be lost easily if mitochondrial leakage would occur. This also holds for low molecular compounds, like carnitine (Table 5.4). The latter compound increased in concentration in the mitochondria, a phenomenon observed already by Idell-Wenger et al (18), who found that carnitine shifts from the cytosol to the mitochondria due to ischemia. They also found retention of coenzyme $A$ in the matrix mitochondrialis (18).

Table 5.4. Mitochondrial matrix components in control and ischemic hearts. Control and ischemic hearts (30 minutes at $37^{\circ} \mathrm{C}$ ), were rapidly cooled in ice-cold isolation medium and mitochondria were isolated (see Methods). Values are mean \pm SD of 4 experiments.

\begin{tabular}{|c|c|c|c|}
\hline & $\begin{array}{c}\text { carnitine acetyl } \\
\text { transferase }\end{array}$ & $\begin{array}{c}\text { propionyl-CoA } \\
\text { carbaxylase }\end{array}$ & L-carnitine \\
\hline Mitochondrial source & $\mathrm{mU} / \mathrm{mg}$ protein & $\mathrm{mU} / \mathrm{mg}$ protein & $\mathrm{nmol} / \mathrm{mg} \mathrm{protein}$ \\
\hline control hearts & $290 \pm 15$ & $21 \pm 2$ & $1.3 \pm 0.2$ \\
\hline ischemic hearts & $308 \pm 32$ & $20 \pm 2$ & $2.6 \pm 0.3$ \\
\hline
\end{tabular}

The observed loss of carnitine from heart- or skeletal muscle during pacing or strenuous exercise $(8,10,30,31)$ may be expected to be at least partly due to its loss from endothelial cells. This leads to our hypothesis that observed acute beneficial effects of intravascular carnitine administration, during pacing or exercise $(6,7,9)$, may be due to restoration of regulatory functions of endothelium on muscle flow.

\section{DISCUSSION}

Endothelial cells possess a large capacity for anaerobic glycolytic energy production $(5,22)$. In aerobiosis they also oxidize fatty acids (15). Vascular smooth muscle cells also catalyse fatty acid oxidation (Tables 5.1 and 5.2), as may have been expected (24). Vascular fatty acid oxidation might still proceed in imminent ischemia, as vascular mitochondria may still have access to some oxygen when mitochondria within the muscle tissue are already fully anaerobic, due to the presence of an oxygen concentration gradient. Perhaps this situation makes the endothelium most suitable for oxygen free radical formation in imminent ischemia. That endothelial cells can be damaged by oxygen radicals has been known for some time (27). Indeed, an early indication of endothelial alteration is its failure to regulate flow $(3,32)$. We have been able to show (14), that the loss of cardiac function during hypoperfusion of rat Langendorff hearts, could partly be overcome by the addition of superoxide dismutase to the perfusion medium. This indicates that at least part of the damaging free radicals are present extracellularly, probably in the interstitium. Intracellularly, the radicals may be formed by various subcellular fractions (2), many cell types are equipped with superoxide dismutase. For endothelium, this may be illustrated by the 
observation of Mügge et al (23), that endothelium derived relaxing factor (EDRF) cannot be secreted from rabbit aorta after inhibition of intracellular superoxide dismutase. In our study (15), the beneficial effect of added, extracellular, superoxide dismutase indicates neutralization of the negative effect of $\mathrm{O}_{2}$ resulting in increased capillary flow. The addition of a vasoconstrictor instead of super oxide dismutase had a similar effect on heart function, which may be explained by improved perfusion pressure during flow limitation. The targets of the interstitial free radicals under our conditions of hypoperfusion have not been studied. It could be the endothelial cell itself, affecting its vasoregulatory messengers (endothelins, endothelium derived relaxing factor, prostacyclin or other autacoids), or their receptors on smooth muscle cells. It is probably not the smooth muscle alpha-adrenergic receptor or guanylate cyclase of smooth muscle cells, as judged by prompt reactions upon vasoxin or nitroprusside addition (15). The observed effect of fatty acids on delaying imminent ischemia, as induced by acidosis (12), is probably located in endothelial cells, the most likely source of $\mathrm{O}_{2} \cdot-$ in preischemia $(14,19,32)$. Our experience that fatty acid and carnitine are both needed to improve force of the paced latissimus dorsi muscle (6), suggests that fatty acids must be activated in order to be effective. Activated fatty acid can protect being a substrate of oxidative phosphorylation. A high rate of ATP generation limits glycolysis and prevents lactic acidosis. More efficient ATP generation may be expected to lower free radical formation, as low cytosolic AMP limits the extracellular generation of substrates for xanthine oxidase, as discussed above. It might help the regulation of intracellular $\mathrm{Ca}^{2+}$ and the reacylation of membrane lysophospholipids, formed by endogenous phospholipase action, and perhaps by membrane stabilization by long-chain acylcarnitine $(13,16)$.

Acute effects of carnitine on stimulated muscle have been discussed above and may well be based on improved flow (cf 16). Carnitine derivatives, such as acetylcarnitine and propionylcarnitine have also been shown to be effective in the prevention of disorders related to hypoperfusion $(20,25)$. Sassen et al $(28)$ observed that propionylcarnitine improved transmural cardiac flow in pigs subjected to ischemic conditions. Acetylcarnitine and propionylcarnitine might be efficient carnitine donors (25). Propionylcarnitine could have an additional advantage over carnitine and acetylcarnitine as after carboxylation, it could generate citric acid cycle intermediates (4). However, the beneficial effect of acetylcarnitine (20), would then require a different explanation as it is not an anaplerotic agent and could lead to further increase the acetyl-CoA/CoA ratio in the mitochondrial matrix. Another possibility is the protection of mitochondria from depletion of $\mathrm{COASH}$ by its conversion to short-chain acyl-CoA, before CoASH is oxidized to CoASSCoA (inactive, oxidized-coenzyme A) by free radicals, known to affect the sulfhydryl status of mitochondria (2). The fate of added carnitine and their short-chain derivatives in imminent ischemia should be studied in endothelial cells, as muscle cell mitochondria are relatively resistant towards ischemia (Table 4 and ref.21). Both propionylcarnitine and acetylcarnitine have been shown to decrease cytoplasmic $\mathrm{Ca}^{2+}$ levels in endothelial cells, subjected to oxidative stress (33). Recent experiments indicate that carnitine addition to fatty acid and glucose containing media increases NADPH in endothelial cells. This is required for EDRF and GSH generation and maybe largely responsible for the observed improvement of flow during oxidative stress. 


\section{ACKNOWLEDGEMENTS}

The authors wish to thank Mr. A Verkerk, department of Cell Biology I Erasmus University Rotterdam, for the culture of smooth muscle cells. The Netherlands Heart Foundation, The Hague and Sigma Tau Pharmaceutical of Rome, Italy, are thanked for financial support. 


\section{REFERENCES}

1. Cederblad G, Lindstedt CD. A method for the determination of carnitine in the picomolar range. Clin Chim Acta (1972)37:235-243.

2. Chance $B$. Sies $H$, Boveris $H$. Hydroperoxide metabolism in mammalian organs. Physiol Rev (1979)59:527-605.

3. Dauber JM, Van Benthuysen KM, McMurthy JF, Wheeler GS, Lesnefsky EJ, Horwitz LD, Neil JV. Functional coronary microvascular injury evident as increased permeability due to brief ischemia and reperfusion. Circ Res (1990)66:986-998.

4. Di Lisa F, Menabo R, Siliprandi N. L-propionylcarnitine protection of mitochondria in ischemic rat hearts. Mol Cell Biochem (1989)88:169-173.

5. Dobrina A, Rossi F. Metabolic properties of freshly isolated bovine endothelial cells. Biochim Biophys Acta (1983)762:295-301.

6. Dubelaar M-L, Lucas CMHB. Hülsmann WC. Acute effect of I-carnitine upon skeletal muscle force tests in the dog. Am J Physiol (1991)260:E189-E193.

7. Dubelaar M-L, Lucas CMHB, Hülsmann WC. The effect of l-carnitine on force development of m.latissimus dorsi in dogs. J Cardiac Surgery (1991)6suppl1:270-275.

8. Ferrannini E, Buzzigoli G, Bevilaqua S, Boni C, DelChiaro D, Oleggini M, Brandi L, Maccari F. Interaction of carnitine with insulin-stimulated glucose metabolism in man. Am J Physiol (1988)255:E964E952.

9. Ferrari $R$, Cucchini $F$, Visioli $O$. The metabolic effects of $L$-carnitine in angina pectoris. Int $\mathrm{J}$ Cardiol (1984)5:213-216.

10. Hiatt WR, Regensteiner JG, Wolfel EE, Ruff L, Brass EP Carnitine and acylcarnitine metabolism during exercise in humans. -dependence on skeletal muscle metabolic state. $J$ Clin Invest (1989)84:1167-1173.

11. Hülsmann WC. Coronary vasodilation by fatty acids. Basic Res Cardiol (1976)71:179-191.

12. Hülsmann WC. De Wit LEA, Schneydenberg C, Verkleij AJ. Loss of cardiac contractility and severe morphologic changes by acutely lowering the $\mathrm{pH}$ of the perfusion medium, protection by fatty acids. Biochim Biophys Acta (1990) 1033:214-218.

13. Hülsmann WC, Dubelaar M-L, Lamers JMJ, Maccari F. Protection by acyl-carnitines and phenylmethylsulfonylfluoride of rat heart subjected to ischemia and reperfusion. Biochim Biophys Acta (1985)847:62-66.

14. Hülsmann WC, Dubelaar M-L. Early damage of vascular endothelium during cardiac ischumia. Cardiovasc Res (1987)21:674-677.

15. Hülsmann WC, Dubelaar M-L. Aspects of fatty acid metabolism in vascular endothelical cells. Biochimie (1988)70:681-686.

16. Hülsmann WC, Dubelaar M-L. Carnitine in metabolism of paced cardiac and skeletal muscles; prevention of acidosis and improvement of vascular flow. In: L-carnitine and its role in medicine, from function to therapy. R. Ferrari, S. DiMauro, G. Sherwood, eds. Academic press Itd.(1992) pp 345 358.

17. Hülsmann WC, Schneydenberg C, Verkleij AJ. Accumulation and excretion of long-chain acylcarnitines by rat heart, studies with aminocarnitine. Biochim Biophys Acta (1991)1097:263-269.

18. Idell-Wenger JA, Grotyohann LW. Neely JR. Coenzyme A and carnitine distribution in normal and ischemic hearts. J Biol Chem (1978)253:4310-4318.

19. Lefer AM, Tsao PS, Lefer DJ, Ma XL. Role of endothelial dysfunction in the pathogenesis of reperfusion injury after myocardial ischemia. FASEB J (1991)5:2029-2034.

20. Liedtke AJ, DeMaison L. Nellis SH. Effect of L-propionylcarnitine on mechanical recovery during reflow in intact hearts. Am J Physiol (1988)255:H169-H176.

21. Maxwell L, Gavin JB. The contribution of ischaemia to the development of microvascular incompetence in the myocardium. Cardiovasc Res (1991)25:491-495.

22. Mertens S, Noll T, Spahr R, Krützfeldt A, Piper HM. Energetic response of coronary endothelial cells to hypoxia. Am J Physiol (1990)258:H689-H694.

23. Mügge A, Elwell JH, Peterson TE, Harrison DG. Release of intact endothelium derived relaxing factor depends on endothelial superoxide dismutase activity. Am J Physiol (1991)260:C219-C225.

24. Odessey $Y Y$, Chace KV. Utilization of endogenous lipid, glycogen, and protein by rabbit aorta. Am $J$ Physiol (1982)243:H128-H132. 
25. Paulson DJ, Traxler J, Schmidt M, Nooman J, Shug AL. Protection of the ischemic myocardium by Lpropionylcarnitine: effects on the recovery of cardiac output after ischemia and reperfusion, carnitine transport and fatty acid oxidation. Cardiovasc Res (1986)20:536-541.

26. Pearson DJ, Chase JFA, Tubbs PK. The assay of carnitine and its O-acylderivatives in: S.P.Colowick \& N.O.Kaplan, eds. Methods of Enzymol (1969)14:612-622, Academic Press Inc.

27. Sacks T, Moldow CF, Craddock PR, Bowers TK. Oxygen radicals mediate endothelial cell damage by complement-stimulated granulocytes. An in vitro model of immune vascular damage. $J$ Clin Invest (1978)61:1161-1167.

28. Sassen LMA, Bezstarosti K, Koning MMG, Van Der Giessen WJ, Lamers JMJ. Effects of administration of L-propionylcarnitine during ischemia on the recovery of myocardial function in the anaesthetized pig. Cardioscience (1990)1:155-161.

29. Scholte HR, Luyt-Houwen IEM, Dubelaar M-L, Hülsmann WC. The source of malonyl-CoA in rat heart. The calcium paradox releases acetyl-CoA carboxylase and not propionyl-CoA carboxylase. FEBS lett (1986)198:47-50.

30. Siliprandi N, DiLisa F, Pieralsi G, Ripari P, Maccari F, Menabo R, Giamberardino MA, Vecchiet L. Metabolic changes induced by maximal exercise in human subjects following L-carnitine administration. Biochim Biophys Acta (1990)1034:17-21.

31. Spagnoli LG, Corsi M, Villaschi S, Palmieri G, Maccari F. Myocardial carnitine deficiency in acute myocardial infarction. Lancet (1982)i:1419-1420.

32. Tsao PS, Lefer AM. Time course and mechanism of endothelial dysfunction in isolated ischemic- and hypoxic- perfused rat hearts. Am J Physiol (1990)259:H1660-H1666.

33. Van Hinsberg VWM, Scheffer MA. Effect of L- propionylcarnitine on human endothelial cells. Cardiovasc Res Ther (1991)5:97-106.

34. Wit-Peeters EM, Scholte HR, Van De Akker F, DeNie I. Intramitochondrial localisation of palmitoylCoA-dehydrogenase, $\beta$-hydroxy-acyl-CoA-dehydrogenase and enoyl-CoA-hydratase in guinea pig heart. Biochim Biophys Acta (1971)231:23-31. 


\section{CHAPTER 6}

CHRONIC L-CARNITINE ADMINISTRATION COMBINED WITH MINIMAL ELECTRICAL STIMULATION PROMOTES TRANSFORMATION OF CANINE LATISSIMUS DORSI MUSCLE

Marie-Louise Dubelaar

Jan FC Glatz

Yvonne F De Jong

Willem C Hülsmann

This chapter is submitted to the journal of Applied Physiology. 


\section{ABSTRACT}

In this study dogs received $1 \mathrm{~g}$ of L-carnitine intravenously (three times weekly) for 8 weeks. The left latissimus dorsi muscle was equipped with electrodes and a pacemaker to perform in vivo contraction measurements weekly, while the right latissimus dorsi muscle served as control. We were surprised to find that only in the left latissimus dorsi carnitine administration caused the percentage of type I fibres (measured with an antibody (R11D10) against type l, heavy chain myosin) to increase from $30 \%$ to $55 \%$. Also in the left muscle only, the contraction speed (measured as percentage ripple) decreased from $75 \%$ to $30 \%$, and cytochrome $\underline{\mathrm{c}}$ oxidase activity increased from $113 \pm 11$ to $179 \pm 16 \mu \mathrm{mol} / \mathrm{min} / \mathrm{g}$ wet weight $(n=4$, mean \pm SEM). None of these changes occurred in the right muscle.

Our experiments led to the following conclusions:

Taking biopsies does not influence the fibre typing of the muscle. Without carnitine administration, a weekly measurements session, does not lead to a change in fibre type. Administration of carnitine, combined with a weekly measurements session of this muscle, consisting of several stimulation patterns lasting, in total, approximately 1 hour, leads to a significant shift in muscle fibre type composition towards a muscle with an increased content of type I fibres. 


\section{INTRODUCTION}

In previous studies our group has shown that continuous electrical stimulation induces an adaptation of canine latissimus dorsi muscle from a mainly white, fast muscle (70\% type II fibres, $30 \%$ type I fibres) to a muscle consisting of almost 100 $\%$ type I fibres $(6,12)$. The ability of the latissimus dorsi muscle to transform to a muscle composed of almost $100 \%$ type I fibres is important for its application to support a failing heart, i.e. dynamic cardiomyoplasty $(2,3,13,14)$. Adaptations of the latissimus dorsi muscle were seen on histological and biochemical levels, whereas the complete transformation was found to require approximately 12 weeks of training $(6,12)$. It is of clinical interest to minimize this adaptation time, since during the first period after such an operation the expected support of the muscle to the failing heart cannot be optimal, due to fatigue that occurs in the untrained, non-transformed muscle. Conditioning of the muscle, prior to cardiomyoplasty has also been suggested, but this has some obvious practical disadvantages. To obtain maximal benefit for the cardiomyoplasty procedure (2) it is our aim to shorten the time required for muscle transformation, quickly allowing an optimal stimulation to support the failing heart.

Previous experiments with L-carnitine showed that administration of this cofactor for fatty acid oxidation to dogs resulted in an acute increase of latissimus dorsi force (4), most likely due to an increase in blood flow (5). Spagnoli et al. (15) recently described an increase in type I fibres in deltoid muscle of patients undergoing regular haemodialysis, when this dialysis was accompanied by a intravenous dose of 2 $\mathrm{g}$ of L-carnitine after each dialysis session (three times weekly). This increase was based mainly on hypertrophy and predominance of type I fibres (15).

These acute $(4,5)$ and chronic (15) effects of L-carnitine led us to perform a study with four dogs which were treated chronically with high doses of L-carnitine. The aim of the present study was to investigate the effect of chronic L-carnitine administration on mechanical, biochemical and immunochemical parameters. To our surprise a difference between the latissimi dorsi occurred.

\section{MATERIAL AND METHODS}

\section{Experimental design}

The experiment was divided in two periods, one prior to carnitine administration, the control period. Then in the second period chronic L-carnitine administration was started. Throughout both periods biopsies for biochemical and immunochemical evaluation were taken from both muscles at $-8,0,4$ and 8 weeks. The left latissimus dorsi was chosen to be used for contraction measurements, for which electrodes and 
a pacemaker had to be implanted so as to allow stimulation of this muscle. Contraction measurements were performed weekly.

\section{Animals and mechanical measurements}

Four adult, male mongrel dogs, ranging in weight from $25-35 \mathrm{~kg}$, were used. Two weeks prior to the first measurements, two electrodes were implanted. Under general anaesthesia an incision of approximately $8 \mathrm{~cm}$ was made behind the dogs left scapula. The firs electrode (negative) was sewn into the proximal part of the left latissimus dorsi muscle near the main branches of the nervus thoracodorsalis, a second electrode (positive) was sewn into the muscle $6 \mathrm{~cm}$ more distally. Any unnecessary tissue damage was avoided. The electrodes were connected to an ITREL ${ }^{T M}$ myostimulator (Medtronic SP7420).

Two weeks were allowed for wound healing, before commencing force measurements. Force measurements were performed under general anaesthesia after positioning of the dog on its right side on the operating table. Subsequently the left forefoot was connected with straps to a force transducer (Grass FT 10, Grass Instruments, Quincy, Mass. USA) in a position in line with the paw and the latissimus dorsi, so as to allow measurement of the isolated force of the latissimus dorsi. The optimal positioning of the paw was tested by administering twitch contractions at varying length of the latissimus dorsi muscle. The length which yielded maximal force was used for further testing. To restrict compensatory movements of the dog during contraction of the left LD muscle, the dog was fixed during the measurement session against two vertical bars, one in front of the thorax, the other at the back of the animal against the scapulae. With this test protocol the contractions of the muscle can be considered isometric. All force measurements were recorded at a speed of $25 \mathrm{~mm} / \mathrm{sec}$ on a multichannel Schwarzer recorder, with a frequency response of $300 \mathrm{~Hz}$, measured for $3 \mathrm{~dB}$ points.

Every week a standard protocol of measurements was performed to assess muscle function. Ripple measurements (i.e. ratio between interpulse amplitude and burst amplitude) were performed to assess contraction speed (12). Ripples were measured by programming the pacemaker with the following parameters: time on 1 $\mathrm{sec}$, time off $10 \mathrm{sec}$. The frequency of the burst was $10 \mathrm{~Hz}$, and was tested for 3 subsequent contractions. The total contraction measurement session lasted about 1 hour.

Six weeks after starting the contraction measurements, the administration of Lcarnitine was started, while the weekly measurements continued. The dogs received $1 \mathrm{~g}$ of L-carnitine (Carnitene ${ }^{T M}$, Sigma Tau, Rome, Italy) intravenously three times weekly, for 8 weeks. 


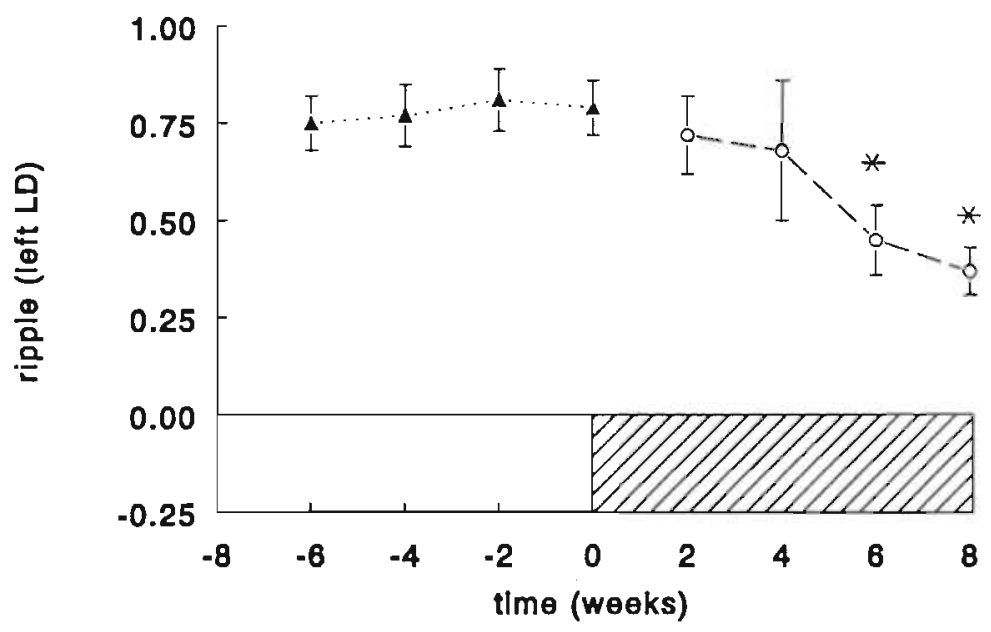

Figure 6.1. Ripple measurements in the left latissimus dorsi. Presented is the ripple value before and due to carnitine treatment (striped area). Values are mean $\pm \operatorname{sem}(n=4)$. * depicts values significantly different from pre carnitine values.

\section{Biopsies and measurements}

At the time of pacemaker implantation, before starting the carnitine injections and after 4 and 8 weeks of carnitine administration, biopsy specimen were taken from the midportions of both the left and right latissimus dorsi muscle, exactly as described before (6).

The techniques used for assay of the palmitate oxidation capacity, pyruvate dehydrogenase complex activity, citrate synthase and fructose-6-phosphate kinase (FPK) were exactly as described before (6). Cytochrome $c$ oxidase activity was determined by the method of Gohill (8). The determination of muscle total L-carnitine was also described before (7). The values of total carnitine in dog soleus and gastronemius muscles and in heart were determined in samples taken from dogs not participating in this protocol.

The procedure for immunohistochemical fibre typing, using an antibody (R11D10) against heavy chain myosin, which occurs in type I fibres, has been described in detail elsewhere (12).

\section{Statistics}

Values are given as mean \pm SEM. The data were evaluated for statistical significance using ANOVA, when appropriate a (paired) t-test was used as indicated. $P$ values smaller than or equal to 0.05 were considered to be statistically significant. 


\section{RESULTS}

The dogs maintained a good condition during the entire experimental period, showed no loss or gain of weight. Their behaviour was not changed and gait or other movements were unaffected. They did not show signs of discomfort due to either the implanted pacemaker, the repeated mechanical measurements or the biopsies.

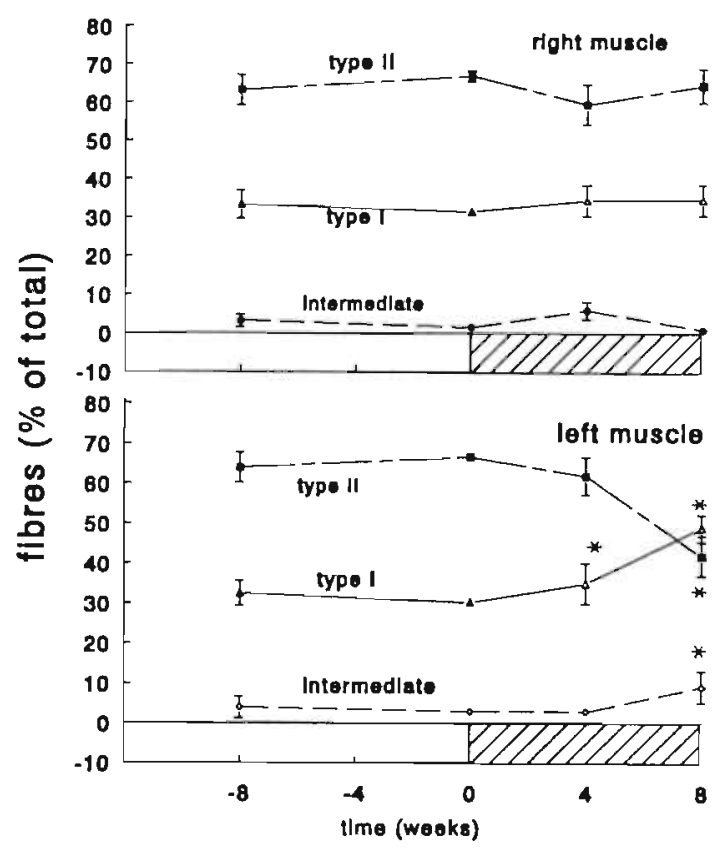

Figure 6.2. Immunochemical evaluation before and during carnitine treatment (dotted area) of the right (top) and left (bottom) latissimus dorsi muscle biopsies using a monoclonal antibody (R11D10) against myosin-heavy chain. The figure represents the percentual area occupied by either type I, intermediate or type II fibres. Values are mean $\pm \operatorname{sem}(n=4)$. * depicts values significantly different from pre-carnitine values.

\section{Mechanical measurements}

The ripple is a mechanical measure to illustrate the contraction pattern of a muscle at a given electrical stimulation with a known burst frequency. The ripple can be calculated from a contraction record by dividing the height of the individual peaks by the total height of the pulse. When expressed as a percentage ripple this value is multiplied with 100 . In the insert of Figure 6.1 representative records of ripple measurements made at the beginning ( -8 weeks) and at the end ( 8 weeks of carnitine treatment) of the experimental protocol are shown. Figure 6.1 further illustrates the measurements performed with the left latissimus dorsi (with a pacemaker). 

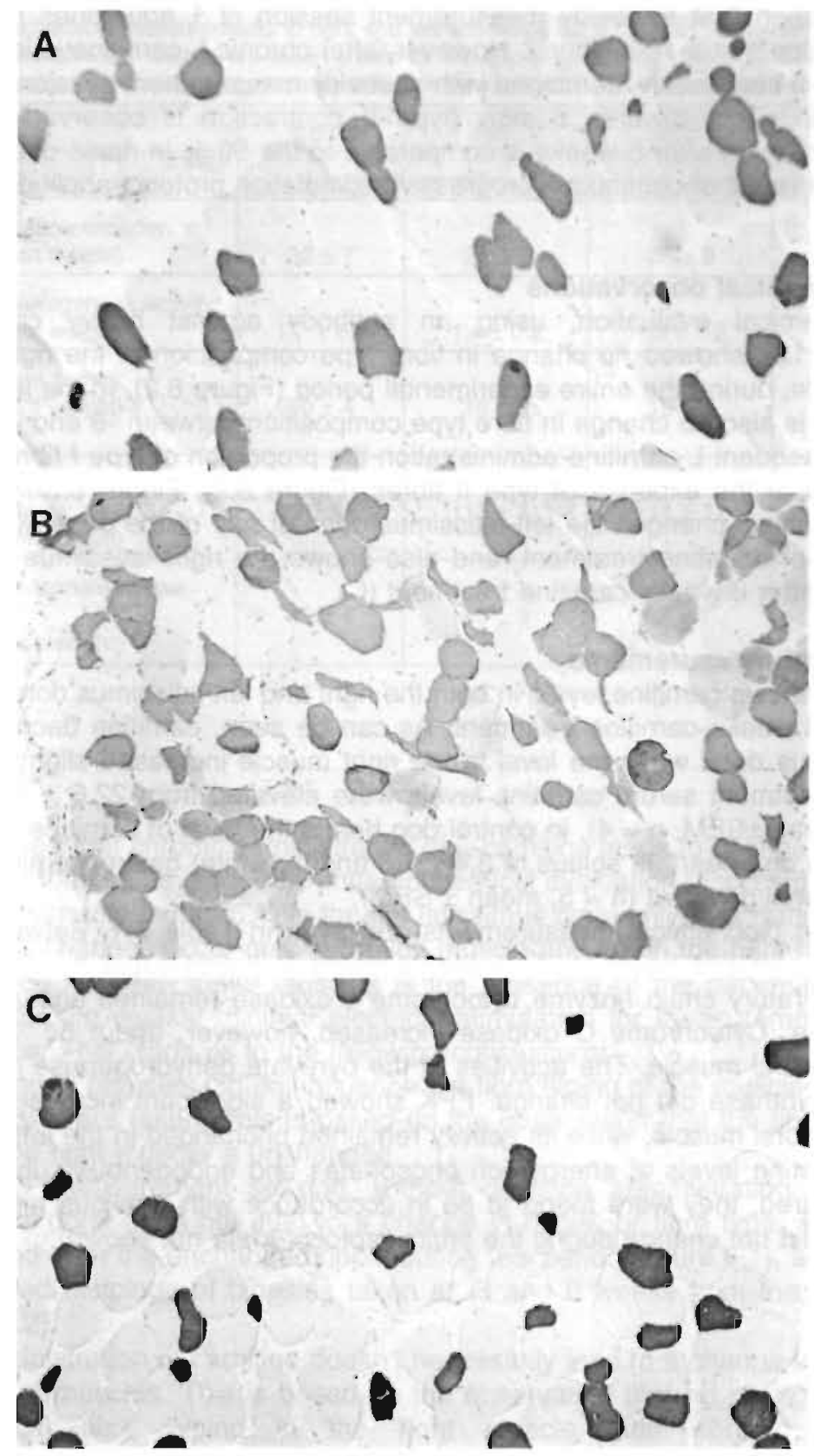

Figure 6.3. Representative pattern of R11D10 staining of left muscle before (A) and after (B) 8 weeks of carnitine administration, and of right latissimus dorsi muscle after (C) 8 weeks of carnitine administration. 
It can be seen that a weekly measurement session of 1 hour does not induce a change in ripple at a $10 \mathrm{~Hz}$ burst. However, after chronic L-carnitine is injected intravenously 3 times weekly, combined with a weekly measurement session of 1 hour, a decrease in ripple towards a slow (type l) contraction is observed. The $50 \%$ decrease in ripple after 8 weeks is comparable to the $50 \%$ in ripple decrease found earlier as a result of continuous progressive stimulation protocol applied for 4 weeks (12).

\section{Immunochemical observations}

Immunochemical evaluation, using an antibody against heavy chain myosin (R11D10) (12), showed no change in fibre type composition in the right latissimus dorsi muscle, during the entire experimental period (Figure 6.2). In the left latissimus dorsi there is also no change in fibre type composition between -8 and 0 weeks, but during subsequent L-carnitine administration the proportion of type I fibres increases significantly at the expense of type II fibres (Figure 6.2). Figure 6.3 illustrates the immunochemical changes the left latissimus dorsi of one of the dogs at $0(A)$ and 8 (B) weeks of carnitine treatment, and also shows the right latissimus dorsi of the same dog after 8 weeks carnitine treatment (C).

\section{Biochemical measurements}

Figure 6.4 shows carnitine levels in both the right and left latissimus dorsi muscles at 0,4 , and 8 weeks carnitine treatment. As can be seen, carnitine decreased in the left latissimus dorsi while the level in the right muscle increased slightly. During Lcarnitine treatment serum carnitine levels were elevated from $22.6 \pm 1.4$ to $37.5 \pm$ $1.1 \mu \mathrm{M}$ (mean $\pm \mathrm{SEM}, \mathrm{n}=4$ ). In control dog hearts the level of carnitine amounted to $1.7 \pm 0.2$ in dog heart, in soleus to $3.4 \pm 1.6$ and in (white) gastrocnemius muscle to $3.7 \pm 1.8 \mu \mathrm{mol} / \mathrm{g}$ wet $w t(n=5$, mean \pm SEM).

Data on biochemical measurements are given in Table 6.1. Between 4 and 8 weeks of L-carnitine treatment both the palmitate oxidation capacity and the activity of the respiratory chain enzyme cytochrome c oxidase remained unchanged in the right muscle. Cytochrome C oxidase increased, however, about $50 \%$ in the left latissimus dorsi muscle. The activities of the pyruvate dehydrogenase complex and of citrate synthase did not change. FPK showed a significant increase in the right latissimus dorsi muscle, while its activity remained unchanged in the left muscle.

The resting levels of energy-rich phosphates and endogenous substrates were also measured, they were found to be in accordance with previous measurements $(6,7)$, and did not change during the entire protocol (data not shown). 
Table 6.1. Biochemical measurements in right and left latissimus dorsi muscles after 4 and 8 weeks of L-carnitine administration. Values are mean \pm sem for 4 dogs. * significantly different value from that of the right muscle at 4 weeks. \# significantly different from value of the left muscie at 4 weeks.

\begin{tabular}{|c|c|c|c|c|}
\hline muscle: & right & left & right & left \\
\hline$+2=1$ & \multicolumn{2}{|c|}{4 woeks L-carnitine } & \multicolumn{2}{|c|}{8 weeks L-carnitine } \\
\hline $\begin{array}{l}\text { Palmitate oxidation capacity. } \\
\text { (nmol/min } / \mathrm{g} \text { wet weight) }\end{array}$ & $32 \pm 7$ & $29 \pm 7$ & $35 \pm 9$ & $44 \pm 4$ \\
\hline $\begin{array}{l}\text { Pyruvate dehydrogenase activity } \\
\text { ( } \mu \mathrm{mol} / \mathrm{min} / \mathrm{g} \text { wet weight) }\end{array}$ & $1.7 \pm 0.1$ & $1.4 \pm 0.2$ & $1.3 \pm 0.2$ & $1.5 \pm 0.2$ \\
\hline $\begin{array}{l}\text { Citrate synthase activity } \\
\text { ( } \mu \mathrm{mol} / \mathrm{min} / \mathrm{g} \text { wet weight })\end{array}$ & $20 \pm 4$ & $19 \pm 2$ & $18 \pm 1$ & $18 \pm 2$ \\
\hline $\begin{array}{l}\text { Cytochrome } c \\
\text { oxidase activity } \\
\text { ( } \mu \mathrm{mol} / \mathrm{min} / \mathrm{g} \text { wet weight) }\end{array}$ & $89 \pm 14$ & $113 \pm 11$ & $114 \pm 11$ & $179 \pm 16^{*}$ \\
\hline $\begin{array}{l}\text { Fructose-6- phosphate kinase } \\
\text { activity } \\
\text { ( } \mu \mathrm{mol} / \mathrm{min} / \mathrm{g} \text { wet weight) }\end{array}$ & $40 \pm 4$ & $45 \pm 3$ & $67 \pm 1^{\circ}$ & $44 \pm 2$ \\
\hline
\end{tabular}

\section{DISCUSSION}

It was observed that chronic administration of L-carnitine leads to changes in muscle fibre type distribution, as judged by immunochemical evaluation (figures $6.2,6.3$ ) and ripple measurements (figure 6.1 ) in the left latissimus dorsi only. It is rather astonishing that these changes occur only in the left muscle and not in the right muscle. The only difference between these muscles is the presence of the pacemaker and its electrodes, for the weekly minimal electrical stimulation for measurement of ripple characteristics. This leads us to the following conclusions:

1. The taking of biopsies did not influence the fibre typing of the muscle from which the biopsies are taken. This is based on the observation that the fibre composition of the right muscle is unchanged.

2. A weekly measurement session, without carnitine administration, in the left latissimus dorsi does not lead to a change in ripple, or fibre type. This can be concluded from the unchanged ripple during this period (figure 6.1), and from the unchanged histology of biopsies taken at -8 and 0 weeks from the left muscle (figure 6.2).

3. The administration of carnitine doesn't necessarily lead to a change in fibre composition of muscles. This is based on the observation that no changes occur in histological fibre typing in the right muscle after chronic L-carnitine administration.

4. Administration of carnitine, combined with minimal stimulation of this muscle leads to a significant shift in muscle fibre type composition towards a muscle composed of more type I fibres, than the original muscle. 
The significant increase in cytochrome $\mathrm{C}$ oxidase activity in the left muscle suggests an increased amount of mitochondria/g wet wt. The reason for the fact that phosphofructokinase showed a significant increase in the right muscle is not known. It suggests maintenance of anaerobic metabolic capacity in the left muscle.

The observation (figure 6.4) that in dogs the white (non-oxidative) muscles show a higher carnitine level than the red muscles which produce energy mainly from fatty acid oxidation, leads us to hypothesize that white muscle serves as a store of carnitine and only a small part is actually involved in fatty acid oxidation.

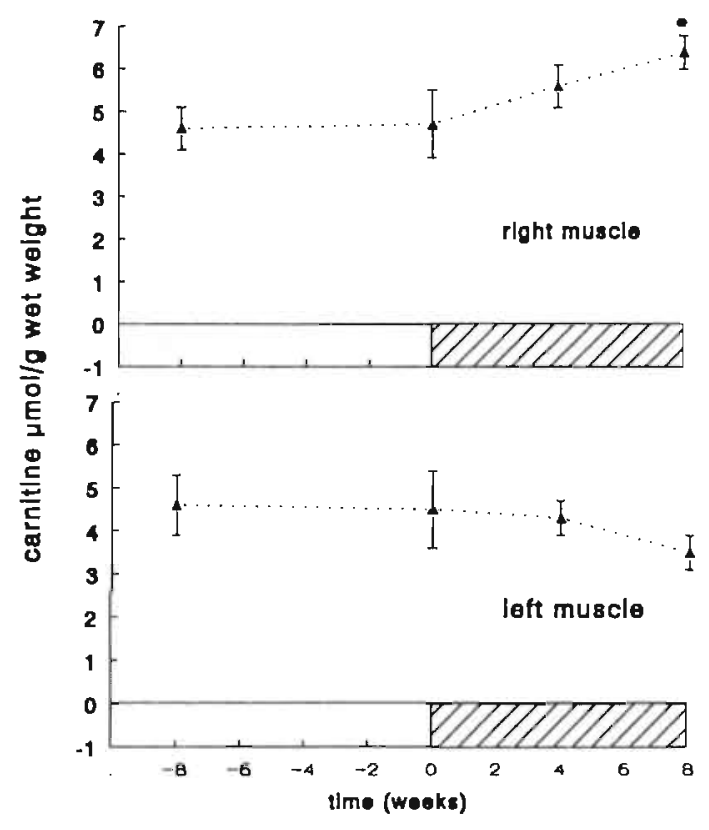

Figure 6.4. Carnitine concentration in right (top) and left (bottom) latissimus dorsi muscle, before and during carnitine treatment (dotted area). ${ }^{*}$ depicts value significantly different from control value.

Blood vessels require carnitine (9). Endothelial cells might require fatty acid oxidation not only for flow regulation (9), but also as initiators of neovascularization. It has been shown that vascular endothelial cells prefer (carnitine dependent) fatty acid oxidation for the generation of ATP (11). An adequate supply of carnitine to these cells, which are extremely vulnerable to oxidative stress (10), may be essential for maintenance of vascular flow regulation during bursts of high intensity exercise, or electrical stimulation.

In conclusion it appears that L-carnitine combined with minimal electrical stimulation induces muscle changes that are beneficial for the adaptation of latissimus dorsi for cardiomyoplasty. Moreover, the conservation of anaerobic capacity combined with increased oxidative metabolic capacity is superior to the adaptations found due to 
chronic electrical stimulation. Although the suitability of canine muscle as a model for human muscle is uncertain, the beneficial effect of L-carnitine on the latissimus dorsi muscle in dogs will stimulate further research into the use of carnitine (combined with minimal stimulation) in the preoperative period for patients waiting for a cardiomyoplasty operation.

\section{ACKNOWLEDGEMENTS}

The authors wish to thank the Netherlands Heart Foundation and Sigma-Tau, Rome (Italy), for financial support. Professor GJ Van Der Vusse and CMHB Lucas, are thanked for interest and advice and J Habets, T Van Der Nagel, R Kruger and E Kloosterman for technical assistance. 


\section{REFERENCES}

1 Bridges CR jr, Clarck III BJ, Hammond RL, Stephenson LW. Skeletal muscle bioenergetics during frequency-dependent fatigue. Am J Physiol (1991)260:C643-C651.

2. Chachques JC, Grandjean PA, Schwartz K, Mihaileanu S, Fardeau F. Swyngedauw B, Fontaliran F, Romero N, Wisnewsky C, Perrier P, Chavaud S, Bourgeois I, Carpentier A. Effect of latissimus dorsi dynamic cardiomyoplasty on ventricular function. Circulation (1988)78(suppl.III):180-190.

3. Cummings DVE, Pattison CW, YacoubMH. Autologous skeletal muscle and cardiac assistance. In: Yacoub M, ed. Annual of cardiac surgery. London: Current Science (1989)pp 75-82.

4. Dubelaar M-L, Lucas CMHB, Hülsmann WC. Acute effect of L-carnitine upon skeletal muscle force tests in the dog. Am J Physiol (1991)260:E189-E193.

5. Dubelaar M-L, Lucas CMHB, Hülsmann WC. The effect of L-carnitine on force development of $\mathrm{m}$. latissimus dorsi in dogs. J Cardiac Surgery (1991)6(suppl 1):270-275.

6. Glatz JFC, Van Der Vusse GJ, Havenith MG, Van Der Veen FH, Lucas CMHB, Penn OCKM, Wellens HJJ. Adaptation of energy metabolism of canine latissimus dorsi muscle in response to chronic electrical stimulation. Plügers Arch (Eur J Physiol) (1922)420:1-8.

7. Glatz JFC, de Jong YF, Coumans WA, Lucas CM, van der Veen FH, van der Vusse GJ. Differences in metabolic response of dog and goat latissimus dorsi muscle to chronic electrical stimulation. accepted for publication J Appl Physiol 1992.

8. Gohil $\mathrm{K}$, Jones DA, Edwards RHT. Analysis of muscle mitochondrial function with techniques applicable to needle biopsy samples. Clin Physiol (1981)1:195-207.

9. Hülsmann WC, Dubelaar M-L. Carnitine requirement of vascular endothelial and smooth muscle cells in imminent ischemia. accepted for publication. Mol Cell Biochem 1992.

10. Hülsmann WC, Dubelaar M-L. Early damage of vascular endothelium during cardiac ischemia. Cardiovasc Res (1987)21:674-677.

11. Hülsmann WC, Dubelaar M-L. Aspects of fatty acid metabolism in vascular endothelial cells. Biochimie (1988)70:681-686.

12. Lucas $C M$, Havenith $M G$, van der Veen FH, Habets $J$, van der Nagel T, Schrijvers-van Schendel JM, Penn OC, Wellens HJJ. Changes in canine latissimus dorsi muscle during 24 weeks of continuous electrical stimulation. Accepted for publication J Appl Physiol 1992.

13. Mayne CN, Anderson WA, Hammond RL, Eisenberg BR, Stephenson LW, Salmons S. Correlates of fatigue resistance in canine skeletal muscle stimulated electrically for up to one year. Am J Physiol (1991)261:C259-C270.

14. Mannion JD, Bitto T, Hammond RL. Histochemical and fatigue characteristics of conditioned canine latissimus dorsi muscle. Circ Res (1986)58:298.

15. Spagnoli LG, Palmieri G, Mauriello A, Vacha GM, D'lddio S, Giorcelli G, Corsi M. Morphometric evidence of the trophic effect of f-carnitine on human skeletal muscle. Nephron (1990)55:16-23. 


\section{CHAPTER 7}

\section{ON THE MECHANISM OF FAT ACCUMULATION IN WRAPPED LATISSIMUS DORSI MUSCLE (CARDIOMYOPLASTY), AND THE EFFECT OF CHRONIC L-CARNITINE ADMINISTRATION}

Marie - Louise Dubelaar

Carolien MHB Lucas

Willem C Hülsmann

This chapter was published in Basic and Applied Myology (1991)1:305-310. 


\section{ABSTRACT}

It has been shown that skeletal muscle has a great ability to adapt to several circumstances. For instance transformation of muscle fibre typing due to electrical stimulation.

It is the aim of the present study to investigate the adaptations that occur in fat metabolism of the goat latissimus dorsi muscle, after it has been used for a so-called cardiomyoplasty $(2,3)$.

It is found that cardiomyoplasty causes complete transformation of the mixed type latissimus dorsi muscle (30\% type I and $70 \%$ type II fibres) towards a muscle composed of solely type I fibres. A complication that occurs in these 'wrapped' muscles is an increase of fat in the muscle tissue from less than $1 \%$ to $23 \%$. Chronic intravenous administration of $1 \mathrm{~g}$ of L-carnitine three times weekly during the postoperative (training) period diminishes this fat accumulation to only $7 \%$. 
INTRODUCTION

\section{Cardiomyoplasty}

Earlier experiments from our group showed adaptation of the latissimus dorsi muscle to continuous electrical stimulation of this muscle $(7,14)$. For the cardiomyoplasty procedure (3) the patients latissimus dorsi muscle is mobilized from its surrounding tissue, leaving its origo near the scapula intact, thus leaving vascular and nerve structures intact. Subsequently the muscle is transposed into the thorax, wrapped around the heart and electrically stimulated by means of a pacemaker, to augment the function of the failing heart. We showed that also under these circumstances ('wrapped' latissimus dorsi muscle) adaptation of the muscle occurred. The adaptations were seen on histological and biochemical levels. One of the effects of the wrapping procedure appeared to be an increase in fat in the wrapped muscle. Another observation was the decrease in muscle carnitine levels $(7,8)$. This led us to the hypothesis that the increased fat content in 'wrapped' latissimus dorsi muscles is due to a discrepancy between fatty acid supply and oxidation.

\section{Lipoprotein lipase}

Lipoprotein lipase (LPL) is synthesized in red muscle cells (and adipocytes), subsequently externalized and bound to the endothelium of the capillaries (19). This enzyme does not occur in white muscle fibres, therefore it may be expected that, if stimulation of the mixed latissimus dorsi muscle $(3,14)$ leads to an increase of red muscle fibres, this will be accompanied by an increase of lipoprotein lipase activity. A consequence of an increased lipoprotein lipase activity is a higher availability of fatty acids, derived from the circulating triglyceride rich lipoproteins (VLDL and chylomicrons) to the muscle cell. This could lead to lipid accumulation in the cells, when the endogenous rate of fatty acid utilization does not increase to a similar extent, for instance due to insufficient oxygen supply (22). This might occur if the oxygen supply to the muscle cells of the transposed latissimus dorsi muscle is endangered either due to damage of the circulation during preparation or wrapping of the muscle or due to impairment of flow regulation by endothelial cells during stimulation of the untrained muscle.

Earlier experiments with carnitine $(4,5,12)$ led us to conclude that the most probable locus of action of the beneficial effect of carnitine administration during imminent ischemia (12) and latissimus dorsi stimulation $(4,5)$ is not in muscle cells per se, but in the vascular compartment. This effect is probably based on the effect of carnitine on endothelial metabolism, and thus on flow-regulatory properties of 
endothelium during imminent ischemia or acidosis. This led us to study changes of carnitine levels and lipoprotein lipase activity in wrapped latissimus dorsi muscles, in relation to muscle lipid content. We also studied the effect of chronic intravenous carnitine administration on this process.

\section{MATERIAL AND METHODS}

\section{Animals and operations}

Eight female domestic goats were used. Their body weight ranged from 35 to $65 \mathrm{~kg}$. All experiments were carried out in accordance with the 'Guide for Care and Use of Laboratory Animals.' (16).

Anaesthesia and ventilation were exactly as described before (14).

The preparation of the latissimus dorsi muscle and the procedure of wrapping the muscle around the heart were performed according to the method of Chachques et al (2), using a SP1005 pacemaker (Medtronic Inc, Minneapolis, MN USA). The whole procedure was performed under strict aseptic circumstances. Antibiotic coverage was obtained by a pre-operative intravenous injection of Amfipen@ $1000 \mathrm{mg}$ followed by a postoperative intramuscular injection of Amfipen@1000 mg.Postoperative analgesia was given by means of intramuscular injections of Temgesic ${ }^{@}$ (buprenorfine $0.6 \mathrm{mg}$ ) twice a day for 4 days.

The animals were kept under close observation in an inside stable for 2 weeks, then they were moved to a stable with meadow for 14 weeks.

At the moment of operation the animals were randomly assigned to either the control group or the carnitine treatment group (each $n=4$ ). The control group received no further treatment, while the carnitine treatment group received intravenous injections of $25 \mathrm{mg} / \mathrm{kg} \mathrm{L}$-carnitine (carnitene ${ }^{T M}$, Sigma Tau, Rome, Italy) 3 times weekly.

After 2 weeks, for wound healing, stimulation of the wrapped muscle was started with a standard training protocol, as currently used for human cardiomyoplasty patients (2). After 8 weeks the synchronisation rate to the heart frequency was 1:1, with 6 pulses in a burst, the maximum contraction rate was fixed at 100 contractions per minute.

\section{Biopsies}

16 weeks after the operation the goats were evaluated (under general anaesthesia (14) for cardiac function and latissimus dorsi assist of the heart, before and after inducing acute heart failure. The results of these hemodynamic experiments will be published elsewhere. At the end of these experiments biopsies were taken from both the right (control) and left (wrapped) latissimus dorsi muscle. One biopsy (approximately $2 \times 100 \mathrm{mg}$.) was frozen in liquid $\mathrm{N}_{2}$ and stored at $-80^{\circ} \mathrm{C}$, until determination of enzymes and carnitine. The second biopsy, used for histologic measurements was positioned for cross sectioning in tissue-tek and subsequently frozen in isopentane cooled in dry ice. 


\section{Biochemical measurements}

Lipoprotein lipase (LPL) was measured in homogenate after crushing the frozen biopsy in a mortar in liquid $\mathrm{N}_{2}$, the frozen powder was transferred to a tube (at $4^{\circ} \mathrm{C}$ ) with a buffer consisting of TRIS and ethyleneglycol $(0.05,1 \mathrm{~mol} / \mathrm{l}$, respectively) at $\mathrm{pH}$ 8.2 to which $5 \mathrm{U} / /$ heparin (Thromboliquine ${ }^{@}$, Organon, Oss, The Netherlands) was added. The contents were homogenized with a Polytron homogenizer for $30 \mathrm{sec}-$ onds. This homogenate was then used undiluted for determination of LPL activity by the method of Nilsson-Ehle and Schotz (18), exactly as described before (19), using $\left[9,10(n)^{3} \mathrm{H}\right]$ Oleic-acid labelled trioleate (Amersham International PLC, Amersham, U.K.) as a substrate.

\section{Histology}

Using an antibody against myosin heavy chain, R11D10 (14), combined with an alkaline phosphatase staining to identify capillaries, the distribution of fibre types, fat droplets and of fat cells (not staining for myosin), was determined as described before (14). The fibre type and fat cell distribution was measured in 7 control goats. The area of type I, type II fibres and fat is expressed as percent of the total area, these values were measured, with a computerized system, in at least 300 fibres, exactly as described before (14).

\section{Statistics}

Values are given as mean \pm SD. The data are evaluated for statistical significance differences using the unpaired two-tailed student t-test, for differences between control and carnitine groups and a paired student $t$ test for differences between control and wrapped muscles in each group. $\underline{P}$ values smaller than or equal to 0.05 were considered to be statistically significant.

\section{RESULTS}

\section{Histology}

The fibre type composition of the right (control) and left (wrapped) latissimus dorsi muscles can be seen from table 7.1. It can also be seen from table 7.1 that the percentual area of the latissimus dorsi, occupied by fat increased from less than $1 \%$ of fat in control latissimus dorsi, to $23 \%$ fat in wrapped latissimus dorsi. Table 7.1 also illustrates that chronic administration of $\mathrm{L}$-carnitine diminished the lipid percentage of the wrapped latissimus dorsi to $7 \%$. The number of capillaries expressed as a ratio over the total number of type I + type II tibres remained unchanged after wrapping, however, when the ratio is expressed over the total number of type I, type II and fatty tissue, there is a significant decrease of capillaries, due to the wrapping procedure (table 7.1). Chronic carnitine treatment prevents this decrease (table 7.1). When the ratio of capillaries over only type I + type II fibres is used, there is even a significant increase in capillaries, as is to be expected in trained muscle. 
Table 7.1. Effect of wrapping and or carnitine on fibre type composition, amount of fatcells, capillary over fibre ratio, carnitine and LPL content. Using a monoclonal antibody against myosin heavy chain the amount of fibres and fat is expressed as \% of occupied area per total area, for each sample at least 300 fibres were measured. The fat is defined as area (or cells) that do not show myosin staining. Values are mean $\pm s d$, measured in the right and left (wrapped around the heart) Latissimus dorsi in both control and carnitine treated animals. " significantly different from control or carnitine value. \# significantly different from wrapped value.

\begin{tabular}{|c|c|c|c|c|}
\hline \multirow[b]{2}{*}{ treatment } & \multicolumn{2}{|c|}{$\begin{array}{l}\text { right latissimus dorsi } \\
\text { control muscle }\end{array}$} & \multicolumn{2}{|c|}{$\begin{array}{l}\text { left latissimus dorsi } \\
\text { wrapped muscle }\end{array}$} \\
\hline & control & camltine & contral & cernitine \\
\hline $\begin{array}{c}\text { type I } \\
\% \text { of Earea }\end{array}$ & $\begin{array}{r}26.6 \pm \\
5.8(7)\end{array}$ & $\begin{array}{l}33.5 \pm \\
8.5(4)\end{array}$ & $\begin{array}{l}64.9 \pm \\
18.3(7)\end{array}$ & $\begin{array}{l}90.7 \pm \\
7.1(4)^{*}\end{array}$ \\
\hline $\begin{array}{c}\text { type II } \\
\% \text { of Earea }\end{array}$ & $\begin{array}{l}72.9 \pm \\
6.2(7) \\
\end{array}$ & $\begin{array}{r}66.4 \pm \\
8.5(4)\end{array}$ & $\begin{array}{l}11.5 \pm \\
14.9(7)\end{array}$ & $\begin{array}{c}1.6 \pm \\
3.3(4)\end{array}$ \\
\hline $\begin{array}{c}\text { fat } \\
\% \text { of } \Sigma \text { area }\end{array}$ & $\begin{array}{l}0.11 \pm \\
0.21(7)\end{array}$ & $\begin{array}{l}0.44 \pm \\
0.87(4)\end{array}$ & $\begin{array}{l}23.6 \pm \\
10.9(7)\end{array}$ & $\begin{array}{c}6.9 \pm \\
4.1(4)\end{array}$ \\
\hline $\begin{array}{l}\text { capillaries/ } \\
\text { ¿typel,II }\end{array}$ & $\begin{array}{l}1.19 \pm \\
0.15(4)\end{array}$ & $\begin{array}{l}1.15 \pm \\
0.25(4)\end{array}$ & $\begin{array}{l}1.16 \pm \\
0.05(4)\end{array}$ & $\begin{array}{c}1.39 \pm \\
0.14(4)^{*}\end{array}$ \\
\hline $\begin{array}{l}\text { capillaries/ } \\
\Sigma \text { I,II,fat }\end{array}$ & $\begin{array}{l}1.18 \pm \\
0.15(4)\end{array}$ & $\begin{array}{l}1.15 \pm \\
0.25(4)\end{array}$ & $\begin{array}{l}0.90 \pm \\
0.07(4)\end{array}$ & $\begin{array}{l}1.24 \pm \\
0.24(4)^{\#}\end{array}$ \\
\hline $\begin{array}{c}\text { carnitine } \\
\mu \mathrm{mol} / \mathrm{g} \text { wetweight }\end{array}$ & $\begin{array}{l}8.6 \pm \\
0.6(4)\end{array}$ & $\begin{array}{l}8.7 \pm \\
2.0(4)\end{array}$ & $\begin{array}{l}3.5 \pm \\
0.7(4)\end{array}$ & $\begin{array}{l}3.2 \pm \\
0.9(4)\end{array}$ \\
\hline $\begin{array}{c}\text { LPL } \\
\mathrm{pmol} / \mathrm{mg} \text { protein }\end{array}$ & $\begin{array}{l}68 \pm \\
33(4)\end{array}$ & $\begin{array}{l}62 \pm \\
36(4)\end{array}$ & $\begin{array}{l}320 \pm \\
102(4)\end{array}$ & $\begin{array}{l}396 \pm \\
86(4)\end{array}$ \\
\hline
\end{tabular}

\section{Biochemistry}

From table 7.1 it can be seen that in wrapped goat latissimus dorsi muscles a decrease in carnitine levels occurs. The decrease in carnitine in the wrapped muscle $(-56 \%)$ is more pronounced than that found $(7)$ in the in situ trained muscle $(-30 \%)$. The decrease in total carnitine levels is not prevented by chronic administration of Lcarnitine (table 7.1), despite the doubling of the plasma total carnitine levels from 62 $\pm 5(n=4)$ to $115 \pm 12(n=4) \mu \mathrm{mol} / \mathrm{l}$.

The lipoprotein lipase activity increased five fold in the wrapped muscle. The lipoprotein lipase activity remains unaffected by chronic carnitine treatment.

\section{DISCUSSION}

The observed transformation towards a muscle consisting mainly of type 1 fibres is in accordance with previous observations of our laboratory $(14,7)$. Also the decrease in carnitine has been observed before (7). The effect of carnitine on the amount of fat in the tissue (table 7.1) is important because it illustrates a protective effect against lipidosis. Fat accumulation in muscle has been observed in carnitine deficiency (6) and other conditions of hampered fatty acid oxidation, like hypoxia/ischemia in for instance claudicatio intermittens $(15,21)$. In both examples carnitine admin- 
istration led not only to improvement of muscle function, but also to decrease of lipid accumulation, as is also seen in table 7.1.

Table 7.2. Total carnitine levels measured in different goat (also ref.2) and dog muscles, compared to carnitine levels from the fiterature in human $(1)$, and rat $(13,17)$ muscles.

\begin{tabular}{|c|c|c|c|}
\hline muscle type & heart & red & whlte \\
\hline dog & $\begin{array}{c}1.7 \mu \mathrm{mol} / \mathrm{g} \text { wet } \\
\text { weight }\end{array}$ & $\begin{array}{c}2.4 \mu \mathrm{mol} / \mathrm{g} \text { wet } \\
\text { weight }\end{array}$ & $\begin{array}{c}3.7 \mu \mathrm{mol} / \mathrm{g} \text { wet } \\
\text { weight }\end{array}$ \\
\hline goat & $\begin{array}{c}2.0 \mu \mathrm{mol} / \mathrm{g} \text { wet } \\
\text { weight }\end{array}$ & $\begin{array}{c}4.8 \mu \mathrm{mol} / \mathrm{g} \text { wet } \\
\text { weight }\end{array}$ & $\begin{array}{c}5.3 \mu \mathrm{mol} / \mathrm{g} \text { wet } \\
\text { weight }\end{array}$ \\
\hline $\begin{array}{c}\text { human } \\
\text { (1) }\end{array}$ & $\begin{array}{c}4.5 \mu \mathrm{mol} / \mathrm{g} d r y \\
\text { weight }\end{array}$ & $\begin{array}{c}13.7 \mu \mathrm{mol} / \mathrm{g} d r y \\
\text { weight }\end{array}$ & $\begin{array}{c}17.9 \mu \mathrm{mol} / \mathrm{g} \\
\text { weight }\end{array}$ \\
\hline $\begin{array}{c}\text { rat } \\
(13)\end{array}$ & $0.80 \mu \mathrm{mol} / \mathrm{g}$ wet weight & $\begin{array}{c}0.67 \mu \mathrm{mol} / g \text { wet } \\
\text { weight }\end{array}$ & $\begin{array}{c}0.81 \mu \mathrm{mol} / \mathrm{g} \text { wet } \\
\text { weight }\end{array}$ \\
\hline $\begin{array}{l}\text { rat } \\
(17)\end{array}$ & $\begin{array}{c}1.32 \mu \mathrm{mol} / \mathrm{g} \text { wet } \\
\text { weight }\end{array}$ & $\begin{array}{c}0.65 \mu \mathrm{mol} / \mathrm{g} \text { wot } \\
\text { weight }\end{array}$ & - \\
\hline
\end{tabular}

The observation that chronic administration of high doses of L-carnitine did not lead to prevention of the decreased muscle carnitine levels was rather unexpected, since it is assumed that muscles with a high capacity for beta-oxidation of fatty acids contain a high amount of carnitine. To verify this hypothesis we determined the carnitine content of several muscles in dog and goat (table 7.2). We observed that, generally speaking, the content of carnitine is higher in 'white' than in 'red' muscles or heart. This apparently also applies to human muscle (1 and table 7.3). Only in rat (see also table 7.3) a higher content is seen in heart and red muscles, compared to white muscles $(13,17)$. This leads to the conclusion that the decrease seen in muscle carnitine levels in the present study reflects adaptation rather than damage.

The mechanism by which carnitine prevents lipidosis in the wrapped muscle, as was hypothesized in the introduction, requires further investigation. Presumably the effect is not exerted in the muscle cells, but in an peri or extramyocytal compartment. In acute experiments with carnitine in dogs, we arrived at the same conclusion $(4,5,12)$. Experiments with microspheres revealed (table 3.1 ) that the acute effect of carnitine is reflected by an increase in flow during muscle contraction (5).

It can be seen from table 7.1 that carnitine-treated animals showed a higher capillary over fibre ratio, than untreated animals. This could imply that here also the main effect of carnitine is maintenance of flow regulation, by means of conservation of endothelial metabolism in imminent ischemia (4).

It has been observed that vascular cells are relatively sensitive to ischemia and acidosis, resulting in impaired vascular function, this can be favourably affected by carnitine supply (4). Endothelial cells, that are indispensable for neovascularization (20) probably prefer (carnitine dependent) fatty acid oxidation over glucose utilization for ATP generation (11). Adequate supply of carnitine to these cells, which are also extremely vulnerable to oxidative stress (10) may be essential for maintenance of vascular competence. 
The main effect of carnitine then is the maintenance of optimal tissue oxygenation in the peri and postoperative period, when the danger of ischemia is significant due to damage and stimulation of the untrained muscle resulting in acidosis and thus impairment of vascular flow regulation.

\section{ACKNOWLEDGEMENTS}

The authors wish to thank the Netherlands Heart Foundation and Sigma-Tau, Rome (Italy), for financial support. Professor GJ Van Der Vusse and Dr JFC Glatz are thanked for interest and advice and J Habets, T Van Der Nagel, R Kruger and E Kloosterman for technical assistance. 


\section{REFERENCES}

1. Cederblad $\mathrm{G}$, Lindstedt $\mathrm{S}$, Lundholm $\mathrm{K}$. Concentration of carnitine in human muscle tissue. Clin Chim Acta (1974)53:311-321.

2. Chachques JC, Grandjean P. Schwartz K. Mihaileanu S. Fardeau S, Swyngedauw B, Fontaliran F, Romero N, Wisnewsky C, Perrier P. Chavaud S, Bourgeois I, Carpentier Y: Effect of latissimus dorsi dynamic cardiomyoplasty on ventricular function. Circulation (1988)78(suppl.III):180-190.

3. Chiu RCJ (ed): Biomechanical cardiac assist: cardiomyoplasty and muscle-powered devices. Futura Publishing Comp. New York, (1986).

4. Dubelaar $\mathrm{M}-\mathrm{L}$, Lucas CMHB, Hülsmann WC: Acute effect of 1 -carnitine upon skeletal muscle force tests in the dog. Am J Physiol (1991)260:E189-E193.

5. Dubelaar M-L, Lucas CMHB, Hüsmann WC: The effect of I-carnitine on force development of m.latissimus dorsi in dogs. J Cardiac Surgery (1991)6suppl1:270-275.

6. Engel AG, Angelini C: Carnitine deficiency of human skeletal muscle with associated lipid storage myopathy: a new syndrome. Science (1973)179:899-901.

7. Glatz JFC, Van Der Vusse GJ, Havenith MJ, Van Der Veen FH, Lucas CMHB, Penn OCKM, Wellens HJJ: Adaptation of energy metabolism of canine latissimus dorsi muscle in response to chronic electrical stimulation. Eur J Physiol (1992)420:1-8.

8. Glatz JFC, De Jong YF, Coumans WA, Lucas CM, Van der Veen FH, Van der Vusse GJ: Differences in metabolic response of dog and goat latissimus dorsi muscle to chronic electrical stimulation. J Applied Physiol (1992)420:1-8.

9. Hülsmann WC, Dubelaar M-L. Lipoprotein lipases and stress hormones: studies with glucocorticoids and choleratoxin. Biochim Biophys Acta (1986)875:69-75.

10. Hülsmann WC, Dubelaar M-L. Early damage of vascular endothelium during cardiac ischemia. Cardiovasc Res (1987)21:674-677.

11. Hülsmann WC, Dubelaar M-L. Aspects of fatty acid metabolism in vascular endothelial cells. Biochimie (1988)70:681-686

12. Hülsmann WC. Dubelaar M-L. Carnitine requirement of vascular endothelial and smooth muscle cells in imminent ischemia. Accepted Moll Cell Biochem (1992).

13. Lennon DFL, Mance MJ. Interorgan coöperativity in carnitine metabolism in the trained state. J Appl Physiol (1986)60:1659-1664.

14. Lucas $\mathrm{CM}$, Havenith MG, Van der Veen FH, Habets J, Van der Nagel T, Schrijvers-van Schendel $J M$, Penn OC, Wellens HJ. Changes in canine latissimus dorsi muscle during 24 weeks os continuous electrical stimulation. J Appl Physiol (to be published) (1991).

15. Mäkitie J, Teräväinen H. Histochemical changes in striated muscle in patients with intermittent claudication. Arch Pathol Lab Med (1977)101:658-663.

16. National Academy of Sciences. Guide fore Care and Use of Laboratory Animals. DHHS publication No. NIH 85-23, revised (1985).

17. Negrao CE, Ji LL, Schaver JE, Nagle FJ, Lardy HA. Carnitine supplementation and depletion: tissue carnitine and enzymes in fatty acid oxidation. J Appl Physiol (1987) 63:315-321

18. Nilsson-Ehle P. Schotz MC. A stable radioactive emulsion for assay of lipoprotein lipase. J Lipid Res (1976):17 536-541.

19. Robinson DS. The function of the plasma triglycerides in fatty acid transport. Comp Biochem (1979) 18:51-116.

20. Schaper $W$. Angiogenesis in the adult heart. Basic Res Cardiol (1991)86suppl.2:51-56.

21. Sjostrom M. Ängquist KA, Rais $O$. Intermittent claudication and muscle fibre fine structure: correlation between clinical and morphological data. Ultrastructural Path (1980) 1:309-326.

22. Van Der Vusse GJ, Prinzen FW, Van Bilzen M, Engels W, Reneman RS. Accumulation of lipids and lipid-intermediates in the heart during ischemia. Basic Res Cardiol (1987)82suppi1:157-167. 
CHAPTER 8

\section{GENERAL DISCUSSION}


The studies described in this thesis revolved around the latissimus dorsi muscle, and its potential use for improvement of the function of the failing heart (cardiomyoplasty). For the cardiomyoplasty procedure (3) the patients latissimus dorsi muscle is dissected from its surrounding tissue, leaving its origo, and hence the vascular and nerve structures near the scapula intact. Subsequently the muscle is transposed into the thorax, wrapped around the heart and stimulated electrically by means of a pacemaker, to support the function of the failing heart.

Although it is known that muscle has a high capacity for adaptation (compare 12,13 ), it can be expected that the use of the predominantly white (fast-twitch or type II) latissimus dorsi muscle at the high and continuous rate of heart contractions encounters some specific problems.

The present thesis focusses on the possibility of using carnitine to augment muscular function during the period immediately following the cardiomyoplasty operation, when due to fatigue the latissimus dorsi muscle cannot function at an optimal rate to support the failing heart. It was also investigated as to whether prolonged optimal muscle metabolism, due to chronic L-carnitine administration during training (of either the in situ muscle or the muscle after wrapping it around the heart (cardiomyoplasty)) will improve muscle adaptation. In chapter 6 the results of chronic L-carnitine administration, combined with minimal electrical stimulation of the in situ latissimus dorsi muscle are presented. The effects of carnitine long term administration on wrapped latissimus dorsi muscle is described in chapter 7 .

The thesis of Lucas (14) describes transformation in muscle typing, optimal training protocol, influence on heart performance and other aspects directly related to the cardiomyoplasty.

Effects of carnitine administration on both skeletal muscle (2) and heart performance (6) have been described by a number of authors. Ferrari et al (6) described increased exercise tolerance in angina pectoris patients following L-carnitine treatment. Brevetti et al (2) showed that L-carnitine treatment improved the walking ability of patients suffering from peripheral vascular disease (claudicatio intermittens).

In chapter 2 the acute effect of $L$-carnitine on $\mathrm{m}$. latissimus dorsi force tests has been described. Because of the promptness of stimulation by carnitine (Figure 2.2), combined with the knowledge that carnitine transport across the plasmalemma of muscle cells is slow, an extramyocytal effect of carnitine was proposed. Since choline (Figure 2.3) failed to exert an effect similar to that of L-carnitine, a nonspecific tertiary amine effect on force development can be excluded. D-carnitine 
did not stimulate $\mathrm{m}$. latissimus dorsi force, in contrast it showed a slight inhibitory effect. Since D-carnitine inhibits carnitine palmitoyl transferase activity (16), it is likely that stimulation of oxidative phosphorylation by L-carnitine does occur. Moreover, insulin, which is known to inhibit fatty acid mobilization, abolishes the L-carnitine effect. This observation suggests involvement of a compartment, other than the striated muscle. The observation in previous experiments that vascular cells are relatively vulnerable during ischemia (10) made us to propose that the latter cells are the target for L-carnitine. The lesser effect of carnitine in the trained muscle compared to the untrained muscle is in line with this hypothesis, since the number of capillaries is known to increase by training. During 12 weeks in situ training of the latissimus dorsi muscle, we found a $40 \%$ increase in capillaries (15), which will lead to a better tissue oxygenation. This effect is thought to prevent functional decompensation of the relatively vulnerable vascular cells. The importance of sufficient oxygen supply to muscle cells, especially during acidosis, is illustrated by the fact that Langendorff perfusion of rat harts with fluorocarbons (to maintain optimal tissue oxygenation) prevents the decline in flow that occurs during acidosis (9).

Cholinomimetic effects of carnitine and its derivatives have been described $(1,7)$. The observation that acetyl-carnitine in contrast to propionyl-carnitine had a positive effect on muscle force (figure 3.2) is in line with a cholinergic effect. Tensilon, a choline esterase inhibitor had an effect similar to that of carnitine, while carnitine had no additional effect in the presence of tensilon (figure 3.3). This points to a common mode of action. Since carnitine lacks cholinesterase inhibitory properties itself, the effect could be improved supply of blood $(4,21)$. Indeed it was found (table 3.1 ) that pacing of latissimus dorsi muscle after intravenous L-carnitine administration, resulted in the presence of more microspheres in the muscle (reflecting a better tissue perfusion) than during pacing in the absence of carnitine.

The vulnerability of vascular cells in ischemia was illustrated in Langendorff perfused rat hearts (10). Moreover the observation that fatty acids can cause vasodilation in rat hearts (8) and the fact that infusion of Intralipid, combined with heparin also had a positive effect on force of paced latissimus dorsi muscle (figure 4.2) points to the vascular compartment as target for the administered L-carnitine. Vascular endothelial cells have a carnitine dependent fatty acid oxidation (11), as have vascular smooth muscle cells (table 5.1). It is hypothesized that the vascular endothelial cells, which are relatively vulnerable in ischemia, continuously lose small amounts of carnitine resulting in a carnitine deficient state in these cells. We hypothesize that this results in impaired fatty acid oxidation in these cells, and worsens the cell condition in imminent ischemia. Rat hearts labelled in vivo with ${ }^{14} \mathrm{C}$-Carnitine lose only $4 \%$ of their carnitine in 20 min reperfusion following 60 min global ischemia (table 5.3). The carnitine released had a higher specific activity than the total carnitine pool in the heart. It indicates compartmentation of carnitine in heart, which is in accordance with release of carnitine from the relatively vulnerable endothelial cells.

Vascular fatty acid oxidation might still proceed in imminent ischemia, as vascular mitochondria may still have access to some oxygen, while muscle mitochondria are already fully anaerobic, due to the presence of a oxygen concentration gradient. Perhaps this situation makes the endothelium most suitable for oxygen radical for- 
mation in imminent ischemia. Endothelial cells can be damaged by oxygen radicals (18), and their dysfunction is known to result in their failure to regulate flow $(5,20)$.

Our experience that fatty acids and carnitine are both needed to improve force of the latissimus dorsi (figure 2.4) suggests that fatty acids must be activated to be effective. A high rate of ATP generation from oxidative phosphorylation limits glycolysis and prevents lactic acidosis. High ATP levels, and thus low cytoplasmic AMP will limit the extracellular generation of substrates for xanthine oxidase and thus formation of free radicals. The fact that part of the damage is due to extracellular (oxygen) radicals is illustrated by the improvement of the function of the low-flow ischemic heart when superoxide dismutase is included in the perfusion medium (10). Moreover, a higher redoxstate of the endothelial cell results in increased NADPH level, enabling (re)generation of reduced gluthation and NO.

The significant increase in cytochrome $\underline{c}$ oxidase activity in a latissimus dorsi muscle of carnitine treated dogs (table 6.1), combined with minimal electrical stimulation, suggests an increased amount of mitochondria in the muscle cells. The fact that phopshofructokinase did not decrease in this muscle suggests maintenance of the anaerobic metabolic capacity. Maintenance of flow regulation during bursts of high intensity exercise by preservation of endothelial metabolism is probably the basis for the positive effect of carnitine on muscle transformation under these circumstances.

Also ischemia in the muscie can occur due to vascular damage during the operation, or as result of the fact that the muscle is wrapped around the heart. In the initial period after a cardiomyoplasty procedure, ischemic circumstances can also occur during pacing (training) of the predominantly white latissimus dorsi muscle. The observed lipidosis in wrapped latissimus dorsi muscles (table 7.1), combined with the failure of the wrapped muscle to develop a higher capillary over fibre ratio (table 7.1 and (14)) indicate ischemic damage to this muscle. The observed lipidosis in wrapped latissimus dorsi muscles in goats (table 7.1) probably results from impaired fatty acid oxidation in muscle cells due to lack of flow regulation by (probably carnitine deficient) vascular endothelium. For instance also in claudicatio intermittens the phenomenon of fat accumulation in muscle is known $(17,19)$. Administration of L-carnitine to these patients not only improved muscle function but also prevented lipid accumulation. Also in chapter 7 the inhibitory effect of carnitine on lipid accumulation was seen. The higher capillary over fibre ratio seen in the carnitine treated situation suggests that also in this situation the vascular endothelium with its regulatory functions on flow and angiogenesis is the main target for the intravenously administered L-carnitine. 


\section{REFERENCES}

1. Bettini V, De Varda E, Guerra B, Pulliero G, Ton P. Studio sperimentale sugli effetti colinomimetici della carnitina in preparati isolati di arteria aorta e masseterina. Cardiologia (1987)32:1039-1042.

2. Brevetti G, Attisano T, Perna S, Rossini A, Policicchio A, Corsi M. Effect of L-Carnitine on the reactive hyperaemia in patients affected by peripheral vascular disease: A double blind crossover study. Angiology (1989)40:857-862.

3. Chiu RCJ (ed): Biomechanical cardiac assist: cardiomyoplasty and muscle-powered devices. Futura Publishing Comp. New York, (1986).

4. Coffman JD, Cohen RA: Cholinergic vasodilation mechanisms in human fingers. Am $\mathrm{J}$ Physiol (1987)252:H594-H597.

5. Dauber JM, Van Benthuysen KM, McMurthy JF, Wheeler GS, Lesnefsky EJ, Horwitz LD, Neil JV. Functional coronary microvascular injury evident as increased permeability due to brief ischemia and reperfusion. Circ Res (1990)66:986-998

6. Ferrari $R$, Cucchini $F$, Visioli $O$. The metabotic effects of L-carnitine in angina pectoris. Int $J \mathrm{Cardiol}$ (1984)5:213-216.

7. Fritz IB. Carnitine and its role in fatty acid metabolism. In: Paoletti R, Kritchevsky D, eds, Adv Lipid Res (1963)1:285-334.

8. Hülsmann WC. Coronary vasodilation by fatty acids. Basic Res Cardiol (1976)71:179-191.

9. Hülsmann WC, De Wit LEA. Acidosis, cardiac stunning and its prevention by oxygen. Cell Biol Int Rep (1990) 14:311-315.

10. Hülsmann WC, M-L Dubelaar. Early damage of vascular endothelium during cardiac ischemia Cardiovasc Res (1987)21:674-677.

11. Hülsmann WC, Dubelaar M-L. Aspects of fatty acid metabolism in vascular endothelial cells. Biochimie (1988)70:681-686.

12. Jöbsis AC. Histochemische indrukken en biochemische waarden. Een vergelijkend onderzoek toegepast op skeletspier na experimentele innervatiewijziging. Thesis University of Amsterdam (1971)

13. Jöbsis AC, Meijer AEFH, Vloedman AHT. Alteration of the maximal activity of the gluconeogenetic enzyme fructose-1,6-diphosphatase of skeletal muscle by cross innervation. A histochemical and biochemical investigation of fatiguability-related aspects. J Neurol Sci (1976)30:1-11.

14. Lucas CMHB. Use of the latissimus dorsi muscle for cardiac assist. Thesis University of Maastricht (1992)

15. Lucas CM, Havenith MG, Van der Veen FH, Habets J, Van der Nagel T, Schrijvers-van Schendel JM, Penn OC, Wellens HJ: Changes in canine latissimus dorsi muscle during 24 weeks os continuous electrical stimulation. J Appl Physiol (1992).

16. Maebashi M, Kawamura N. Sato M, Yoshinaga K, Suzuki M. Urinary excretion of carnitine in man. J Lab Clin Med (1976)87:760-766.

17. Mäkitie J, Teräväinen $\mathrm{H}$ : Histochemical changes in striated muscle in patients with intermittent claudication. Arch Pathol Lab Med (1977)101:658-663.

18. Sacks T, Moldow CF, Craddock PR, Bowers TK. Oxygen radicals mediate endothelial cell damage by complement-stimulated granulocytes. An in vitro model of immune vascular damage. $J$ Clin Invest (1978)61:1161-1167.

19. Sjöström M. Ängquist KA, Rais $\mathrm{O}$ : Intermittent claudication and muscle fibre fine structure: correlation between clinical and morphological data. Ultrastructural Path (1980)1:309-326.

20. Tsao PS, Lefer AM. Time course and mechanism of endothelial dysfunction in isolated ischemic-and hypoxic- perfused rat hearts. Am J Physiol (1990)259:H1660-H1666.

21. Weinstock M, McCarty R: Vasodilator responses to cholinergic and adrenergic stimulants in spontaneously hypertensive (SHR) and Wistar-Kyoto (WKY) normotensive rats (41545). Proc Soc Exp Biol Med (1983)172:194-201. 


\section{SUMMARY}

One of the remedies for patients suffering from severe heart failure is heart transplantation. Lack of donors and problems with rejection of the graft have inspired many investigators to find alternatives for heart transplantation. The use of grafts constructed from the patients own muscle tissue overcomes the problem of tissue rejection. In Maastricht, investigations are currently performed to explore the possibility to use the latissimus dorsi muscle to support the failing heart. It can be expected that the use of the predominantly white (type $\mathrm{II}$, fast) latissimus dorsi muscle encounters some problems. For instance fatigue is likely to occur in this muscle, which is generally used for incidental contractions. Red muscles are able to perform continuously and do not suffer from fatigue. Red (type 1, slow) and white muscles have different metabolic properties. To work in a continuous fashion, a type II skeletal muscle has to be changed into a type I skeletal muscle, which can be achieved by training. For this purpose the stimulation of the muscle by the implanted pacemaker must be gradually adapted to continuous contractions. A full 'training period' takes 6 12 weeks. Since cardiac function of the patients is already depressed at the moment of operation it is important to shorten this 'training' period, or at least have an optimal strength of the muscle during this period. Because red fibres derive a large part of their energy from fatty acid oxidation, and because carnitine is a key substance in fatty acid oxidation we decided to investigate the role of carnitine in latissimus dorsi muscle performance.

In this thesis the acute effect of carnitine on electrically stimulated (paced) skeletal muscle has been investigated as part of the cardiomyoplasty project. Two main aspects are studied in this thesis. Firstly the acute effects of L-carnitine on latissimus dorsi function, using in situ stimulated latissimi dorsi. Secondly the chronic effects of L-carnitine are studied in in situ and in wrapped latissimus dorsi muscles. Chapters 2 to 7 have been published as full papers. General conclusions reached from this work are presented below.

Chapter 2 shows that L-carnitine improves force of the in situ stimulated latissimus dorsi muscle by $34 \%$. This effect of carnitine is acute, and (stereo)specific, since neither D-carnitine nor the structural analogue choline (also a tertiary amine) have a positive effect on contractile force. Insulin (with glucose) administration abolished the carnitine effect, probably by lowering the supply of fatty acids. Chapter 3 adds two aspects to these observations, firstly the fact that L-carnitine increases blood flow in the paced latissimus dorsi. Secondly the observation that Tensilon, a choline esterase inhibitor, induces a similar effect. The combination of 
Tensilon and carnitine does not lead to an additional effect. Tensilon is also able to stimulate blood flow in skeletal muscle.

The acute positive effect of carnitine is rather unexpected, since no change in overall muscle carnitine levels occurred. Therefore there must be another compartment involved in the carnitine effect besides the striated muscle cells. During pacing of muscles, a considerable lowering of interstitial $\mathrm{pH}$ may occur. This is mainly due to secretion of lactic acid from pre-ischemic, striated muscle cells. Chapter $\mathbf{4}$ discusses that continued pacing may lead to local acidosis which influences plasmalemmal changes, resulting in alteration of cellular ion fluxes, including $\mathrm{Ca}^{2+}$. Another consequence of hypoperfusion of the muscle is the increase of oxygen free radicals, as has been discussed as well.

Endothelial cells are more vulnerable to oxidative stress than muscle cells and are prone to loose carnitine early during hypoperfusion. This is illustrated by the observation that rat hearts labelled in vivo with ${ }^{14} \mathrm{C}$-carnitine loose, as paced Langendorff heart, only $4 \%$ of their carnitine in 20 min perfusion, following 60 min global ischemia. The carnitine released had a much higher specific radioactivity than the carnitine that was not released (chapter 5). This indicates compartmentation of carnitine in heart. Endothelial incompetence in flow regulation could be delayed by the addition of carnitine and fatty acids in pre-ischemia.

Chapter 6 shows the results of a study in which dogs received $1 \mathrm{~g}$ of L-carnitine intravenously (three times weekly) for 8 weeks. The left latissimus dorsi muscle was equipped with electrodes and a pacemaker to perform in vivo contraction measurements weekly, while the right latissimus dorsi muscle served as control. Only in the left latissimus dorsi carnitine administration caused the percentage of type I fibres to increase from $30 \%$ to $55 \%$. Also only in the left muscle the contraction speed (measured as percentage ripple) decreased from $75 \%$ to $30 \%$, and cytochrome c oxidase activity increased from 113 to $179 \mu \mathrm{mol} / \mathrm{min} / \mathrm{g}$ wet weight.

It is found that cardiomyoplasty causes complete transformation of the mixed type latissimus dorsi muscle towards a muscle composed of solely type I fibres. A complication that occurs in these 'wrapped' muscles is an increase of fat in the muscle tissue from less than $1 \%$ to $23 \%$. Intravenous administration of $1 \mathrm{~g}$ of L-carnitine three times weekly during the postoperative (training) period diminishes this fat accumulation to $7 \%$, as is described in chapter 7 . 


\section{SAMENVATTING}

Hart en vaatziekten komen in Nederland veel voor, soms is de enig overgebleven remedie een harttransplantatie. Een gebrek aan donoren en afstotingsproblemen hebben in de hele wereld al veel mensen geïnspireerd tot het zoeken van alternatieven. Een van de mogelijkheden om zowel het donor probleem als de afstoting te omzeilen is het gebruik van een eigen spier van de patiënt om de het falende hart te ondersteunen. In Maastricht wordt op het ogenblik de mogelijkheid onderzocht de latissimus dorsi spier te gebruiken als ondersteuning van het falende hart. Voor de "wikkelhart" of "cardiomyoplastiek" operatie wordt de latissimus dorsi spier vrijgeprepareerd van de omringende spieren. Hierbij wordt de oorsprong van de spier ongemoeid gelaten, waardoor de zenuw- en bloed-voorziening behouden blijtt. Vervolgens wordt de spier in de thorax gebracht en om het hart gewikkeld. Door middel van twee electroden in de spier wordt deze, met behulp van een pacemaker, synchroon met het hart tot contractie gebracht.

Men kan zich nu voorstellen dat intensief gebruik van deze houdingsspier specifieke problemen met zich meebrengt. De latissimus dorsi wordt gewoonlijk slechts gebruikt voor incidentele contracties. De metabole eigenschappen van de rode skeletspier en de hartspier zijn heel anders dan van de voornamelijk witte latissimus dorsi spier. Langzame aanpassing van de latissimus dorsi spier wordt bereikt door een weloverwogen trainingsprogramma. In het begin wordt de spier slechts kort geprikkeld, bovendien niet bij elke hartslag. ledere twee weken wordt de prikkelduur en frequentie iets aangepast totdat na ongeveer $6-12$ weken een optimale prikkel aan de latissimus dorsi spier bij elke (of bij een hoge hartfrequentie, elke tweede) hartslag kan worden toegevoegd.

Een aantal basale vragen rond het wikkelhart wordt nog steeds op dierexperimenteel nivo onderzocht. Een van de aspecten is de metabole aanpassing van de gewikkelde (of getrainde) latissimus dorsi, en de beïnvloeding daarvan. Omdat rode spieren hun energie vooral afleiden uit de verbranding van vetzuren, en omdat carnitine een belangrijke rol speelt bij de verbranding van vetzuren hebben we het effect van L-carnitine op de functie van de latissimus dorsi spier bestudeerd. Het onderzoek valt uiteen in twee delen. Ten eerste worden de acute effecten van L-carnitine bestudeerd, hiervoor werd de in situ gestimuleerde latissimus dorsi gebruikt. Ten tweede werden een aantal chronische effecten van L-carnitine bestudeerd, hiervoor werd zowel de in situ spier als de gewikkelde latissimus dorsi als model gebruikt.

In hoofdstuk 1 wordt een inleiding gegeven over skeletspier metabolisme en over de functie van carnitine. De hoofdstukken 2 tot en met 7 zijn wetenschappelijke 
artikelen over dit onderwerp. In het kort volgen hier een aantal conclusies uit deze hoofdstukken. Hoofdstuk 2 laat zien dat de kracht van de geprikkelde latissimus dorsi spier in situ met $34 \%$ toeneemt door inspuiting van L-carnitine ten opzichte van de kracht in afwezigheid van carnitine. Dit is een (stereo)specifiek effect van carnitine daar noch D-carnitine, noch de structuur analoog choline een soortgelijk effect kunnen bewerkstelligen. Bovendien bleek dat de aanwezigheid van vetzuren essentieel is, daar een hoog insuline gehalte het effect van carnitine voorkwam. Hoofdstuk 3 voegt twee nieuwe aspecten aan deze waarnemingen toe, namenlijk het feit dat L-carnitine de flow in de geprikkelde spier verhoogt. Ten tweede het feit dat Tensilon, een choline-esterase remmer, een soortgelijk effect te zien geeft, terwijl tensilon plus carnitine niet leidt tot een extra verhoging van de kracht van de latissimmus dorsi. Ook Tensilon is in staat de bloedvoorziening van de skeletspier te bevorderen.

Het acute positieve effect van carnitine is overwacht, daar het totaal carnitine gehalte van de spier niet beïnvloed wordt. Er moet dus een ander compartiment dan de gestreepte spiervezels betrokken zijn bij het effect van carnitine.

Hoofdstuk 4 gaat in op een aantal gevolgen van het prikkelen van de hart of skeletspier. Bij het prikkelen van spieren kan locaal een acidose ontstaan, die door verstoring van het metabolisme van de endotheelcel tot een verlaging van de flow in de spier kan leiden. Een ander gevolg van van hypoperfusie van de spier is de toename van de hoeve /heid zuurstof radicalen. In hoofdstuk 5 wordt de kwetsbaarheid van endotheelcellen tijdens ischemie besproken in relatie tot het carnitine afhankelijke vetzuurmetabolisme van deze cellen. Bij perfusies werd gebruik gemaakt van ratteharten met een radioactief gelabelde carnitine voorraad. Met deze perfusies werd geillustreerd dat bij ischemie in Langendorff geperfundeerde en geprikkelde ratteharten slechts $4 \%$ van de totale carnitine pool verloren gaat, en dat de specifieke activiteit van het uitgescheiden L-carnitine veel hoger is dan die in het hart.

Hoofdstuk 6 beschrijft de resultaten van chronische L-carnitine toediening aan honden. Het blijkt dat L-carnitine in combinatie met het wekelijks gedurende korte tijd prikkelen van de spier leidt tot een toename van type I vezels van $30 \%$ naar $55 \%$. De contractie snelheid van de spier, gemeten als ripple, nam af van $75 \%$ naar $30 \%$. Cytochroom c oxidase activiteit nam toe van $113 \%$ naar $179 \%$.

Een van de problemen die bij post-mortem onderzoek van gewikkelde spieren waarneembaar was, is het vervetten van de gewikkelde spier. In een normale latissimus dorsi is minder dan $1 \%$ vet aanwezig, 16 weken na wikkelen en stimuleren van de spier is dit percentage $23 \%$. Intraveneuze toediening van L-carnitine aan een deel van deze geiten, bleek het vetpercentage te beperken tot $7 \%$, hetgeen beschreven staat in hoofdstuk 7. 


\section{PUBLICATIONS}

1 Van Eijk HG, van Noort WL, Dubelaar M-L, Van der Heul C. The microheterogeneity of human transferrins in biological fluids. Clin Chim Acta (1983)132:167-171.

2 Hülsmann WC, Dubelaar M-L, Stam H, Janssen H, Lamers JMJ. Effect of stress hormones on (phospho)lipase activity of vascular endothelial plasmamembranes; a role in the initiation of atherosclerosis. In: Pathogenesis of stress-induced heart disease (R.E. Beamish, V.Panagia, N.S. Dhalla, eds) Martinus Nijhoff Publishing, Boston, Dordrecht, Lancaster (1985) pp 369-379.

3 Hülsmann WC, Dubelaar M-L, Lamers JMJ, Macari F. Protection by acylcarnitines and phenyl-methyl-sulfonyl-fluoride of rat heart subjected to ischemia and reperfusion. Biochim Biophys Acta (1985)847:62-66.

4 Hülsmann WC, Dubelaar ML. Lipoprotein lipases and stress hormones: studies with glucocorticoids and choleratoxin. Biochim Biophys Acta (1986)875:69-75.

5 Scholte HR, Luyt-Houwen IEM, Dubelaar ML, Hülsmann WC. The source of malonyl-CoA in rat heart. The calcium paradox releases acetyl-CoA carboxylase and not propionyl-CoA carboxylase. FEBS lett (1986)198:47-50.

6 Hülsmann WC, De Wit LEA, Dubelaar M-L, Stam H. Substrates for energy metabolism in the heart: the role of the interstitial compartment. Basic Res Cardiol (1987)82 suppl.1:3-10.

7 Hülsmann WC, Dubelaar M-L. Early damage of vascular endothelium during cardiac ischemia. Cardiovasc Res (1987)21:674-677.

8 Hülsmann WC, Dubelaar ML. Aspects of fatty acid metabolism in vascular endothelial cells. Biochimie (1988)70:681-686.

8a Hülsmann WC, Dubelaar M-L. Aspects du métabolisme des acides gras dans les cellules endothéliales vasculaires. Biochemie (1988)70,suppl. 
9 Hülsmann WC, Dubelaar M-L, De Wit LEA, Persoon NLM. Cardiac lipoprotein lipase: effects of lipopolysaccaride and tumor necrosis factor. Mol Cell Biochem (1988)79:137-145.

10 Hülsmann WCH, Dubelaar M-L. Effects of tumor necrosis factor (TNF) on lipolytic activities of heart. Mol Cell Biochem (1988)79:147-151.

11 Groot PHE, Hartog JM, Dubelaar ML, Scheek LW, Verdouw PD, Lamers JMJ. The effects of diets supplemented with lard fat or mackerel oil on plasma lipoprotein lipid concentrations in domestic swine. Atherosclerosis (1989)77:1-6.

12 Dubelaar M-L, Lucas CMHB, Hülsmann WC. Acute effect of I-carnitine upon skeletal muscle force tests in the dog. Am J Physiol (1991)260:E189-E193.

13 Dubelaar M-L, Lucas CMHB, Hülsmann WC. The effect of I-carnitine on force development of the latissimus dorsi muscle in dogs. J Cardiac Surgery (1991)6suppl 1:270-275.

14 Hülsmann WC, Dubelaar M-L. Carnitine in metabolism of paced cardiac and skeletal muscles; prevention of acidosis and improvement of vascular flow. In: Lcarnitine and its role in medicine, from function to therapy. R. Ferrari, $S$. DiMauro, G. Sherwood, eds. Academic Press (1992)pp 345-358.

15 Lorusso R, Lucas C, Van der Veen FH, Van der Nagel Th, Dubelaar M-L, Wellens HJJ, Penn OC. Fibrin Sealant application during dynamic cardiomyoplasty surgery. In: Heart surgery. d'Alessandro (ed), (1991)pp 579584.

16 Dubelaar M-L, Glatz JFC, De Jong YF, Hülsmann WC. Chronic L-carnitine administration combined with minimal electrical stimulation promotes transformation of canine latissimus dorsi muscle. Summitted J Appl Physiol (1992).

17 Dubelaar M-L, Lucas CMHB, Hülsmann WC. On the mechanism of fat accumulation in wrapped latissimus dorsi muscle (cardiomyoplasty), and the effect of chronic L-carnitine administration. Basic Appl Myol. (1991)1:305-310.

18 Hülsmann WC, Dubelaar ML. Carnitine requirement of vascular endothelial and smooth muscle cells. Accepted Mol Cell Biochem (1992).

19 Lucas CM, Lorusso RC, Dubelaar ML, Van Der Veen FH, Vos MA, Habets J, Van Der Nagel Th, Penn OC, Wellens HJ. Hemodynamic study following cardiomyoplasty: Comparison of different stimulation protocols. Submitted for publication.

20 Lucas CM, Dubelaar ML, Van der Veen FH, Kloosterman - Castro-Ravelo E, Havenith M, Habets J, Van Der Nagel Th, Penn OC, Wellens HJ. Submitted for publication. 


\section{ABSTRACTS}

1 Lucas CMHB, Van der Veen FH, Dubelaar ML, Koks C, Van der Nagel T, Wellens HJJ, Hülsmann WC. The acute effect of L-carnitine on skeletal muscle fatigue tests in the dog. In: 2nd international symposium on lipid metabolism in the normoxic and ischemic heart. (GJ van der Vusse, JFC Glatz, H Stam eds.) RUL 1988, p50.

2 Dubelaar M-L, Lucas CMHB, Van der Veen FH, Wellens HJJ, Hülsmann WC. The acute effect of L-Carnitine on skeletal muscle force tests in the dog. Pflügers Archiv (1990)416:3.

3 Dubelaar ML, Lucas CMHB, Van der Veen FH, Wellens HJJ, Hülsmann WC. The acute effect of L-carnitine on skeletal muscle force tests in the dog. In: Abstractbook $4^{\text {th }}$ World Symposium on transformed skeletal muscle for cardiac assist, Palm Springs, 1990.

4 Lucas C, Dubelaar M-L, Van der Veen FH, Terpstra B, Wellens H. Optimal stimulation of the goat latissimus dorsi muscle using the "Prometheus" pacemaker system. PACE (1991)14:735;A469.

5 Lucas C, Dubelaar M-L, Van der Veen FH, Terpstra B, Wellens H. A Comparison of two conditioning protocols on goat latissimus dorsi muscle. PACE 14 (1991) 691.

6 Lorusso R, Lucas C, Van Der Veen FH, Van Der Nagel T, Habets J, Dubelaar $M-L$, Wellens $H$, Penn O. Observations during early muscle stimulation following dynamic cardiomyoplasty. PACE 14 (1991) 669; A205.

7 Hülsmann WC, Verkerk A, Dubelaar ML. Carnitine requirement of vascular endothelial and smooth muscle cells. Abstract $3^{\text {rd }}$. International Symposium on Lipid Metabolism in the normoxic and ischemic heart. (1991)

8 Dubelaar M-L, Hülsmann WC. Carnitine effect on paced skeletal muscle; prevention of acidosis and improvement of flow. Pflügers Arch (1991)418:R146. 


\section{NAWOORD}

De invoering van de 'twee fasen structuur voor wetenschappelijk onderwijs' is door velen als negatieve ontwikkeling ervaren. Voor mij als 'HBO-er' kwam deze invoering precies op het juiste moment: in het vooruitzicht een verhuizing van Rotterdam naar Limburg met de noodzaak een zeer leuke vaste baan op te geven. In de periode op de afdeling Biochemie van de Erasmus Universiteit was een ding heel duidelijk geworden: onderzoek is leuk! Het stellen van vragen binnen een project, het verzinnen van een proefopzet en de hoop een antwoord op de vraag te vinden bleek een plezierige bezigheid. De (eindeloze?) discussies binnen onze groep provoceerden de wil om zelf een inbreng, of eigenlijk liever dé inbreng in de volgende experimenten te hebben. Hoewel mijn collega's Ina Kalkman, Elly de Wit, Sietske Broekhoven, Hans Stam, Kees Schoonderwoerd en Niek Persoon hier een rol in speelden, was $U$, toen vooral Professor Hülsmann de belangrijkste persoon in het tot stand komen van de wens meer eigen inbreng te hebben. Deze wens ontstond niet door een gebrek aan inspraak, maar juist door de stimulatie van een eigen mening.

De mogelijkheid tot het verkrijgen van een AIO-plaats op de afdeling Fysiologie van de Universiteit Limburg was dan ook meer dan welkom. Ik ben dan ook blij dat de vakgroep Cardiologie haar AIO plaats voor dit project beschikbaar heeft gesteld. Toen werd $U$, professor, vooral $U$, Wim, en bovendien mijn promotor. Deze plaats lijkt mij zeer geschikt om $U$ te bedanken voor beide fases in de tot standkoming van dit proefschrift.

Ook Prof van der Vusse wil ik bedanken voor zijn rol als begeleider en promotor. Ondanks mijn, vaak vergaande, eigenwijzigheid blijf je altijd geduldig andere gezichtspunten en verbeteringen aanvoeren.

De leden van de beoordelingscommissie: Prof. Dr. RS Reneman, Prof. Dr. HJJ Wellens, Prof. Dr. A Huson, Prof. Dr. PD Verdouw, Prof. Dr. HR Scholte wil ik bedanken voor het beoordelen van het manuscript.

Mijn kamergenoten Michael Vork en Appie Kleine wil ik bedanken voor waardevolle discussies en suggesties en niet te vergeten hun bereidheid af en toe onze kamer te verlaten als de belangen van Tara en Kieran weer eens behartigd moesten worden, dit geldt ook voor Frans van Nieuwenhoven en Berry Jansen, mede- bewoners van kamer 3.160, UN50.

Jo Habets, Theo van der Nagel, Jet Leunissen, Ruud Kruger, Frans Slangen en Peter Franssen hebben een belangrijke rol gespeeld bij de operaties, metingen en verzorging van de honden en geiten die aan dit proefschrift hebben bijgedragen. De 
vele tochtjes op te grote laarzen door de weilanden van het BMC hebben een ander perspectief aan het AIO-schap gegeven.

Carolien Lucas is altijd mijn maatje geweest in dit onderzoek, de vele gezamelijke operaties, experimenten en discussies rond de data verwerking zijn een wezenlijk deel van dit promotie onderzoek, waarvoor dank!

Jan Glatz jij was altijd aanspreekbaar voor het spuien van ideeën, frustraties of zomaar. Bovendien heeft jou analytische kijk op zaken menig artikel (en de vele voorlopers) in goede banen geleid.

Eric van der Veen zorgde voor alle organisatorische aspecten en speelde ook een belangrijke rol in de rest van het onderzoek.

Mede AlO's vormen een groep apart, niet alleen tijdens het AlO onderwijs, maar vooral binnen onze eigen vakgroep wil ik hen bedanken voor hun plezierige samenwerking, steun en discussies.

Yvonne de Jong heeft veel biochemische bepalingen in de latissimus dorsi biopten verricht, gelukkig werd ze nooit boos of ongeduldig als de experimenten weer eens uit liepen of verplaatst werden. Peter Willemsen, Theo Roemen en Will Coumans zijn als bemanning van het chemisch lab vaak tot steun geweest en zorgden altijd voor een gezellige sfeer op het lab.

Frans van Nieuwenhoven heeft een de milieu aspecten van dit onderzoek behartigd, in de recente enquete over het woon werk verkeer konden we beiden "carpooler" invullen dankzij jouw bereidheid mij dagelijks met grote stiptheid van en naar Maastricht te vervoeren. Daarbij kwam het voordeel dat de reistijd een uitstekende kans bood voor het bediscussiëren van proeven en ideeën. Ik vraag me nog steeds af of het feit dat we nu op dezelfde kamer zitten toeval is of een poging van de overheid (kamerindeler) om dit carpool gedrag te bevorderen.

Een onderzoek wordt niet verricht door een persoon of door een paar personen maar is het resultaat van een samenspel van mensen (en in dit onderzoek ook dieren), al degenen die hier niet met name genoemd zijn worden hierbij bedankt voor hun rol in dit samenspel.

De paranimfen, Michaël Vork en Niek Persoon wil ik bedanken voor het feit dat ze deze rol op zich hebben willen nemen.

Mijn ouders hebben een belangrijke rol gespeeld in het tot standkomen van dit proefschrift, hun bereidheid om samen met mijn schoonouders veelvuldig op de kinderen te passen is maar een klein aspect van deze rol, maar het toont wel de grenzeloosheid aan.

Tenslotte wil ik ook Denis, Tara en Kieran noemen die omwille van dit proefschrift menigmaal even 'niet aan de beurt waren'. 


\section{CURRICULUM VITAE}

De schrijfster van dit proefschrift werd geboren op 15 januari 1960 te Amsterdam.

$\mathrm{Na}$ het eindexamen HAVO aan het Mgr. Frencken College te Oosterhout (NBr) werd in 1978 met de studie Hoger Natuurwetenschappelijk Onderwijs begonnen aan het Dr. Struycken Instituut te Etten Leur. Tijdens deze studie werd als afstudeer opdracht onderzoek gedaan naar het voorkomen van transferrinen in liquor cerebrospinalis bij de mens, op de afdeling Chemische Pathologie (Prof. Dr H.G. Van Eijk) van de Erasmus Universiteit Rotterdam.

$\mathrm{Na}$ het voltooien van de studie werd van 1983-1988 onderzoek verricht aan de Erasmus Universiteit Rotterdam in de functie van analiste bij de afdeling Biochemie (Prof. Dr. W.C. Hülsmann).

Van 1988 - 1992 werd, als AIO cardiologie, het onderzoek beschreven in dit proefschrift verricht bij de afdeling fysiologie van de Rijksuniversiteit Limburg te Maastricht. 


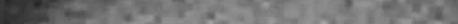

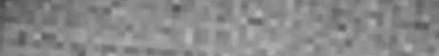
stion 79

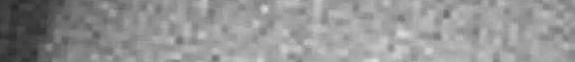

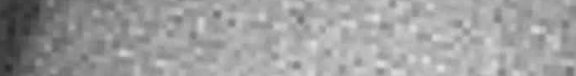

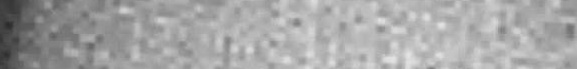

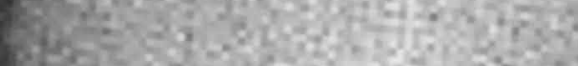

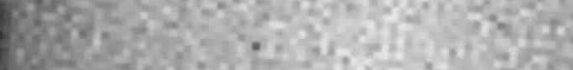

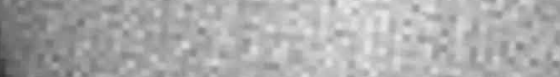

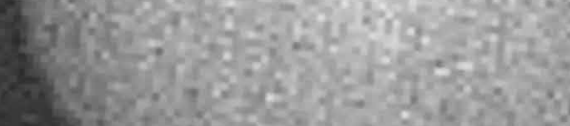
2a: $\sin$

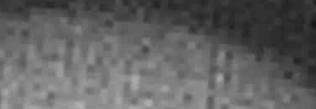

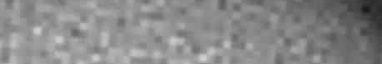

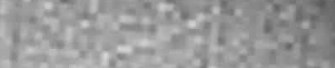
An:eras

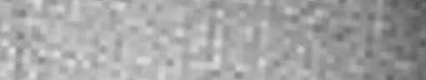

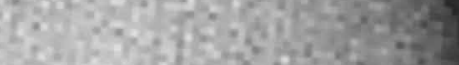

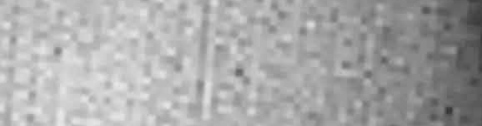

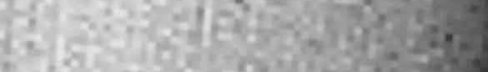

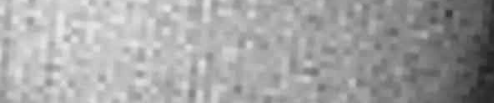
7.

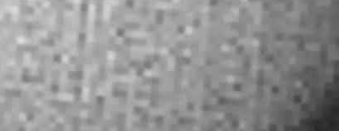
-

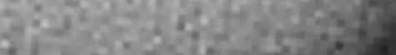
if $34 y^{2}=4$

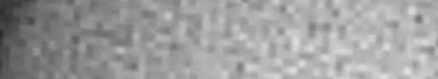

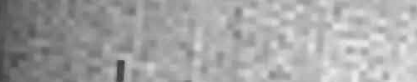

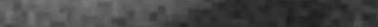
15. 